\title{
DIGITALCOMMONS
}

@WAYNESTATE-

Wayne State University

Wayne State University Dissertations

January 2019

\section{The Role Of Periodic Conventions In Generating And Undermining Constitutional Loyalty}

Kevin Gerald Lorentz

Wayne State University, kglorent@gmail.com

Follow this and additional works at: https://digitalcommons.wayne.edu/oa_dissertations

Part of the Political Science Commons

\section{Recommended Citation}

Lorentz, Kevin Gerald, "The Role Of Periodic Conventions In Generating And Undermining Constitutional Loyalty" (2019). Wayne State University Dissertations. 2175.

https://digitalcommons.wayne.edu/oa_dissertations/2175

This Open Access Dissertation is brought to you for free and open access by DigitalCommons@WayneState. It has been accepted for inclusion in Wayne State University Dissertations by an authorized administrator of DigitalCommons@WayneState. 


\title{
THE ROLE OF PERIODIC CONVENTIONS IN GENERATING AND UNDERMINING CONSTITUTIONAL LOYALTY
}

\author{
by \\ KEVIN G. LORENTZ II \\ DISSERTATION \\ Submitted to the Graduate School \\ of Wayne State University, \\ Detroit, Michigan \\ in partial fulfillment of the requirements \\ for the degree of \\ DOCTOR OF PHILOSOPHY
}

2019

MAJOR: POLITICAL SCIENCE

Approved By:

Advisor

Date 
(C) COPYRIGHT BY

KEVIN G. LORENTZ II

2019

All Rights Reserved 


\section{DEDICATION}

To my mom and dad, whose steadfast support, love, and faith made this dissertation possible. 


\section{ACKNOWLEDGMENTS}

Much like raising a child, a dissertation takes a village. I would like to thank my villagers, as it were, whom offered various kinds of support and assistance during this long process. First, I owe a great deal of gratitude to my advisor, Dr. Brady Baybeck, and my dissertation committee members: Dr. Mary Herring, Dr. Jeff Grynaviski, and Professor Justin Long. Each provided thoughtful commentary and mentoring from the prospectus through the defense that not only improved this dissertation but also made me a better scholar. In particular, Dr. Baybeck's constant guidance helped me stay focused, and his words of encouragement were often the way out of seemingly dead-ends. He embodies the traits that every mentee wants in a mentor, and I am ever thankful he agreed to see me through this journey.

Second, I want to thank my family, who have provided immeasurable love and support my entire graduate career. My parents, Judy and Kevin, Sr., never gave up on me, and their faith and encouragement have been the fuel that finished this dissertation. My sister, Amanda, played the role of constant cheerleader well, as every little sibling should aspire to. Last, but certainly not least, the love of my life, Dr. Nicholas Timmer, who was my constant companion during my trials - both good and bad. His love and support have meant the world to me and make finishing this journey all the merrier.

Third, to my friends, whose support have been critical over the past several years. Many of you served as sounding boards for ideas and, more commonly, frustrations and fears. When I needed encouragement, insights, or just someone to slack off with, you all went above and beyond. While I cannot list you all here, I want to particularly thank Rebecca Idzikowski, Kim SaksMcManaway, Sylvia Gancheva, Cody Melcher, and Connor Sutton. 
Finally, I want to thank my political science colleagues and mentors here at Wayne State University and elsewhere. Numerous professors deserve special recognition for taking me under their wings and molding me into the scholar I am today, especially Drs. Erik Trump, Julie Keil, Cherie Strachan, and Mary Herring. I also want to extend my deepest thanks to the Wayne State University political science faculty, graduate teaching assistants, and students who welcomed me into their classes, providing me with the data I needed to finish this project. Without you, this dissertation would never have gotten off the ground. 


\section{TABLE OF CONTENTS}

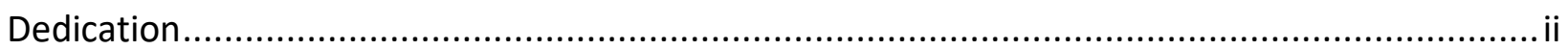

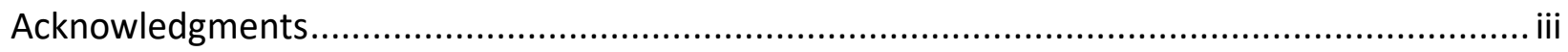

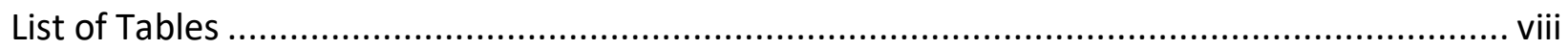

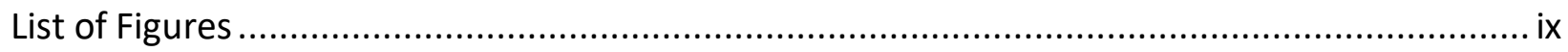

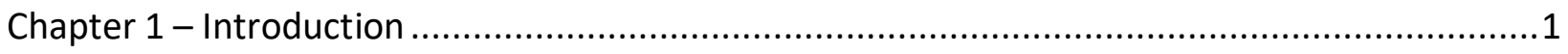

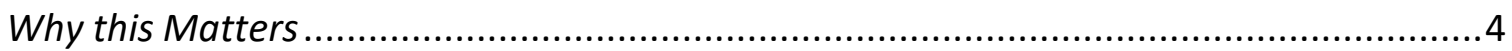

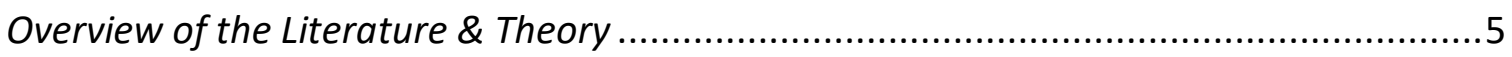

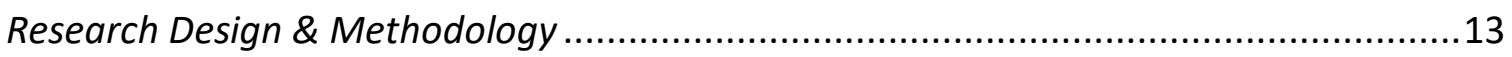

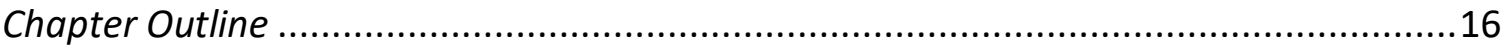

Chapter 2 - Constitutional Loyalty: Important to the Founders but Ignored by the Discipline ...18

Institutional Support \& Legitimacy Theory ……………........................................18

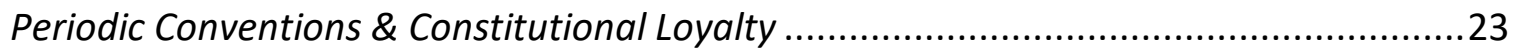

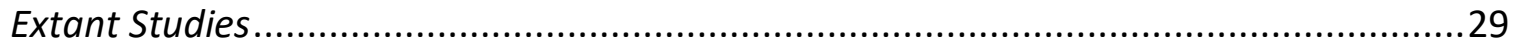

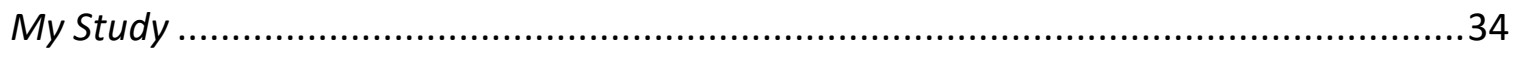

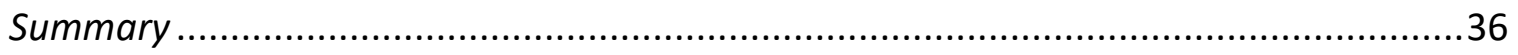

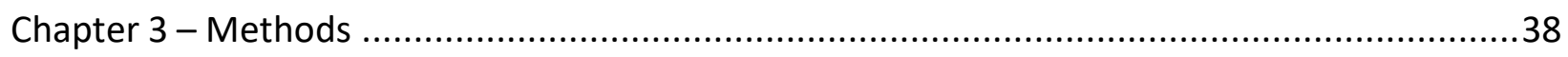

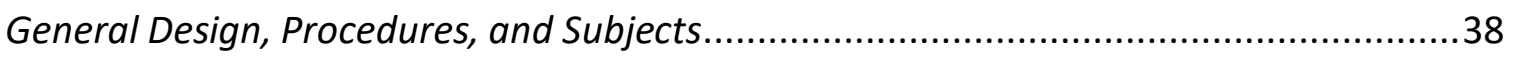

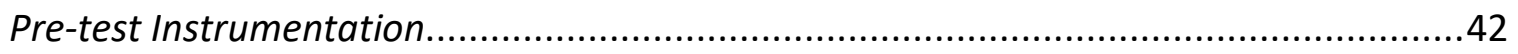

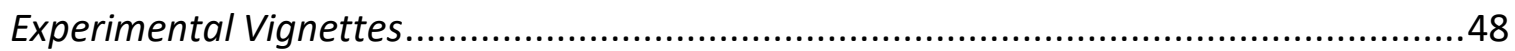

Post-test Instrumentation ...................................................................................5

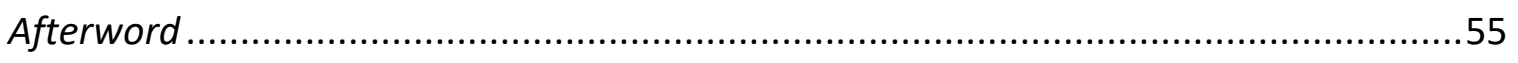


Chapter 4 - What Generates Constitutional Loyalty?

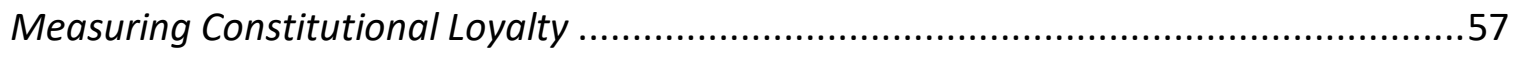

Does Constitutional Loyalty Vary Between Individuals?...........................................63

Generators of Constitutional Loyalty ............................................................... 70

What About Constitutional Approval?........................................................... 83

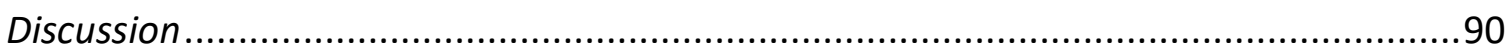

Chapter 5 - Periodic Conventions \& Constitutional Loyalty ............................................92

How Do Periodic Conventions Influence Constitutional Loyalty?................................99

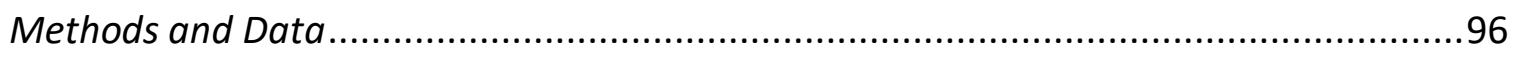

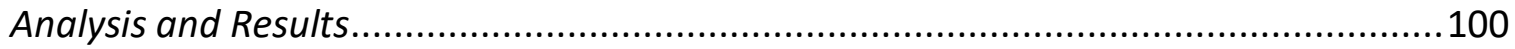

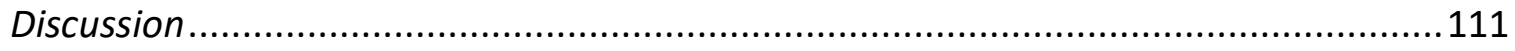

Chapter 6 - The Impact of Constitutional Knowledge.................................................... 117

Civic Knowledge and Its Influence on Constitutional Support.................................117

Does Civic Knowledge Predict Constitutional Loyalty? .........................................131

Periodic Conventions, Constitutional Knowledge, and Constitutional Loyalty ...............144

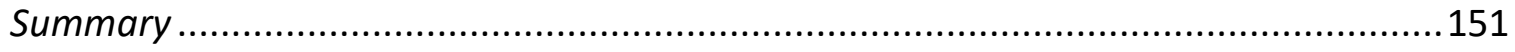

Chapter 7 - Conclusions, Implications \& Future Work ....................................................153

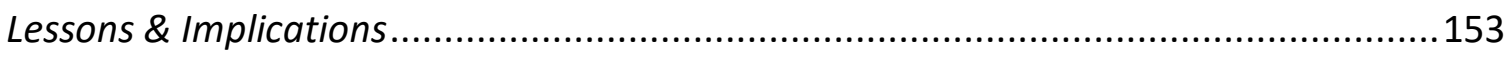

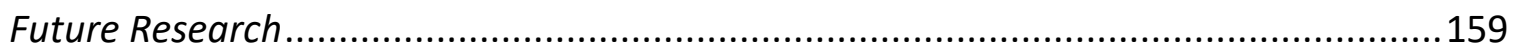

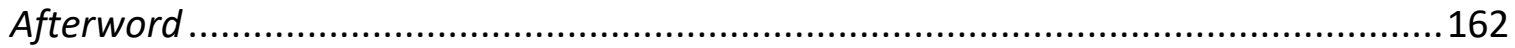

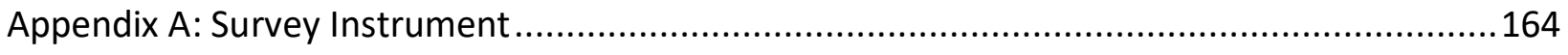

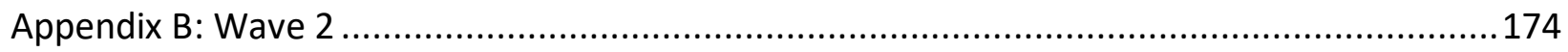




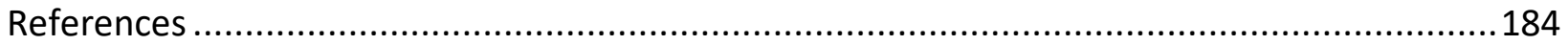

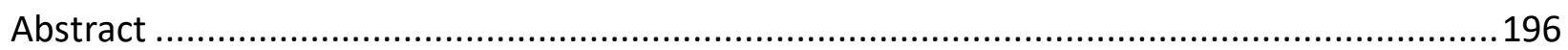

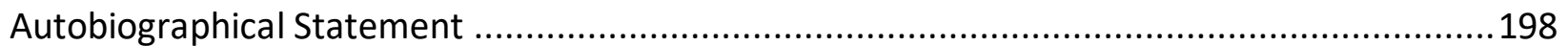




\section{LIST OF TABLES}

Table 1: Constitutional Loyalty Towards the U.S. and Michigan State Constitutions .................61

Table 2: Mean U.S. Constitutional Loyalty by Demographic Attributes ..................................65

Table 3: Regression Modeling of Federal Constitutional Loyalty ........................................73

Table 4: Regression Modeling of Michigan Constitutional Loyalty .................................... 80

Table 5: Regression Modeling with Constitutional Approval .............................................8

Table 6: Hypotheses - Summary and Results..........................................................102

Table 7: Federal Constitutional Knowledge Questions .................................................123

Table 8: Michigan Constitutional Knowledge Questions ...............................................126

Table 9: Predictors of Federal Constitutional Loyalty..................................................134

Table 10: Predictors of Michigan Constitutional Loyalty ...............................................139

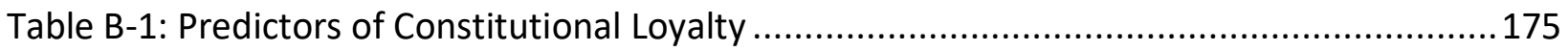




\section{LIST OF FIGURES}

Figure 1: Mean Federal and Michigan Constitutional Loyalty by Partisanship and Ideology .......67

Figure 2: Mean Federal and Michigan Constitutional Loyalty by Institutional Attitudes 69

Figure 3: Michigan Constitutional Approval Scores by Experimental Condition 104

Figure 4: Michigan Constitutional Approval Scores by Prior Knowledge .107

Figure 5: Federal Constitutional Approval Scores by Experimental Condition .110

Figure 6: Federal Constitutional Approval Scores by Prior Knowledge

Figure 7: Michigan Constitutional Support by Prior Periodic Convention Knowledge. .145

Figure 8: Michigan Constitutional Approval Scores by Constitutional Knowledge .147

Figure 9: Federal Constitutional Approval and the Reverse "Warmglow" Effect .... .148

Figure B-1: Michigan ConCon Ballot Question Support by Constitutional Knowledge .178

Figure B-2: Michigan Constitutional Approval by Constitutional Knowledge..... 179

Figure B-3: Michigan Constitutional Loyalty by Constitutional Knowledge .180

Figure B-4: Federal Constitutional Attitudes and the Reverse "Warmglow" Effect. .181 


\section{CHAPTER 1 - INTRODUCTION}

Allegations of vote rigging during the 2016 presidential election cycle - from both the Left and Right - have prompted concerns regarding citizens' continued confidence in our nation's governing institutions. While predominately focused on electoral apparatuses and formal governmental institutions (e.g. Congress, the presidency, and judiciary), it is not difficult fathoming how the U.S. Constitution itself may also face legitimacy concerns if citizens believe our political system no longer, at large, represents or works for us. While institutional loyalty ${ }^{1}$ among citizens is generally immune to these short-term accusations (Gibson and Caldeira 2009a; Gibson and Caldeira 2011), recent scholarship on citizen support for the nation's courts indicates that negative information may harm long-term institutional loyalty (see, e.g., LaRowe and Hoekstra 2014). ${ }^{2}$ Consequently, accusations assaulting the integrity of our nation's electoral institutions, if expanded, could signal a troubling development in citizens' larger institutional loyalties, shaking the very foundations of our sociopolitical system. Our federal Constitution and (albeit to a lesser extent) state charters are integral components of that foundation.

"If the United States has a sacred text," opined Sanford Levinson (2018), "it's the Constitution. Americans are taught, from an early age, to venerate the 231-year-old document, which occupies what can only be described as a shrine at the National Archives." Scholars of constitutional veneration note that popular support, or belief, in the Constitution forms the basis of an institutional stability (Hunsicker 2012), avoiding fundamental punctuations that could affect

\footnotetext{
${ }^{1}$ I use institutional loyalty, institutional support, institutional legitimacy, and diffuse support interchangeably, as is common in legitimacy theory studies (see below and also Chapter 2).

${ }^{2}$ See also Hibbing and Theiss-Morse (1995) for a similar discussion on Congress's legitimacy and negative public attitudes.
} 
the continuity of government. Public support for the federal Constitution is indeed widespread, with state constitutional charters enjoying similar, albeit less extensive, support. On average, Americans rate their federal Constitution a " 7.8 out of 10 , while [their] state constitutions earn a somewhat lower rating of 6.7" (Stephanopoulos and Versteeg 2016, 116; see also Zink and Dawes 2016). Such support is necessary, argued James Madison, in maintaining a constitution's legitimacy; popular support for the laws ensures continued obedience to them. Constitutions with widespread societal support are more resilient and likely to endure, helping citizens overcome coordination and enforcement problems related to constitutional practice (Elkins, Ginsburg, and Melton 2009). Yet, critics have noted that blind support, or excessive veneration, can have negative consequences, including saddling a political community with suboptimal institutions. Support must be balanced with the necessity of "periodic repairs," allowing each generation to review the prior's work (Jefferson 1984, 1402). In modern parlance, critics advocate for periodic constitutional conventions, permitting constitutional revisions irrespective of tradition or presumed legal permanence.

I explore this relationship between constitutional loyalty and periodic conventions, against a larger political environment where institutional support generally is under stress. Existing scholarship on constitutional support, while limited, has noted several factors (e.g. demographic attributes, sociopolitical attitudes, and constitutional knowledge) that have a role in generating support for constitutional charters. However, this literature has focused primarily on a constitution's specific support, or an individual's current satisfaction with the charter's outputs, provisions, and/or performance. Little research has explored the factors responsible in generating feelings of constitutional loyalty, or what Easton (1965) and other legitimacy scholars 
call diffuse support (see below). Moreover, emphasis is placed on the federal Constitution, although recent studies examine support for state charters. The literature on periodic conventions has enjoyed greater attention, especially from legal scholars. In particular, legal scholars have debated the merits of periodic conventions, with consensus divided: some posit that conventions would damage constitutional support by violating the law's stability, an echo of Aristotle's argument that "habit breeds obedience;" others note that conventions may bolster support since past conventions signal to succeeding generations that the constitution was either accepted or rejected "deliberately rather than fatalistically" (Brennan 2017, 941).

It is this latter contention upon which this dissertation is primarily focused: Is constitutional loyalty reinforced or undermined by knowledge that the document is and has been susceptible to change? Put another way, does the existential threat that periodic conventions represent towards constitutions influence a person's constitutional loyalty? To operationalize this question, I explore a real-world example: Does an individual's Michigan state constitutional loyalty change given the knowledge that the document can be scrapped every 16 years? How does one's support change knowing prior periodic convention referenda were rejected (approved) by voters? These questions address a constitution's diffuse support, or its loyalty, rather than the charter's specific support (or approval). As such, the underlying research can further develop the literature on constitutional support by incorporating measures of diffuse support, exploring its covariates, while also providing a critical test of periodic conventions and how these exercises influence an individual's support of constitutional charters. It could be that awareness of periodic conventions influences one's specific support but her diffuse support remains unaffected. My dissertation explores these inquiries. 


\section{Why This Matters}

From a practical standpoint, constitutional loyalty is normatively important for the nation's (or a state's) civic health. Understanding how constitutional support is generated has piqued the interest of scholars, politicians, and ordinary citizens alike. This dissertation adds to the discussion; do periodic conventions weaken the institutional loyalty of constitutions, or do they encourage citizen deliberation on an important political issue? This information is useful for proponents and opponents of periodic conventions when they appear on ballots, especially in how they prime the issue for voters. For instance, if periodic conventions reinforce status quo biases, then opponents need only highlight how past conventions have been defeated. The role of periodic conventions affecting constitutional support is even more important at the state level given the weaker status quo biases exhibited (Zink and Dawes 2016). Relatedly, there is much to be gained by having a better grasp of what encourages greater levels of citizen specific and, more importantly, diffuse support. This is especially true given that institutional support "allows political institutions...to persist and retain their authority even when they must cope with stress resulting from their policy discord with the public" (Cann and Yates 2008, 300). Constitutional approval and loyalty are similarly important.

Using Michigan's experience with periodic conventions affords some larger, practical lessons, too. Periodic conventions are a means for the people to review their fundamental charters, to consciously reevaluate whether the present constitutional configuration meets their needs and expectations. Yet, if the priming exercise here works, it could be that periodic conventions have an unintended consequence: they reinforce the present constitution's entrenchment. This raises questions about the efficaciousness of periodic conventions. 
Moreover, using Michigan affords my research a means of mundane realism (see Chapter 3 for an elaboration) using an actual, and relatively recent, political event. This permits subjects to make judgments not only on a past political event. Information gleaned here may help to better inform proponents, opponents, and voters themselves during the next convention ballot question (scheduled for November 2026).

Academically, this research extends and adds to several literatures. Extant research on constitutional support and attitudes is relatively small and novel but is complimented by a much more established research program in legitimacy theory and political support for institutions. Indeed, institutional legitimacy is a concept "central to political science" (Tanenhaus and Murphy 1981, 24). While these studies suggest several factors that influence an individual's specific support, none incorporate a constitution's susceptibility to change into their modeling - and none directly aim to explore a constitution's diffuse support (loyalty). Legal scholars and political theorists, meantime, have debated the merits of periodic conventions and explored their internal organizations, initiating referenda, and outputs, but there have been no empirical studies examining the law's (or a constitution's) susceptibility to change and how that awareness influences individuals' support (for a discussion, see Brennan 2017). This dissertation seeks to fill the gaps.

\section{Overview of the Literature \& Theory}

Institutional Legitimacy: Specific versus Diffuse Support

When examining institutional support, the predominant theoretical framework in political science is David Easton's (1965) legitimacy theory. For Easton, institutional legitimacy (or support) is based on the idea that citizens accept the moral authority of institutions to make 
decisions for society at-large. Such support, moreover, is likely to be a "[strong] inner conviction" (Easton 1965, 278), explaining why citizens may disagree with specific policy outputs of institutions yet still "accept the validity of the policy decisions because of their deep-seated beliefs regarding the uprightness of the institution" (Cann and Yates 2008, 303). This diffuse support, or institutional loyalty, is the core of legitimacy theory, and differs from what scholars call specific support, or job approval (Baird 2001; Caldeira and Gibson 1992; LaRowe and Hoekstra 2014). Unlike specific support that tends to be rational, short-term, and tied with specific policy outputs (e.g. particular constitutional amendments or proposals), diffuse support is more durable and connotes a preference to avoid fundamental changes (Caldeira and Gibson 1992; Gibson, Caldeira, and Spence 2003a; Gibson and Caldeira 2009a).

It is important to understand the conceptual dichotomy between specific and diffuse support. Easton (1965; see also Easton 1975) describes specific support as consisting of attitudes towards an institution based upon whether particular demands, policies, or actions are fulfilled. Diffuse support, conversely, is the "reservoir of favorable attitudes or good will that helps members to accept or tolerate outputs to which they are opposed or the effects of which they see as damaging to their wants" (Easton 1965, 273). Studies on the U.S. Supreme Court's (SCOTUS) public support provide convenient examples of the distinction between specific and diffuse support. Specific support for SCOTUS is based on one's agreement with its rulings (Franklin and Kosaki 1989), although it may fluctuate due to short-term factors, including: support for other institutions (Caldeira 1987); opinions on how the Court is conducting its business (Hibbing and Theiss-Morse 1995); and/or controversy over the nomination process and nominees (Gibson and Caldeira 2009a; Hoekstra and LaRowe 2013). Alternatively, diffuse support 
is one's support for the Court's role in the political system, normally expressed by a person's unwillingness to make fundamental changes to the Court's functional/structural role. For example, Gibson, Caldeira, and colleagues (see, e.g., Caldeira and Gibson 1992; Gibson et al., 2003a; Gibson, Caldeira, and Spence 2003b; Gibson and Caldeira 1992; and Gibson and Caldeira 2009a) have developed a widely used measurement index asking respondents how willing they are to change the Court's jurisdiction, do away with the Court itself, believe the Court gets too mixed up with politics, and how trustful they are of the Court. Whereas specific support is often ephemeral and context-dependent, scholars view diffuse support as a more durable orientation toward the Court's institutional role; people often do disagree with the Court on particular rulings, but they nonetheless still express a strong institutional loyalty (Gibson, Caldeira, and Baird 1998).

While somewhat semantical, scholars refer to specific support as simply support, satisfaction, and/or approval, while labeling institutional legitimacy, institutional loyalty, and/or institutional support as diffuse support. I follow this nomenclature in my conceptualization of constitutional support. Feelings on a constitution can be conceptually divided into constitutional approval (specific support) and constitutional loyalty (diffuse support). ${ }^{3}$ Questions asking for thermometer ratings on constitutions, approval of specific constitutional provisions, and/or satisfaction with the current constitution or its performance (all of which are ubiquitous in general surveys on constitutions; see Stephanopoulos and Versteeg 2016, 120) are better described as tapping into a person's specific rather than diffuse support. Queries ascertaining a willingness (or not) to modify the document fundamentally (e.g. replace it) are analogous to the

\footnotetext{
${ }^{3}$ Note that this conceptualization refers to an individual's feelings on the constitution's legitimacy, as defined here.
} 
diffuse support index used by judicial scholars. It is likely that periodic and more general constitutional conventions tap into an individual's diffuse support, or constitutional loyalty, more than her specific support given the substance.

Periodic Conventions \& Constitutional Loyalty: A Theory

Various articles exist on state and federal constitutional development related to periodic conventions, including descriptive statistics on popular constitutional support (see, e.g., Benjamin 2002; Dinan 2009; Dinan 2010; Grad and Williams 2006; May 1987; and Tarr 2016). The periodic convention literature is heavily focused on examining formational institutional properties of conventions; reasons for calling conventions; intra-convention process politics; and mechanisms of constitutional amendment/ratification resultant from conventions (for a review, see Snider 2017, 258). ${ }^{4}$ Unfortunately, these works do not address the role of periodic conventions in constitutional approval and loyalty.

However, the debate between James Madison and Thomas Jefferson concerning the efficacy of periodic conventions provides some insight into the role these conventions may play influencing constitutional approval and loyalty. Madison, writing in Federalist 49, feared that "frequent appeals" (e.g. periodic conventions) to the people would "deprive the government [or constitution] of the veneration that time bestows upon everything" (Madison [1788] 1961, 311), ultimately reducing constitutional support by negating its semi-permeance. Jefferson, meantime, advocated for periodic conventions as a means for succeeding generations to conduct "periodic repairs" and consciously reevaluate the status quo every generation (or every 19 years by his calculation). Thus, by holding periodic conventions to scrutinize the Constitution, Jefferson

\footnotetext{
${ }^{4}$ This literature is more extensively reviewed in Chapter 2.
} 
believed future generations can give explicit consent by affirmatively endorsing the status quo, revising the social contract, and/or redressing suboptimal institutions (Brennan 2017; Levinson 2012).

From this debate, two mechanisms are uncovered that may help generate constitutional support. The first concerns the idea that habit breeds obedience, generating both constitutional approval and loyalty. Constitutional support becomes self-reinforcing: the longer a charter goes without being replaced or changed, the more likely any proposed change will be rejected (Zink and Dawes 2016). This is often termed Aristotelian support since Aristotle argued that the law's strength lies in the habitual obedience it inspires within citizens. A second mechanism concerns a constitution's susceptibility to change; does knowing that the document has a sunset provision matter in hardening or weakening habitual obedience? Ironically, and despite his opposition to periodic conventions, Madison's Federalist 49 provides some rationale for periodic conventions strengthening constitutional support rather than weakening it: "The reason of man, like man himself, is timid and caution when left alone, and acquires firmness and confidence in proportion to the number with which it is associated. When the examples which fortify opinion are ancient as well as numerous, they are known to have a double effect" (emphasis in original; Madison [1788] 1961, 311-312). Rather than reducing loyalty, periodic conventions "might have encouraged Americans to see the Constitution as something not to be respected not only because of its origin in 1787 but also because of its endorsement by later generations" (Brennan 2017, 940).

Scholars have found indirect evidence for both mechanisms. Options framed as the "status quo," for example, are more likely to be chosen by individuals than when no default point 
is specified (Samuelson and Zeckhauser 1988; Tversky and Kahneman 1991). Moreover, individuals assume that the status quo is preferable because it exists, a tendency that grows stronger the longer the status quo remains in place (Eidelman et al., 2010; Eidelman and Crandall 2014). In this same vein, individuals prefer to avoid current losses over seeking unrealized gains (Kahneman, Knetsch, and Thaler 1991), while also being more susceptible to frames that emphasize risks (Eckles and Schaffner 2011). Consequently, periodic conventions may, much to Jefferson's chagrin, encourage further support for the current constitution given the inherent risks associated with replacing it (however accurate or realized those risks may be). The question remains, though, if Madison's contention is accurate: does telling the public that prior conventions were rejected induce greater constitutional loyalty?

\section{Existing Research \& Shortcomings}

The research on constitutional support is relatively sparse and novel, with a focus on constitutional approval rather than constitutional loyalty. To date, Stephanopoulos and Versteeg (2016) is the only work that comprehensively analyses factors generating constitutional approval. A couple of others works (Blake and Levinson 2016 and Zink and Dawes 2016), though, do provide some insight into constitutional loyalty, albeit under the guise of examining constitutional veneration. ${ }^{5}$ Collectively, these studies explore two broad themes: (1) whether a constitutional status quo bias exists and (2) what factors generate or influence constitutional approval (specific support). Public attitudes toward both the federal and state constitutions tend to be positive, with the federal charter enjoying greater approval than state constitutions (Stephanopoulos and Versteeg 2016; Zink and Dawes 2016). Zink and Dawes (2016) attribute this finding to the lower

\footnotetext{
${ }^{5}$ See Chapter 2 for an elaboration.
} 
status quo bias that exists at the state level, finding that a strong degree of constitutional attachment, or existence bias, exists in Americans despite their ideological, political/policy preferences, risk orientations, and constitutional knowledge.

Scholars have also found that other factors figure prominently in generating constitutional support. Blake and Levinson (2016) find that one's legal consciousness (e.g. their preferred mode of constitutional interpretation) shapes constitutional attitudes and support; in examining support for a federal constitutional convention, the authors find that convention support is linked to how one evaluates her legal standing relative the constitutional status quo bias. Put another way, those who find that the Constitution offers them full political citizenship and engagement opportunities are less likely to support a convention; those who feel the process is "broken" are more likely to favor change. Similarly, Stephanopoulos and Versteeg (2016) find that constitutional approval is heavily linked with an individual's constitutional knowledge and feelings on other governmental institutions, but not one's demography or partisanship/ideology (although race and age were exceptions; see Chapter 2 for more information). Importantly, Stephanopoulos and Versteeg (2016) also examine non-substantive factors of a constitution (including its age, length, and amendment rate), factors that arguably encourage obedience; they find no relationship, though, with constitutional approval. More likely, though, is that these factors (especially a constitution's age) become salient when invoked (e.g. framing/priming).

While I review these works more extensively in Chapter 2, I do note three collective shortcomings here. First, the implicit assumption within these works is that a constitutional status quo bias exists, and studies have sought to examine what factors promote that bias or support. This is arguably related to the Aristotelian mechanism of support above: habit breeds 
obedience. Little research has explored how knowledge that a constitution can be fundamentally changed influences this habit. Zink and Dawes (2016), however, do find that framing a policy change as a constitutional amendment rather than a statutory modification invokes greater opposition. However, they do not address wholescale constitutional replacement. Blake and Levinson (2016) are closer to the mark examining federal constitutional convention support, but their study is geared more towards constitutional interpretation rather than determining if a person's constitutional loyalty was affected.

Second, the federal Constitution, with a history of not having periodic conventions, is arguably ill-suited for testing these inquiries. State constitutions are, with only nine states having had just one constitutional convention (Levinson 2012, 342-343). Despite this history, there has been a steep decline in state constitutional conventions being held and supported at the ballot box by voters (Snider 2017). This context suggests a fertile ground to assess the impact of periodic conventions on constitutional approval and loyalty, complimented by the fact that 14 states ask voters whether they would like to hold a constitutional convention at set intervals (see Chapter 2 for further information).

Finally, there is a focus on specific support, or assessment of constitutional approval and satisfaction. This dissertation's focus, meantime, is aiming at approximating diffuse support (constitutional loyalty) more than constitutional approval. Given the knowledge that a constitution could be fundamentally changed and was/was not, how do feelings on its legitimacy vary (if at all)? Conceptualized this way, Blake and Levinson's (2016) analysis is closer to measuring constitutional loyalty, ${ }^{6}$ while Zink and Dawes (2016) demonstrate how the same policy

\footnotetext{
${ }^{6}$ Albeit support for a federal constitutional convention.
} 
framed as a constitutional amendment enjoys less support than when characterized statutorily. Neither, however, discuss a constitution's prior susceptibility to change (e.g. being informed that prior conventions were rejected), with Blake and Levinson (2016) suggesting individuals are making a contextualized, short-term assessment, viz. how is the constitution at present doing? Measuring constitutional loyalty requires not only a more appropriate question battery but also a different prime: If people are aware of the consequences of a convention, how does their constitutional loyalty (and, to a lesser extent, approval) vary?

\section{Research Design \& Methodology}

To explore these questions, I use a between-subjects survey experiment administered to Wayne State University undergraduates. Students were asked to participate in an anonymous survey exploring their knowledge and feelings towards the federal and Michigan state constitutions. Participants were first given a pre-test measuring their demographic characteristics (e.g. age, race, and socioeconomic status), sociopolitical variables (e.g. ideology, partisanship, and political orientations), and initial specific and diffuse support for the federal and Michigan state constitutions. Subjects were then randomly assigned to one of four experimental conditions. Depending on condition (i.e. treatment) assigned, subjects encountered varying information concerning Michigan's 2010 periodic convention and its abilities (specifically to replace the Michigan constitution) via a mock newspaper article. After reading the experimental vignette (i.e. the newspaper article), subjects completed a post-test with three tasks: (1) two questions on how likely they are to support a constitutional convention at the federal and state levels; (2) two short question batteries on federal and Michigan state 
constitutional knowledge; and (3) complete, again, the specific and diffuse support question batteries from the pre-test.

While I elaborate on my methodology and operationalization in Chapter 3, I provide a summary of my treatments here given their central importance. The treatments explore how additional information about periodic conventions influence subjects' constitutional loyalties, including whether the inclusion of a prime (i.e. prior conventions were rejected/approved) modifies results. These primes help to test for the second mechanism noted above: does prior knowledge about the constitution's susceptibility to change condition constitutional loyalty? Subjects assigned to the "control" received a "plain" article on the 2010 convention question. ${ }^{7}$ The article did not frame, prime, or otherwise emphasize features of a periodic convention (specifically that it can wholescale replace the present charter) and balances discussion by providing an affirmative and negative position on holding the convention.

The remaining treatments were based on altered articles: Subjects assigned to the "more information" group read the control article but with an added paragraph describing how a seated convention could fundamentally alter or replace the current constitution. This treatment effectively measures whether a constitutional status quo bias exists by inducing the subject to consider replacing the charter (see also Zink and Dawes 2016). The remaining treatments explore whether Madison's contention in Federalist 49 is correct - or, rather, if a prime matters. The "negative prime" treatment presents subjects with the article found in the "more information" group but with another added paragraph highlighting how past convention referenda were

\footnotetext{
${ }^{7}$ For a discussion about how I constructed these mock articles, including source material, see relevant discussion in Chapter 3.
} 
rejected by voters. Conversely, the "positive prime" article emphasizes a series of past referenda that were approved by voters, suggesting that the public in the past has been critical of the state's constitution, albeit earlier versions. Knowledge that voters have voted to fundamentally review the state constitution may work against the charter's institutional loyalty.

Importantly, these treatments inquire about the Michigan state constitution. Assessing subjects on Michigan constitutional loyalty is prudent given: (1) subjects are attending a Michigan public university; (2) subjects are likelier to have a greater understanding of the Michigan periodic convention mechanism as well as the Michigan constitution; and (3) Michigan is one of 14 states that use periodic conventions in their constitutional practice, providing a degree of mundane realism that reduces the need for artificiality. As a result, the experiment can speak more generally to other states using periodic conventions and to states (or nations) that are considering them.

Finally, this design mitigates against many threats to internal and external validity. Random assignment to the treatment conditions ensures roughly equivalent groups, while changes in the general environment should be balanced among both control and treatment groups (Campbell and Stanley 1963). Moreover, the between-subjects design makes it difficult for a subject to infer experimenter intent, given that: (1) the subject is unaware of which condition he was placed within and (2) the blurring line between the experimental sections and the non-randomized material all respondents encounter (Mummolo and Peterson 2017). While the sampling of college students may threaten the study's external validity (see Sears 1986), this threat is less concerning for research dealing in framing and priming effects (Druckman and Kam 2011; Druckman and Nelson 2003). Given the dissertation's focus on priming subjects to be 
aware of the Michigan constitution's susceptibility to change, it would appear that the use of a college student sample is not necessarily a knock against external validity. Indeed, there is nothing in the larger literatures on institutional or constitutional support suggesting that college students differ systemically in how they respond to primes (for further elaboration, see relevant discussions in Chapter 3), while the experiment controls (albeit post-hoc) for various confounders that may explain differences in how constitutional loyalty is generated (i.e. the pre-test questions).

\section{Chapter Outline}

The remainder of the dissertation proceeds as follows: Chapter 2 surveys the relevant literatures on legitimacy theory, constitutional support, and periodic conventions. I relate these works to my theory and present study, noting my hypotheses and how my findings contribute to existing scholarship. Chapter 3 lays out my study's methodology. My experimental design, variable operationalizations, subject recruitment, and finally notes on reliability, validity, and objectivity are thoroughly discussed. Empirical findings, analyses, and implications are detailed in the next three chapters. Chapter 4 engages in an exploratory analysis regarding predictors of constitutional loyalty using both descriptive and regression techniques. Chapter 5 turns to the experimental results, evaluating the bulk of my hypothetical expectations and discussing the substantive implications. Chapter 6 concludes my empirical analysis by exploring the relationship between constitutional knowledge and constitutional support, offering an improved measurement scheme. Finally, Chapter 7 provides a comprehensive discussion about my study's implications and "big picture" ramifications, especially in an era of hyperpartisanship and low 
constitutional understanding. Here, I also discuss future avenues of research and address unanswered questions. 


\section{CHAPTER 2 - CONSTITUTIONAL LOYALY: IMPORTANT TO THE FOUNDERS BUT IGNORED BY THE DISCIPLINE}

Extant research on constitutional support and attitudes is relatively small and novel, but these existing works are complimented by a more established research program in legitimacy theory and political support for institutions. Other scholars, meantime, have debated the merits of periodic conventions and explored their internal organizations, initiating referenda (and voter support of them), and convention outputs. In this chapter, I provide an overview of this literature and how it relates to my present study. First, I explore the theoretical background of institutional support, extending this basis to public support for constitutions. Next, I examine the relationship between periodic conventions and constitutional loyalty using the recurring debate over constitutional veneration and change. I also provide a detailed account of what prior, seminal works on constitutional support and periodic conventions have found. Finally, I relate these works and theory to my present study, noting my hypothetical expectations that will guide my inquiry.

\section{Institutional Support \& Legitimacy Theory}

Institutional legitimacy is a concept "central to political science" (Tanenhaus and Murphy 1981, 24), and a topic with which congressional, presidential, and court scholars have long been fascinated. Legitimacy refers to the "belief that a rule, institutions, or leader has a right to govern," an individual's judgment and feelings about the rightfulness of the institution's command over its subject (Hurd 2007), commonly (and broadly) referred to as political support. When examining political and institutional support, the predominant theoretical framework in political science is David Easton's (1965) legitimacy theory. Easton envisions political support as 
an input into the larger political system, alongside sociopolitical and policy demands. The system processes these demands and support in a manner that is not specified by Easton, but the system's outputs are predicated on these demands and support. Subsequent outputs, in turn, affect future demands and support, generating a feedback loop. While some scholars (e.g. Hibbing and Theiss-Morse 1995) argue that support is better conceptualized not as an input but a trait that conditions how inputs are handled, for our purposes Easton's conceptualization is fine: we are more concerned with exploring what generates public support for constitutions and how this support can be influenced, not necessarily how it plays in the larger political system. ${ }^{1}$

For Easton, institutional legitimacy is based on the idea that citizens accept the moral authority of institutions to make decisions for society at-large. Citizens' sense of legitimacy is contingent upon such authorities conforming to citizens' "own sense of what is right and proper in the political sphere" (Easton 1965, 278). Such support, moreover, is likely to be a "stronger inner conviction" (Easton 1965, 278), explaining why citizens may disagree with specific policy outputs of institutions yet still "accept the validity of the policy decisions because of their deepseated beliefs regarding the uprightness of the institution" (Cann and Yates 2008, 303). This diffuse support, or institutional loyalty, is the core of legitimacy theory, and differs from what scholars call specific support, or job approval (Baird 2001; Caldeira and Gibson 1992; LaRowe and Hoekstra 2014). Unlike specific support that tends to be rational, short-term, and tied with specific policy outputs (e.g. specific constitutional amendments or proposals), diffuse support is

\footnotetext{
${ }^{1}$ Although these implications are important. Constitutional support is undoubtedly an important ingredient in political stability, good governance, and the political system's larger legitimacy (see Elkins, Ginsburg, and Melton 2009).
} 
more durable and connotes a preference to avoid fundamental changes (Caldeira and Gibson 1992; Gibson, Caldeira, and Spence 2003a; Gibson and Caldeira 2009a).

Specific versus Diffuse Support

Understanding the conceptual dichotomy between specific and diffuse support can be distilled from studies on the U.S. Supreme Court's (SCOTUS) public support. The SCOTUS's specific support is usually based on one's agreement with its rulings (Franklin and Kosaki 1989), although it can fluctuate due to other short-term factors, including: support for other institutions (Caldeira 1987); opinions on how the Court is conducting its business (Hibbing and Theiss-Morse 1995); and/or controversy over the nomination process and nominees (Gibson and Caldeira 2009a; Hoekstra and LaRowe 2013). Alternatively, diffuse support is one's support for the Court's role in the political system - normally expressed by a person's unwillingness to make fundamental changes to the Court's functional role. For example, Gibson, Caldeira, and colleagues (see, e.g., Caldeira and Gibson 1992; Gibson, Caldeira, and Spence 2003a and 2003b; Gibson and Caldeira 1992; and Gibson and Caldeira 2009a) have developed a widely used measurement index that asks respondents how willing they are to change the Court's jurisdiction, do away with the Court itself, believe the Court gets too mixed up with politics, and how trustful they are of the Court. Whereas specific support is often ephemeral and context-dependent, scholars view diffuse support as a more durable orientation toward the Court's institutional role; people often do disagree with the Court on specific rulings, but they nonetheless still express a strong institutional loyalty (Gibson, Caldeira, and Baird 1998).

However, the distinction between specific and diffuse support does not enjoy universal backing. Hibbing and Theiss-Morse $(1995,13)$ provide a trenchant critique: 
What Easton calls diffuse support is closer to traditional notions of support, reaching deeper than the superficial and ephemeral reactions to particular outputs. Yet... [specific and diffuse] support... [are] not immutable since [they] can be affected by particular outputs, scandals, and conditions.... Support of any kind is by definition more than reactions to any single output or action. Rather it is the combination of personal predispositions and remembered events. (internal citations omitted)

Despite these theoretical concerns, some judicial scholars have found that specific and diffuse support are empirically independent of one another (see Gibson and Caldeira 1992). ${ }^{2}$ While specific support may, indeed, be "superficial and ephemeral reactions to particular outputs" (Hibbing and Theiss-Morse 1995, 13), it is still telling that people are capable of reacting one way towards an institution's outputs and quite another way to the institution's overall legitimacy. While somewhat semantical, scholars (predominantly Gibson et al.) have begun referring to specific support as simply support, satisfaction, and/or approval, while labeling institutional legitimacy, institutional loyalty, and/or institutional support as diffuse support.

I follow this nomenclature in my conceptualization. Feelings on constitutions can be conceptually divided into constitutional approval (specific support) and constitutional loyalty (diffuse support). ${ }^{3}$ Questions asking for thermometer (likeability) ratings on constitutions, approval of specific constitutional provisions, and/or satisfaction with the constitution's current performance - all of which are ubiquitous in the literature - are better described as tapping into a person's specific rather than diffuse support. As Stephanopoulos and Versteeg $(2016,120)$ argue:

When people are asked how strongly they approve of their constitution, they are prompted to consider and then rate their current views of the document. They are not

\footnotetext{
${ }^{2}$ Some scholars argue that it is too difficult to effectively disentangle the two concepts empirically-speaking (see, e.g., Davidson and Parker 1972).

${ }^{3}$ Note that this conceptualization refers to an individual's feelings and attitudes towards a constitution's legitimacy or their loyalty to it, as defined here.
} 
induced to reflect on whether they still would adhere to its commands if they thought them unjust, or whether they would like to scrap it and start afresh. Constitutional approval, like equivalent questions about judicial, legislative, and executive branch approval, thus taps people's opinions on constitutional performance. It does not capture their feelings on constitutional legitimacy. (emphasis in the original)

Questions ascertaining a willingness (or not) to modify the document fundamentally (i.e. start anew) are analogues to the diffuse support index used by judicial scholars measuring the SCOTUS's institutional loyalty. It is likely that periodic and more general constitutional convention calls tap into an individual's diffuse support more than her specific support given the substance.

An analogy helps to clarify the conceptual distinction between specific and diffuse support. Marital relationships include both specific and diffuse support elements. Specific support refers to a partner's current feelings toward her spouse, which are context dependent and will likely wax and wane depending on the spouse's outputs (e.g. forgetting to take the garbage out). However, marital diffuse support is the long-term commitment to the institution of marriage; while she may express dissatisfaction that he has not taken the garbage out, she nonetheless remains committed to the marriage (as an institution). This explains the distinction between momentarily disagreements between spouses (specific support) and the underlying marital commitment (diffuse support). However, continual quarrels (i.e. low specific support) may generate a decline in diffuse support (and, ultimately, a fundamental change in the underlying institution - or marriage). Connecting this analogy with constitutional approval and loyalty, one sees how the spouses' current feelings toward each other are analogous to constitutional approval; how much one currently "likes" the constitution is a specific, timedependent appraisal. Meantime, the underlying belief in marriage is similar to a person's 
underlying commitment to the constitution (or the governmental system it creates) - which we term constitutional loyalty.

\section{Periodic Conventions \& Constitutional Loyalty}

\section{Studying Periodic Conventions}

Various articles exist on state and federal constitutional development related to periodic constitutional conventions ("periodic conventions") and descriptive statistics on popular support for constitutions (see, e.g., Benjamin 2001; Dinan 2009 and 2010; Grad and Williams 2006; May 1987; and Tarr 2016). The periodic convention literature is heavily focused on examining formational institutional properties of conventions; reasons for calling conventions; intraconvention process politics; and mechanisms of constitutional amendment/ratification resultant from convention work (for a review, see Snider 2017). Unfortunately, these works do not address the role of periodic conventions in constitutional approval and loyalty.

While I do not comprehensively review these works here, I do discuss some pertinent themes. First, given the lack of federal experience, research on periodic conventions is almost exclusively on state constitutions. Indeed, the state experience in America provides evidence that Americans are quite willing (if not downright eager) to replace their charters. As Dinan notes (2009; see also Tarr 2016), there have been over 230 state constitutional conventions since 1776, translating into an average of five per state (see Snider 2015). Many of these conventions did not just recommend various amendments to their current state's charter; many wholescale replaced the document with a new constitution. Since World War II, moreover, a majority of states have replaced their constitutions through conventions (Grad and Williams 2006), with Louisiana being the most recent in 1992. It is hard to argue, then, that there exists a general "disposition to 
'venerate' all constitutions or believe that they are impervious to change, including change through conventions," (Blake and Levinson 2016, 3) at least where state charters are concerned. At least among state legislatures, a willingness to countenance constitutional conventions at the federal level is also apparent given that over 28 states have approved resolutions calling for an Article V convention (Blake and Levinson 2016).

However, in the modern era there has been a marked decline in state periodic conventions held relative to the nineteenth century. While the 1960s and 70s saw a burst of convention activity ( 20 states held constitutional conventions), since the 1980 s not a single periodic convention referendum has been approved by voters. The trend is especially apparent between 2008 and 2012: in four short years, ten convention referenda were soundly rejected by voters, with 2010 representing a historical high when four were shot down (Snider 2015). Meantime, the median age of state constitutions has increased from 96 years in 1994 (Lutz 1995) to over 110 years today (Levinson 2012, 335). Scholarship on the decline of periodic conventions ${ }^{4}$ broadly argues that conventions are used as a "modernizing" tool by elected officials and political elites (Benjamin 2001; Dinan 2010; Kogan 2010), although others (Snider 2017) assert the convention as a means of the people circumventing the state legislature's agenda control (and gatekeeping power) regarding constitutional revision. In short, the decline can arguably be attributed to opponents' emphasis on "runaway" conventions that could harm the underlying constitutional system of government (or legislators' unwillingness to permit unrestrained

\footnotetext{
${ }^{4}$ Some scholarship argues that the recent decline in periodic conventions is simply a "valley" within a long-term pattern of peaks and valleys (see, e.g., Adrian 1967; Dinan 2000; and Tarr 2014).
} 
conventions that may limit the legislature's institutional powers) while tapping into Americans' general proclivity to avoid fundamental constitutional revisions (see below).

Another relevant theme concerns the interconnected structural factors that have led to a decline in periodic conventions. One factor is legislature hostility, particularly given legislators with long-term career goals of entrenching the legislature's power vis-à-vis the other branches and people (Sturm 1970). A second factor concerns the growth of what Snider (2017) terms "constitutional sclerosis." This results from increased interest group opposition to constitutional change generally, given that interest groups use state constitutions as a "safety vault" for entrenching favorable laws (Irvine and Kresky 1962; see also Olson 1982 for the background theory). Periodic conventions become threats to cracking open these "vaults," and special interests work tirelessly to convince voters to not approve the referenda (using various techniques, including the notion that a "runaway" convention may "gut" the constitution). A third, and related, factor concerns the public's ignorance on periodic conventions, allowing for manipulation by legislative and political elites. Not surprising, researchers (Thomas 1968 and Snider 2017) have found that voters turn to familiar cues to determine their vote choice on periodic conventions. Michigan and New York (both states with long histories of periodic conventions) provide two prominent examples: During the 1960 s series of convention referenda, Michigan voters' partisanship was the deciding factor in determining support (Thomas 1968), while legislative advertising highlighting risks and associated "dangers" of constitutional conventions carried greater weight with New York voters than more positive messages (Snider 2017). 
Madison and Jefferson: Debating the Merits of Periodic Conventions

As the previous section illustrates, periodic convention scholars have directed their energies towards explaining the decline of periodic conventions, with structural factors being predominant. However, an interesting question emerges: Do efforts to frustrate convention referenda influence voters' underlying constitutional support? While the scholarship reviewed above asserts that voters are responding to interest group and other political cues, a question remains whether these cues are tapping into a more fundamental propensity within voters (e.g. their constitutional loyalty). Perhaps periodic conventions are soundly defeated because voters do recognize they represent an existential threat to the charter's integrity. Then again, perhaps voters are merely following their partisanship, with their underlying constitutional attitudes having little impact on their vote choice.

Similar questions and concerns over federal periodic conventions vexed James Madison and Thomas Jefferson during the Second Founding. Their debate provides some insight into the role periodic conventions may play influencing constitutional approval and loyalty. Madison, writing in Federalist 49, feared that "frequent appeals" to the people would "deprive the government [or constitution] of the veneration that time bestows upon everything" (Madison [1788] 1961, 311), ultimately reducing constitutional loyalty and approval by negating its semipermanence. This theme is not unlike Aristotle's notion that the law's strength lies in the habit of obedience it inspires within citizens; instability, or questioning, of its permeance weakens the very notion of law itself (see Politics, Book II, section 8). Other scholars have echoed this sentiment (see, e.g., Elkins et al., 2009; Holmes 1995; and Strauss 2010), but Madison and his proponents did not favor excessive veneration or blind support; amendments addressing a 
charter's deficient aspects should be entertained and considered (Bailey 2012), but a citizenry "high" on the status quo may be unable to do so (see also Hunsicker 2012, 55-58).

Conversely, Jefferson advocated for periodic conventions as a means for succeeding generations to conduct "periodic repairs" and consciously reevaluate the status quo every generation (or every 19 years by his calculation). ${ }^{5}$ Thus, by holding periodic conventions to scrutinize the constitution, Jefferson believed that future generations can give explicit consent by affirmatively endorsing the status quo or revising the social contract (Brennan 2017). ${ }^{6}$ Besides renewing the social contract, periodic conventions permit an opportunity to redress suboptimal institutions; as Levinson (2012) notes, an overabundance of loyalty towards a constitution can make a people complicit in its own political dysfunction.

From this debate, there are two mechanisms that may help generate constitutional support. The first concerns the idea that habit breeds obedience, generating both constitutional satisfaction and loyalty. Scholars have found indirect evidence of this mechanism in the research on status quo bias. Options framed as the "status quo" are more likely to be chosen by individuals than when no default point is specified (Samuelson and Zeckhauser 1988; Tversky and Kahneman 1991). Moreover, individuals tend to associate the existence of a status quo with normative "goodness;" persons assume that the status quo is preferable because it exists, a tendency that grows stronger the longer the status quo remains in place (Eidelman, Pattershall, and Crandall 2010; Eidelman and Crandall 2014). By extension, constitutional support becomes selfreinforcing: the longer the charter goes without being replaced or changed, the more likely any

\footnotetext{
${ }^{5}$ Ironically, Elkins et al. (2009) find that the average lifespan of a constitution (albeit it national charters) is 16 years, making the U.S. Constitution a significant exception.

${ }^{6}$ Rousseau (1994) makes a similar argument in the Social Contract (188-190).
} 
proposed change will be rejected outright without any appeal to the merits (Zink and Dawes 2015).

An alternative mechanism concerns a constitution's susceptibility to change; does knowing the document has a sunset provision matter in hardening or weakening habitual obedience? Ironically, and despite his opposition, Madison's Federalist 49 provides some rationale for periodic conventions strengthening constitutional support rather than weakening it:

The reason of man, like man himself, is timid and caution when left alone, and acquires firmness and confidence in proportion to the number with which it is associated. When the examples which fortify opinion are ancient as well as numerous, they are known to have a double effect. (emphasis original; Madison [1788] 1961, 311-312).

Rather than reducing loyalty, periodic conventions "might have encouraged Americans to see the Constitution as something not to be respected not only because of its origin in 1787 but also because of its endorsement by later generations" (Brennan 2017, 940). Again, there is indirect evidence to suggest this may be the case from the status quo and risk aversion literatures: Framing the current constitution as the reference point leads individuals to forgo evaluating alternatives on the merits (see Samuelson and Zeckhauser 1988), causing convention referenda to reinforce existing constitutional support. In this same vein, individuals prefer to avoid current losses over seeking unrealized gains (Kahneman, Knetsch, and Thaler 1991). Risk-averse persons, therefore, are likely to favor alternatives that exhibit characteristics associated with the status quo (Kam and Simas 2012), while also being more susceptible to frames that emphasize risks (Eckles and Schaffner 2011). Consequently, periodic conventions may, much to Jefferson's chagrin, encourage further support for current constitutions given the inherent risks associated with replacing them (however accurate or realized those risks may be). 


\section{Extant Studies: What Generates Constitutional Approval? Loyalty?}

However, there is a dearth of direct empirical studies on constitutional approval and loyalty, with most works focused on examining the former. To date, Stephanopoulos and Versteeg (2016) is the only study that directly analyses factors that generate constitutional approval. A couple of other works (Blake and Levinson 2016; Zink and Dawes 2016), though, do provide some insight into constitutional loyalty, albeit under the guise of examining constitutional veneration. ${ }^{7}$ Collectively, these studies explore two broad themes: (1) whether a constitutional status quo bias exists and (2) what factors generate or influence specific constitutional support. Generally, these works present several common themes but also important differences. Public attitudes toward both the federal and state constitutions tend to be positive, with the federal charter enjoying greater approval than state constitutions (Stephanopoulos and Versteeg 2016; Zink and Dawes 2016). Zink and Dawes (2016) attribute this finding to the lower status quo bias that exists at the state level. In particular, these authors' survey experiments found that a strong degree of constitutional attachment, or existence bias, exists in Americans despite their ideological, political/policy preferences, risk orientations, and constitutional knowledge.

Meantime, other scholars have found that additional factors figure prominently in generating constitutional opinions. Blake and Levinson (2016) find that one's legal consciousness shapes constitutional attitudes and support; in examining support for a federal constitutional convention, the authors find that one's willingness to support a convention is linked to how one

\footnotetext{
${ }^{7}$ For these studies, support for holding a constitutional convention and/or amending the present charter is synonymous with low veneration. It is likely, though, that what these studies attribute as veneration is a measure approximating diffuse support.
} 
evaluates her legal standing relative the constitutional status quo. Put another way, those who find that the Constitution offers them full political citizenship and engagement opportunities are less likely to support a convention; those who feel the process is "broken" (or biased against them) are more likely to favor change. Thus, the constitutional bias exhibited by Zink and Dawes's (2016) subjects is contingent on an individual's participative and efficacy orientations. ${ }^{8}$ Similarly, Stephanopoulos and Versteeg (2016) find that constitutional support is heavily linked with an individual's constitutional knowledge but not one's demography, partisan beliefs, ${ }^{9}$ or sociopolitical attributes. However, two demographic variables did exhibit a significant impact: The older an individual, the stronger one's constitutional approval. Race also mattered: African Americans (and other racial/ethnic minorities, albeit to a lesser extent) correlated with lower levels of constitutional approval. These findings, however, mirror Blake and Levinson's (2016) insights: if one considers themselves a "loser" under the current constitutional regime, then they are less likely to express satisfaction with the document as is. ${ }^{10}$

Two other findings deserve further elucidation: First, the relationship between constitutional knowledge (or familiarity) and constitutional approval is a qualified one. Using a self-reported measure of constitutional familiarity, Stephanopoulos and Versteeg (2016) found those expressing greater knowledge of the federal Constitution rated the document significantly

\footnotetext{
${ }^{8}$ This sentiment could also be interpreted to convey whether an individual finds the Constitution "just," another component of diffuse support - further suggesting that rather than measuring constitutional veneration, these studies are capturing constitutional loyalty.

${ }^{9}$ Blake and Levinson (2016) note that partisanship mattered regarding a respondent's propensity for supporting a federal constitutional convention (i.e. Republicans and conservatives were less likely to support than Democrats and liberals). This finding may suggest that partisanship does matter in generating constitutional loyalty; I address this more in Chapter 4.

${ }^{10}$ Gibson and Caldeira (1992) find a similar tend among African Americans and diffuse support for the SCOTUS given the institution's historical role in discrimination against blacks.
} 
higher than low-knowledge persons. The same relationship held for state constitutional approval. However, respondents were not assessed on actual constitutional knowledge, while highknowledge persons fared no better on the survey's reading comprehension quizzes than lowknowledge respondents. These findings offer only tentative evidence, therefore, of a relationship between constitutional knowledge and support. Second, Blake and Levinson (2016) explore whether support (albeit specific support) for the Constitution's created governmental institutions influences one's support for holding a federal constitutional convention. From a descriptive standpoint, they find that higher approval ratings for the president, Congress, and the SCOTUS correspond with a lower likelihood of supporting a constitutional convention. Therefore, Blake and Levinson's findings suggest a positive relationship between institutional attitudes and constitutional loyalty, raising interesting questions regarding how a constitution may be evaluated more by what its created institutions do rather than on the charter's own merits.

Finally, Stephanopoulos and Versteeg (2016) examine non-substantive factors of a constitution that arguably proxy features that encourage obedience. The charter's age (in years), length (in words), and amendment rate (in number of amendments) were all regressed on an individual's level of constitutional approval, yielding null findings. These results are interesting and offer a basis for further research: an older constitution, for example, arguably should be more entrenched than a younger one. If habit breeds obedience, then older constitutions should elicit stronger approval and loyalty. However, a constitution's age does not appear to matter, or at least becomes insignificant in the face of other factors. More likely, though, is the fact that these non-substantive factors enter the equation elsewhere or become salient when invoked (Zink and Dawes 2016). 


\section{Shortcomings}

Several shortcomings can be noted of these works. First, all three examine the Aristotelian mechanism of institutional support: habit breeds obedience. Indeed, the implicit assumption has been that a constitutional bias exists, and studies have sought to examine what factors promote that bias or support. Little research has attempted to ascertain how knowledge that a constitution can be fundamentally changed influences this habit. Zink and Dawes (2016), however, do find that framing a policy change as a constitutional amendment rather than a statutory modification invokes greater opposition. However, this is on a specific policy or feature of a constitution; it does not address wholescale constitutional replacement, arguably the existential threat represented by periodic conventions. Blake and Levinson (2016) get closer to this question, though, by examining support for a federal constitutional convention; they find that one in three Americans support holding a convention, suggesting that constitutional support is low for these individuals. However, they also find that some respondents indicated that the Constitution had "held up well" yet still favored holding a convention. This questioning is closer to the mark (i.e. measuring both specific and diffuse support), but it still falls short: as Blake and Levinson (2016) found, support for a federal constitutional convention was contingent on how one viewed themselves in relation to the extant constitutional order, a contextual appraisal. The poll's questioning was also geared more towards constitutional interpretation rather than constitutional endurance, suggesting the influence of a prime.

Second, the federal Constitution is arguably ill-suited for addressing questions about periodic conventions influence on constitutional loyalty and approval. State constitutions are more amendable. As reviewed above, the states "have held 233 constitutional conventions, 
adopted 146 constitutions, and ratified over 6,000 amendments to their current constitutions"

(Dinan 2009, 7), while "only nine of the fifty states have had just one constitutional convention"

(Levinson 2012, 342-343) in their histories. Coupled with the long-term decline in state constitutional convention incidence (see above), state charters represent a more fertile ground to assess the impact of periodic conventions on constitutional approval and loyalty. This is especially true given that 14 states $^{11}$ ask voters whether they would like to hold a constitutional convention at set, regular intervals. ${ }^{12}$

Finally, there is a focus on specific support, or assessment of constitutional approval and satisfaction. As Stephanopoulos and Versteeg (2016) indicated (and discussed above), their work approximates specific support. My research, though, is aimed at exploring constitutional loyalty, or diffuse support: Given the knowledge that a constitution could be fundamentally changed and was/was not, how does one's loyalty vary? Does it? Conceptualized this way, Blake and Levinson's (2016) analysis is closer to measuring diffuse support (i.e. support for a constitutional convention, albeit at the federal level), while Zink and Dawes (2016) demonstrate how the same policy framed as a constitutional amendment enjoys less support than when characterized statutorily. But both still fall short: neither discusses a constitution's prior susceptibility to change, while both use methods that invoke short-term assessments by respondents. Meantime, the periodic

\footnotetext{
${ }^{11}$ The states are (along with their automatic submission cycles and next election when the ballot question appears): Hawaii (9 years; 2028); Alaska (2022), lowa (2020), New Hampshire (2022), and Rhode Island (2022) (10 years); Michigan (16 years; 2026); and Connecticut (2028), Illinois (2028), Maryland (2030), Missouri (2022), Montana (2030), New York (2037), and Ohio (2032) (20 years). Interestingly, the Oklahoma state constitution requires constitutional convention questions be submitted to voters every 20 years, but the state government has not followed the provision since 1970, the last time the ballot question appeared (and was rejected by voters). ${ }^{12}$ The idea for mandatory convention referenda dates back to the late eighteenth century, appearing in the constitutions of Massachusetts, New Hampshire, and Kentucky (Dinan 2000), although no state today has mandatory constitutional conventions - just mandatory convention questions (Snider 2017). This is somewhat different from Jefferson's original preference but is more in line with his later thinking and Madison's own beliefs.
} 
convention literature could be bolstered by exploring whether voters' constitutional opinions are fundamentally affected by convention referenda. In sum: Assessing constitutional loyalty requires not only a more appropriate question battery but also a different testing medium: periodic conventions.

\section{My Study: Research Questions, Goals, and Expectations ${ }^{13}$}

Several questions can be distilled from this philosophical debate and empirical literatures. Is constitutional loyalty reinforced or undermined by periodic conventions? Literature on risk aversion and constitutional status quo bias suggests that once voters are aware of the potentiality that a periodic convention represents (i.e. replacing a constitution), voters are less inclined to support it. Thus, I would expect periodic conventions to increase a subject's constitutional loyalty since conventions represent a threat to the charter's integrity.

Hypothesis 1a: Subjects exposed to more information about periodic conventions will exhibit higher constitutional loyalty.

Yet, the literature on diffuse support would seem to discount this possibility, given its long-term, and resilient, nature. Periodic conventions, though, may influence a person's constitutional approval, given specific support's ephemeral nature.

Hypothesis 1b: Subjects exposed to more information about periodic conventions will exhibit higher constitutional approval.

Madison's contention, though, remains: Does knowing that prior periodic conventions were rejected by voters (or were approved) affect constitutional loyalty? If the position is valid, then constitutional loyalty should increase among voters who know a constitution was successfully

\footnotetext{
${ }^{13}$ For further refinement of these hypothetical expectations as they relate to my inquiry, see Chapters 5 and 6.
} 
retained in prior elections. Voters informed that prior conventions were approved, though, should express weakened loyalty.

Hypothesis 2a: Subjects informed about prior periodic conventions being rejected by voters will have higher constitutional loyalty than those told prior periodic conventions were approved.

Hypothesis 2b: Subjects informed about prior periodic conventions being rejected by voters will have higher constitutional approval than those told prior periodic conventions were approved.

Again, the nature of diffuse support should argue against Madison's contention, but I assume its potentiality given the goal of empirically evaluating it.

The literature on periodic convention support also suggest two further hypotheses. First, individuals informed about periodic conventions representing existential threats to constitutions express their dissatisfaction electorally. While it is an open question about whether a prime (i.e. informing voters that prior conventions had been rejected/approved) matters, my general presumption is that a person's constitutional status quo bias (once activated) undercuts electoral support.

Hypothesis 3: Subjects exposed to more information about a periodic convention will indicate lower likelihoods of voting to hold a convention.

Second, and relatedly, persons more familiar with periodic convention referenda may respond differently to information about periodic conventions. My expectation, therefore, is that any significant results detected will likely be driven by subjects who were previously ignorant of periodic conventions. 
Hypothesis 4: Subjects less familiar with periodic conventions will be more susceptible to the treatment than subjects with greater familiarity.

Finally, the extant literatures on institutional support broadly and constitutional approval specifically both suggest evidence of "positivity bias" at work. As described by Gibson and colleagues, persons who know more about an institution (e.g. the SCOTUS) also express greater loyalty towards it (see, e.g., Gibson and Caldeira 2009a and 2009b; Gibson, Caldeira, and Baird 1998; and Gibson and Nelson 2015). My general expectation is that persons with greater constitutional knowledge will exhibit greater constitutional loyalty. I also assume that highknowledge persons will be less susceptible to stimuli surrounding periodic conventions than lowknowledge individuals.

Hypothesis 5: Subjects possessing less constitutional knowledge will be more susceptible to the treatment than subjects with greater constitutional knowledge.

As described in Chapters 3 and 6,1 improve on the standing measures of constitutional knowledge by using actual knowledge rather than self-professed familiarity.

\section{Summary}

Constitutional loyalty is an understudied component of the American political system. Its importance, however, is not only noted by the Founders themselves but arguably presumed by citizens and political elites alike. Borrowing from the theoretical and empirical literatures on institutional support and periodic conventions, my study aims to provide a better picture of Americans' underlying commitments to their constitutional charters and how these feelings are influenced by various factors. In the coming chapters, I illustrate how various sociopolitical and demographic characteristics influence constitutional loyalty, while empirically evaluating 
Madison's and Jefferson's contentions about how periodic conventions may influence constitutional loyalty and approval. Before doing so, I describe my research methodology, including variable operationalizations, data collection, and subject recruitment in the next chapter. 


\section{CHAPTER 3 - METHODS}

Having reviewed the extant literature and discussed my theory and expectations, I now turn to discussing how I design my inquiry. This dissertation seeks to accomplish three related tasks: (1) assess whether constitutional loyalty is reinforced or undermined by periodic conventions; (2) provide a measure of constitutional loyalty approximating diffuse support found in the larger legitimacy theory literature; and (3) evaluate whether actual (versus self-described) constitutional knowledge influences constitutional loyalty. To explore these questions, I develop and use a survey experiment administered to undergraduate students that captures their constitutional knowledge, measures their levels of constitutional approval and loyalty, and test how periodic conventions affect their constitutional support. I discuss each component of the experiment below, including survey instrumentation, how variables are operationalized, notes on reliability, validity, and objectivity, and finally case selection.

\section{General Design, Procedures, and Subjects}

My inquiry proceeds using a between-subjects survey experiment. Subjects were undergraduates at Wayne State University (Detroit, MI) recruited through introductory American government courses (1000 level) ${ }^{1}$ during the Winter 2018 semester. ${ }^{2}$ Students were asked to participate in an anonymous survey exploring their knowledge and feelings towards the federal and Michigan state constitutions. Surveys were administered during regular class time. Participation was voluntary, with consent derived through an information sheet that noted the

\footnotetext{
${ }^{1}$ Wayne State University offers two kinds of American government courses that differ in course designator and credit hours only. Substantive material and instructors are the same for both. For ease of clarity, I describe these courses as one: introduction to American government.

${ }^{2}$ A second wave of surveys were deployed during the Fall 2018 semester. Those surveys are not reported herein. For results and a discussion about the second wave, see Appendix B.
} 
anonymous nature of the survey (indicating that consent was assumed through students' survey participation and submission). Students electing to participate were given 15-20 minutes of class time to complete the survey packet. Students wishing not to participate sat quietly during the survey's administration. Several steps were taken to reduce the likelihood of coercion: No curricular benefit was given for participation (e.g. extra credit), neither the primary investigator nor his advisor were the instructor of record for participating sections, and course faculty and teaching assistants handed out consent forms and survey packets to reduce the possibility students may feel coerced to participate. (For subjects' descriptives, see Chapter 5.)

Subjects were first given a pre-test measuring their demographic characteristics (e.g. age, race, and socioeconomic status), sociopolitical variables (e.g. ideology, partisanship, and political orientations), and initial specific and diffuse support for the federal and Michigan state constitutions. Subjects were then randomly assigned to one of four experimental conditions (see below). ${ }^{3}$ Depending on condition (i.e. treatment) assigned, participants encountered varying information concerning Michigan's 2010 periodic convention and its abilities via a mock newspaper article. After reading the experimental vignette (i.e. the newspaper article), subjects completed a post-test with three sets of questions: (1) two questions on how likely they are to support a constitutional convention at the federal and state levels; (2) two short question batteries on federal and Michigan state constitutional knowledge; and (3) the specific and diffuse support batteries from the pre-test. The complete survey instrument, including pre-test, manipulations, and post-test, is available in Appendix A.

\footnotetext{
${ }^{3}$ To ensure that students were not prematurely made aware of the experimental nature, students were given survey packets that included all three components together (pre-test, experimental vignette, and post-test), with experimental condition randomly assigned before distribution.
} 
Procedurally, this design mitigates against many threats to internal validity. Random assignment to the control and treatment conditions ensures roughly equivalent groups, while changes in the general environment should be balanced among both control and treatment groups (Campbell and Stanley 1963). To prevent demand effects (Druckman and Kam 2011; Singleton and Straits 2010; Orne 1962), the design includes a "distractor" before the support batteries (i.e. the constitutional knowledge tests), ensuring that observed effects are genuine and resultative of the treatment. There is precedent for this approach in other works (see, e.g., Kam, Wilking, and Zechmeister 2007; LaRowe and Hoekstra 2014; and McDermott 2002). Moreover, the between-subjects design makes it difficult for a subject to infer experimenter intent, given that: (1) the subject is unaware of which condition he was placed within and (2) the blurring line between the experimental sections and the non-randomized material all respondents encounter (Mummolo and Peterson 2017).

The choice of undergraduates as subjects, however, does raise validity concerns, especially for external validity. General thinking suggests that using college students limits generalizability to other populations (Sears 1986). However, Druckman and Kam (2011) argue that college student samples are appropriate for most research designs, excepting those where the larger population does not vary on key characteristics or varies in systematic ways that influence the hypothesized relationship. Moreover, Druckman and Nelson (2003) find that threats to external validity are less concerning with research dealing in framing and priming effects. Given this dissertation's focus on priming a subject to be aware of a constitution's susceptibility to change, it would appear the process at play here is applicable across other groups. Likewise, a student-only sample is justifiable if the hypothesized process likely applies 
across groups (Bello et al., 2009; Ellsworth and Gonzales 2007). The literature on constitutional support does suggest that some sub-populations do vary (e.g. older persons; racial/ethnic minorities), but these factors are accounted for in the experiment (via both random assignment and pre-test variables). It matters more that the pattern observed among college students applies similarly to other groups rather than specific estimates (Ellsworth and Gonzales 2007). From a theoretical standpoint, there is nothing in the literature to suggest that college students vary systemically from other groups in how they may respond to this priming exercise.

It may matter, however, when the survey is administered during the semester. Since the sample pool is American government courses, the U.S. Constitution is a subject taught during the semester, likely early (i.e. within the first month). Thus, students surveyed earlier in the semester may have lower constitutional knowledge scores generally compared to students surveyed later in the semester (after being exposed to the Constitution unit). Consequently, I administer surveys in the middle of the semester (approximately the second/third month) to account for students having been exposed to, minimally, a preliminary lesson in the U.S. Constitution. Surveying thereafter ensures some variation on the constitutional knowledge questions, which seemingly may have been much lower. The point here is to assess how knowledge of constitutional processes and features influences constitutional loyalty, thus requiring a degree of prior knowledge to build off.

There are further reasons that a college sample is appropriate given the study's goals and context. First, student samples may be appropriate in circumstances where the goal is to theory test and generate, not generalize to larger populations (Bello et al., 2009; Ellsworth and Gonzales 2007; Kam et al., 2007; Mook 1983; Pernice et al., 2008). My study does this: I explore whether 
periodic conventions influence constitutional loyalty - a contention that has never undergone empirical testing. The point is to see if the hypothesized relationship happens, not if it typically does. As such, internal validity is preferred (McDermott 2002). Second, while I am utilizing a convenience sample, my survey experiment does enjoy other characteristics of a classic experiment, including: random assignment to interventions; a relatively controlled environment; and measurement of a respondent's reaction to stimuli. Third, and finally, scholars have noted that research using college student samples should be considered a first step, paired with replication studies using national samples (Ellsworth and Gonzales 2007; Peterson and Merunka 2014). Future research, therefore, should seek to replicate my findings produced here. ${ }^{4}$

\section{Pre-test Instrumentation}

\section{Sociopolitical and Prior Knowledge Variables}

The pre-test will be administered to all subjects regardless of experimental condition. Subjects' demographic and sociopolitical characteristics will be collected, along with the initial measures of their constitutional approval and loyalty for the federal and Michigan state constitutions. Demographic and sociopolitical questions reflect various covariates that prior studies have found to influence constitutional support and institutional support more broadly (see below). Where possible, the verbiage of questions utilized are based on prior studies, permitting comparisons with prior works as well as introducing an element of validity.

\footnotetext{
${ }^{4}$ Collectively, these points argue in favor of a research agenda/program: a single study, regardless of its sample pool, should be evaluated based on what it contributes to the larger research program (which can be theory building or determining a theory's empirical parameters). Moreover, a Popperian approach to causation suggests that evidence of causation is accumulated over multiple tests/studies (Druckman and Kam 2011). As such, research using college students should not be considered conclusive by any measure; further replication is necessary by default.
} 
First, subjects are asked several sociopolitical questions related to their partisanship, ideological orientations, and news consumption habits. Prior studies on institutional legitimacy (see, e.g., Durr, Martin, and Wolbrecht 2000) and constitutional support (Blake and Levinson 2016; Stephanopoulos and Versteeg 2016) have found that persons sharing ideological and partisan proximity with a governmental institution are more likely to support it, while more attentive news consumption habits correspond with greater constitutional approval (Stephanopoulos and Versteeg 2016). Partisanship is captured on a standard seven-point scale (anchored by "strong Democrat" and "strong Republican"), while ideology used a five-point scale (anchored by "very liberal" and "very conservative"). News consumption included two questions, one for national news and the other for local news, using a frequency-based response set (anchored by "almost daily" and "never"). Subjects are then asked about their general approval (i.e. specific support) of federal and state institutions. There is mixed evidence about whether specific support for one governmental institution or branch influences support (specific or diffuse) for others, ${ }^{5}$ although Blake and Levinson (2016) find that support for constitutionallymandated (created) bodies may affect the overall support for the constitutional system and charter. These questions are taken/adapted from the TIME/Abt SRBI Poll conducted in June 2011 on constitutional attitudes (see Blake and Levinson 2016 for more information; questions are accessible from the Roper Center's iPOLL website). ${ }^{6}$

\footnotetext{
${ }^{5}$ Compare Jones and McDermott (2002), Lebo (2008), and Mondak et al. (2007) with Chanley, Rudolph, and Rahn (2000) and Patterson, Ripley, and Quinlan (1992). See also Durr et al. (2000) who find no relationship.

${ }^{6}$ For federal institutions, I ask subjects their approval (i.e. specific support) for President Trump, the U.S. Congress, and the U.S. Supreme Court. For Michigan, I inquire about the state-level counterparts: Governor Snyder, the Michigan State Legislature, and the Michigan Supreme Court. Specific support measurements of executive officeholders are tied with the incumbent rather than the office itself (for the latter reference would be a diffuse support measure). Thus, I ask for opinions on President Trump and Governor Snyder rather than U.S. President or Michigan Governor. Given that the questioning for the legislatures and courts is not tied with any statements
} 
Next, subjects are asked a few questions about their prior knowledge on Michigan's state constitution and periodic convention mechanism. These questions help establish a baseline for the experimental treatments (e.g. Does the priming effect matter if people already knew about periodic conventions?). As such, I opt for a series of true/false questions that ask subjects the following: (1) whether Michigan has a state constitution or not; (2) whether the subject knows Michigan asks a periodic convention ballot question ever 16 years; and (3) whether the subject knows what a periodic convention may do (see Appendix A for exact question wording). These questions are designed to approximate prior knowledge and not alert the subject to the impending treatment's goal. I also do not include the convention support questions on the pretest for similar reasons: (1) I do not want to potentially alert subjects to the treatment and (2) subjects may not be aware what a constitutional convention is, thus biasing initial measures and yielding invalid comparisons with post-treatment scores (Gerber and Green 2012).

\section{Measuring Constitutional Loyalty and Approval}

Subjects are then asked two short question batteries assessing their specific and diffuse support for the federal and Michigan state constitutions. These batteries establish a baseline of constitutional approval and loyalty, with constitutional loyalty serving as the experiment's primary dependent measure. Unlike other institutions in the legitimacy theory literature, though, there exists no standard battery for measuring a constitution's diffuse support. However, the work done by the legion of scholars on the U.S. Supreme Court's (SCOTUS) institutional loyalty

asking about fundamental changes to the institutions, the literature considers this syntax to be gauging specific support (or approval) for each. 
(and courts more generally) proves instructive and provides a model to extrapolate questions. ${ }^{7}$ Here, I use the work by Gregory Caldeira, James Gibson, and their various colleagues (whose diffuse and specific support questions are considered the gold-standard for studies of court legitimacy) to create my constitutional loyalty measures.

Prior works on institutional loyalty (a term used interchangeably to connote diffuse support) have operationalized diffuse support as opposing significant structural and functional changes to the institution (Boynton and Loewenberg 1973), an operationalization that has become ubiquitous within the courts literature (see, e.g., Caldeira and Gibson 1992; Gibson and Caldeira 1992; Gibson, Caldeira, and Baird 1998; and Gibson, Caldeira, and Spence $2003 a$ and 2005). To the extent that "people support fundamental structural changes to an institution, are willing to punish the institution for its policy outputs, and generally distrust it," people are extending little loyalty (diffuse support) to that institution (Gibson and Caldeira 2009a, 45). This stands in contrast to specific support, which consists of attitudes towards an institution based upon whether particular demands, policies, or actions are fulfilled (Easton 1965; see also Easton 1975). However, scholars have often contaminated measures of specific support and diffuse support in their operationalizations (for example: compare Caldeira and Gibson's 1992 questions with Murphy and Tanenhaus's 1990 wording). Questions on how well an institution is performing its job are dependent on whether the individual agrees with the institution's outputs, a specific support measure. Diffuse support, meantime, captures the enduring components of an institution, and whether citizens are willing to accept, make, or countenance major changes in

\footnotetext{
${ }^{7}$ This is because courts deal frequently with constitutional issues. It could also be that the SCOTUS's diffuse support is strongly correlated (or even a proxy for) constitutional loyalty, serving as an alternative conceptualization for a constitution's diffuse support.
} 
an institution's fundamental character. ${ }^{8}$ Analogously, persons willing to replace or otherwise fundamentally alter their constitution are displaying low loyalty (minimal diffuse support), compared to persons whom oppose any modification (high diffuse support).

Consequently, existing studies on constitutional support broadly capture constitutional approval rather than diffuse support (Stephanopoulos and Versteeg 2016), although others (Blake and Levinson 2016; Zink and Dawes 2016) do utilize questioning that approximates diffuse support in terms of supporting constitutional conventions. Specifically, Blake and Levinson (2016) inquire whether one supports a federal constitutional convention to propose amendments to the U.S. Constitution, while Zink and Dawes (2016) gauge a person's support for various public policies framed as statutes versus constitutional amendments. This questioning is a better approximation of constitutional loyalty, but it still falls short. As Zink and Dawes (2016) note, Americans have a great degree of "constitutional status quo bias" in addition to regular risk aversion (see Chapter 2). Respondents were not asked to think about whether they would support more fundamental structural and functional changes, nor wholescale replacement of the charter.

Rather than asking a singular question or using a hypothetical amendment to determine one's willingness to change a constitution, I follow Gibson et al.'s (2003a) guidance that multiple measures exploring one's willingness to limit the power of an institution is a superior way to validly capture diffuse support. To wit, I take the standard SCOTUS diffuse support battery created by Caldeira and Gibson (1992) and Gibson and Caldeira (1992) and modify the questions

\footnotetext{
${ }^{8}$ For an example regarding measurement and conceptual difficulties concerning specific and diffuse support, see Caldeira and Gibson 1992, 637-642 (on the SCOTUS).
} 
to address similar themes. ${ }^{9}$ Additionally, I opt to make these scale responses (1-5, anchored by "strongly agree" and "strongly disagree" and fully labeled) rather than a binary choice given the greater validity of the former in capturing diffuse support (Gibson et al., 2003a). ${ }^{10}$ Subjects will also be asked the same questions concerning their loyalty to the Michigan state constitution, with corresponding verbiage modifications to emphasize the state constitution as target. This adapting exercise is common in legitimacy theory works (see, e.g., Gibson et al., 2005, 200 for an example).

Measuring constitutional approval, or specific support, is easier, and takes the form of two questions: one on the federal Constitution and the other Michigan's. For continuity purposes, I use the performance questions on state and federal constitutions that Stephanopoulos and Versteeg (2016) deploy, with a slight wording modification. I use a numbered approval scale, asking respondents to circle how strongly they approve of the federal/Michigan constitution. The scale is qualitatively labeled, with five being "strongly approve." Relative Stephanopoulos and Versteeg (2016), though, I reduce the scale's range from ten to five for more intuitive interpretation.

\footnotetext{
${ }^{9}$ The themes are: (1) willingness to change the institution's structure or functionality; (2) wholescale elimination of the institution; (3) whether the institution is too controversial (i.e. "mixed up in politics"); and (4) whether the individual believes the institution is unjust towards some groups more than others (i.e. the institution favors some groups).

${ }^{10}$ There is debate concerning the optimal number of gradations in a response set (e.g. 5 categories versus 7). Weijters, Cabooter, and Schillewaert (2010) argue that when using student populations more response categories can be used since these respondents generally rate higher on cognitive ability, verbal skills, and prior questionnaire experience than non-college populations. However, Revilla, Saris, and Krosnick (2014) found that quality decreases with more categories, suggesting that five-point scales yield better-quality data. While I am using a student population here, I have opted to go with the five-point scale given the better-quality data provided, especially prudent considering that there is little prior research on constitutional loyalty. Thus, quality concerns should be privileged. Moreover, I opt to use labeled scales (i.e. each number is labeled rather than just the poles) since labeling makes the scale more interpretable for any population (Weijters et al., 2010). (For reviews on recent literature concerning scales, see Revilla et al., 2014 and Weijters et al., 2010).
} 


\section{Demographics}

Finally, subjects are asked demographic questions and whether they are a U.S. citizen and permanent resident of Michigan. Wording is adopted from Stephanopoulos and Versteeg's (2016) survey, although these questions are roughly equivalent to other batteries across the discipline and beyond. For race/ethnicity, I use the standard response set from the U.S. Census. For determining socioeconomic status, I base the question off the MacArthur Scale of Subjected Social Status (The MacArthur Foundation 2007). It permits subjects to effectively estimate their socioeconomic status without knowing household incomes, educational levels, and occupations.

\section{Experimental Vignettes}

After completing the pre-test, subjects were randomly assigned to one of four experimental treatments (conditions). The treatments aim to explore how additional information about periodic conventions, namely how a convention may wholescale replace the Michigan constitution, influences a subject's constitutional loyalty, including whether the inclusion of a prime (i.e. prior conventions were rejected/approved) modifies results. There is precedent in the literature for this approach: Zink and Dawes (2016) conducted two experiments exploring the degree of constitutional bias present in people generally, and how it manifests specifically in Michigan and California during the 2012 election cycle. They found that how one frames proposals matters in terms of support: policy changes presented as constitutional amendments were far less likely to be supported than when those same proposals were characterized as statutory changes. Similar logics may be at work here regarding Madison's propositions: priming the public that past convention referenda have been rejected by the public may increase a person's constitutional loyalty. 
Before continuing, I briefly note the selection of Michigan. Assessing subjects on Michigan's constitution is prudent given: (1) Subjects are attending a Michigan public university, with the bulk of the student population (and sample) coming from Michigan; (2) Given the Michigan-based sample, subjects are also likelier to have a greater understanding of the Michigan periodic convention mechanism as well as the Michigan constitution; and (3) Michigan is one of 14 states that actually uses periodic conventions in its constitutional practice, providing a degree of mundane realism that reduces the need for artificiality (see footnote 10 , below). The experiment, moreover, can speak more generally to other states using periodic conventions as a result.

During the treatments, subjects are exposed to varying information about Michigan's 2010 periodic convention referendum (the last time the ballot question appeared) through a mock newspaper article. In composing the article, I used John Minnis's (2010) article published in the Oakland Legal News as a model (predominately borrowing phrasing), although my instruments differ significantly from the original piece. Minnis's piece is a great model given its comprehensive account of the ballot question, including direct quotes from various organizations and officials supporting and opposing the convention, as well as positive and negative justifications for why a convention is (un)necessary. I lift various paragraphs, editing and reorganizing them in a manner that approximates the article I sought. Moreover, using a newspaper article to convey the manipulation increases the experiment's mundane realism. ${ }^{11}$

\footnotetext{
${ }^{11}$ Mundane realism refers to "the similarity of experimental events to everyday experiences" (Singleton and Straits 2010, 213). Mundanity is usually considered less important in an experiment given the experiment's contrived nature, since controlling and isolating variables sacrifices some degree of mundane realism. However, using Michigan overcomes some of the challenge here.
} 
Subjects assigned to the "control" (Condition 0) received a "plain" article on the 2010 convention question. The article did not frame, prime, or otherwise emphasize features of a periodic convention (specifically that it can wholescale replace the present charter) and balances discussion by providing an affirmative and negative position on holding the convention. The remaining conditions received altered articles. Subjects assigned to the "more information" group (Condition 1) read the control article but with an added paragraph describing how a seated convention could fundamentally alter or replace the current constitution. Condition 1 effectively measures whether a constitutional status quo bias exists by inducing the subject to consider replacing the charter (see also Zink and Dawes 2016). The remaining treatments (Conditions 2 and 3) examine whether including a prime modifies results. The "negative prime" treatment (Condition 2) presents subjects with the article found in Condition 1 ("more information") but with a new paragraph near the end highlighting how past convention referenda were rejected by voters (using the actual vote margins). Conversely, the "positive prime" article (Condition 3) emphasizes a series of past referenda that were approved by voters, suggesting that the public in the past has been critical of the state's constitution, albeit earlier versions. Knowledge that voters have voted to fundamentally review the state constitution may work against the charter's institutional loyalty (and perhaps approval).

\section{Post-test Instrumentation}

Following the vignette, subjects encounter a common post-test. The post-test will: (1) ask subjects about their support for a constitutional convention at the federal and state levels; (2) record their knowledge of the federal and Michigan state constitutions; and (3) measure, again, their constitutional loyalty and approval using the pre-test question batteries. 


\section{Convention Support}

First, subjects are asked about their probability of supporting a constitutional convention at the state and federal levels. These questions are designed to be direct measures of the experimental treatments. While the experiment is directed at state conventions, I include the federal convention question to somewhat tease out whether the treatments influence just state constitutional loyalty or bleed into federal loyalty. I adapt Zink and Dawes's (2016) verbiage, replacing the response set with a five-point scale (anchored by "very likely" and "very unlikely").

\section{Constitutional Knowledge}

Next, subjects are asked a series of questions designed to estimate their federal and state constitutional knowledge. Examining the relationship between constitutional knowledge and one's constitutional loyalty serves two functions: First, knowledge of a constitution likely contributes to a "positivity bias," where greater familiarity with an institution corresponds with greater levels of specific and diffuse support (Gibson and Caldeira 2009a). Blake and Levinson (2016) and Stephanopoulos and Versteeg (2016) found that respondents who described themselves as knowing more about the federal or their state constitutions tended to support the charter at greater rates. The problem is that there exists no formal question battery for measuring actual constitutional knowledge (either state or federal varieties), unlike the common measures used to assess general civic knowledge (see Delli Carpini and Keeter 1996). This is an important shortcoming in the literature: most studies rely on self-described measures of constitutional knowledge to examine the relationship between constitutional knowledge and approval. There is evidence indicating that these self-professed measures are invalid: Stephanopoulos and Versteeg $(2016,146)$, for example, found that "purportedly higher- 
knowledge respondents" did not score any higher on survey comprehension checks compared to "their ostensibly lower-knowledge peers." This suggests a considerable gap "between professed and actual understanding of the constitution" (146) casting doubt on whether a relationship between knowledge and constitutional support exists and/or our present measure is faulty.

Second, asking subjects questions on their constitutional knowledge prior to remeasuring their specific and diffuse support helps to reduce the possibility of demand effects from the experiment (Druckman and Kam 2011). As discussed above, prior works on framing and the SCOTUS's loyalty have used similar devices in their experiments to ensure that the differences in pre- and post-measures are more genuine and attributable to the experiment's treatment.

To measure constitutional knowledge, I look towards the political and civic knowledge literatures for conceptualization and measurement strategies. While there is disagreement over how best to measure political knowledge, there appears to be "consensus on the central importance of the individual's ability to understand and retain concrete political facts" (Nie, Junn, and Stehlik-Barry 1996, 22). Today, Delli Carpini and Keeter's (1996, 304-305) five-question battery (based off questions asked by the American National Election Studies) is considered the gold standard in political science. The five questions range in difficulty from easy to complex, while measuring different kinds of political knowledge (e.g. knowledge of democratic norms, political officials, and current political facts; see Nie et al., 1996, 22-25 for a discussion). Questions on the (Federal) Constitution appearing in professional and scholastic surveys often follow this conceptualization: factual knowledge on constitutional norms, principles, and/or practices, with 
many being open-ended. ${ }^{12}$ Green and colleagues (2011) provide a convenient example: to operationalize knowledge of constitutional principles, they focus on respondents' understanding of civil rights and liberties accorded by the Bill of Rights and other amendments. This approach operationalizing constitutional knowledge in terms of rights - is perhaps appropriate given the dominance of the Bill of Rights in civics instruction (see Glendon 1991). Nonetheless, structural principles (e.g. federalism, separation of powers, and legislative processes) should not be ignored.

For federal constitutional knowledge, I ask six questions designed to assess subjects' factual understanding in three areas: structural factors; principles and norms; and general facts. In line with Gibson and Caldeira's (2009b) critique of political knowledge surveys, I eschew openended, recall questions in favor of closed-ended inquiries stressing cognition. Utilized this way, citizens are far more likely to answer questions correctly and demonstrate less ignorance than recall questions would suggest. ${ }^{13}$ My questions reflect their high frequency appearing on multiple surveys, and are adapted or inspired from various surveys, including the Annenberg Public Policy Center's annual Constitution Day Civics Survey; the National Assessment of Educational Progress (NAEP) civics exam; the American National Election Studies; and prior works on political and civic knowledge (see, e.g., Blake and Levinson 2016; Delli Carpini and Keeter 1996; Gainous and

\footnotetext{
12 Some examples: The United States Capitol Historical Society's online quizzes; the Annenberg Public Policy Center's annual Constitution Day Civics Survey; the National Assessment of Educational Progress (NAEP) civics exam; and various online quizzes from think tanks and other constitutional-oriented interest groups. ${ }^{13}$ I also aim for a "humbler" conceptualization of ignorance (Gibson and Caldeira 2009b). Like Lupia (2006), Gibson and Caldeira (2009b) argue that the public's purported ignorance on civic and political issues is significantly overstated since political knowledge surveys are biased towards facts that scholars think citizens ought to know, rather than a practical understanding.
} 
Martens 2012; Green et al., 2011; and Niemi and Junn 1998). ${ }^{14}$ I have opted to limit this battery to six questions to prevent fatigue. Finally, I include an introductory note leading the constitutional knowledge battery as recommended by Delli Carpini and Keeter (1996).

Assessment of Michigan constitutional knowledge requires an altogether different approach. In general, people's knowledge of their state governments is less than their familiarity with federal institutions (Delli Carpini and Keeter 1996; Niemi and Junn 1998; Lyons, Jaeger, and Wolak 2013). This holds true for state constitutional knowledge: A survey by the National Center for State Courts found that 54 percent of respondents incorrectly responded that their state had no constitution (see Lyons et al., 2012, note 1; see also Snider 2017). No wonder Roeder (1994, 34) has argued that state politics represents an "invisible layer of government" for most citizens. Measurement of state constitutional knowledge, therefore, is difficult; if most persons are unaware that their state even has a constitution, how can one accurately measure true constitutional knowledge?

I use a recognition measure like the one used by Stephanopoulos and Versteeg (2016, 134). These authors asked respondents to identify whether they would like to see a substantive provision included in their state's constitution. Provisions presented were based on similar ones present in state charters but did not appear in the federal Constitution. I propose an analogous exercise: present a substantive or structural provision and inquire whether it is part of the Michigan Constitution of 1963 or not. ${ }^{15}$ Subjects able to identify constituent provisions of the

\footnotetext{
${ }^{14}$ Green et al. (2011) and Niemi and Junn (1998) provide convenient questions with better discriminating power. Green and colleagues also used high school students for their study, suggesting that their questions may be especially prudent to use on college students with varying civics backgrounds.

${ }^{15}$ Zackin (2013) also notes how state constitutions are the repositories for positive, substantive rights in American constitutional jurisprudence, suggesting that citizens may be more familiar with their state constitution when
} 
Michigan Constitution are likelier more informed about the document than others. This battery is, like the federal question bank, preceded by an introductory note as adapted (and recommended) from Delli Caprini and Keeter (1996).

It should be noted that this question battery is likely to result in poor and/or rough approximations of Michigan constitutional knowledge. Citizens generally tend to perform poorly on measures assessing state politics and government (Patterson et al., 1992; Lyons et al., 2013) and are also unable to transfer conceptual knowledge of national institutions to corresponding state constitutions (Niemi and Junn 1998). It is likely that even general knowledge of a state constitution is likewise missing from most citizens' minds (see Snider 2017, 279).

\section{Re-measuring Constitutional Loyalty and Approval}

Finally, subjects will again complete the diffuse and specific support question batteries from the pre-test. In experiments, especially between-subjects designs, it is imperative to record measures of the dependent variables before the treatment is applied and again afterwards (Gerber and Green 2012; Singleton and Straits 2010). Pre-test measures of constitutional loyalty and approval will provide initial descriptive statistics and baseline scores for comparison with post-test measures that will capture the treatment's effect (if any).

\section{Afterword}

The next three chapters discuss these data collected and evaluate the hypotheses discussed in Chapter 2. First, Chapter 4 outlines descriptive data and examines predictors of constitutional loyalty. Next, Chapter 5 explores the experimental results, including post-hoc 
analysis. Finally, Chapter 6 discusses the role of constitutional knowledge in generating constitutional loyalty and whether it served as a mediator during the experiment. 


\section{CHAPTER 4 - WHAT GENERATES CONSTITUTIONAL LOYALTY?}

Having reviewed the extant literature and discussed the general methodological procedures of my study, I now present findings. In this chapter, I examine one facet of these data: What generates constitutional loyalty? In doing so, I first identify overall levels of federal and Michigan constitutional loyalty and discuss its measurement. Next, I examine loyalty across three dimensions: personal attributes (demography), political affiliations, and institutional attitudes. ${ }^{1}$ Finally, I turn to regression analysis to explain how these various factors collectively influence a person's constitutional loyalty. Alongside these presentations, I also explore constitutional approval, comparing my findings with the established literature while also examining the relationship between approval and loyalty.

\section{Measuring Constitutional Loyalty}

Before discussing the results, a note on the main dependent variables: federal and Michigan constitutional loyalty, also referred to as a constitution's diffuse support. Prior works on institutional loyalty (a term used interchangeably to connote diffuse support) have operationalized diffuse support as opposing significant structural and functional changes to the institution (Boynton and Loewenberg 1973), an operationalization that has become ubiquitous within the courts literature (see, e.g., Caldeira and Gibson 1992; Gibson and Caldeira 1992; Gibson, Caldeira, and Baird 1998; and Gibson, Caldeira, and Spence 2003a, 2005). As Gibson and Caldeira (2009a) describe it, "To the extent people support fundamental structural changes in an institution, are willing to punish the institution for its policy outputs, and generally distrust it, they are extending little legitimacy (loyalty) to that institution" (45). Analogously, persons willing

\footnotetext{
${ }^{1}$ Chapter 6 adds a fourth dimension: civic knowledge. The results reported here will be expanded upon below.
} 
to replace or otherwise fundamentally alter their constitution are displaying low loyalty (minimal diffuse support), compared with individuals who oppose any modification (high diffuse support, or institutional fealty).

As noted above in the literature review (Chapter 2), institutional loyalty differs from specific support, or what scholars term institutional approval. For my purposes here, constitutional approval captures a person's specific support for a constitution. Existing studies on constitutional support broadly capture constitutional approval rather than diffuse support (Stephanopoulos and Versteeg 2016), although others (Blake and Levinson 2016; Zink and Dawes 2016) do utilize questioning that approximates diffuse support. Specific support is normally distilled through "feeling thermometers" or approval scales, and is a more contextualized appraisal of one's support; how does one presently "feel" about the constitution? Respondents are not "induced to reflect on whether they still would adhere to (the constitution's) commands if they thought them unjust, or whether they would like to scrap it and start afresh" (Stephanopoulos and Versteeg 2016, 120). Therefore, measures that approximate a current assessment or feeling on the constitution should be considered a measure of approval, not loyalty.

Therefore, a different approach to capturing a person's constitutional loyalty is necessary. Blake and Levinson (2016) and Zink and Dawes (2016) represent two studies that induce respondents to consider their underlying loyalty towards the federal constitution. Specifically, Blake and Levinson inquire whether one supports a constitutional convention to propose amendments to the U.S. Constitution, while Zink and Dawes gauge a person's support for various public policies framed as statutes versus constitutional amendments. This questioning is a better 
approximation of constitutional loyalty, but it still falls short. As Zink and Dawes note, Americans have a great degree of "constitutional status quo bias" in addition to regular risk aversion (see Chapter 2 for a greater elaboration). Respondents were not asked to think about whether they would support more fundamental structural and functional changes, nor wholescale replacement of the document.

Rather than asking a singular question or using a hypothetical amendment to gauge one's willingness to change a constitution, I derive a new measure of constitutional loyalty from Gibson, Caldeira, and Spence's (2003a) United States Supreme Court diffuse support battery. Their battery poses a series of statements about eliminating the Court as an institution, reducing its institutional powers, and general trust in the institution. Respondents indicate their degree of agreement (or disagreement) on a five-point Likert scale. From here, a "scale of support" is generated by counting the number of "supportive" answers given by a respondent. Since the statements are written in the negative, respondents answering with "disagree" or "strongly disagree" are coded as being "supportive" of the institution. ${ }^{2}$ Thus, these individuals have higher diffuse support, or institutional loyalty, than those who agree or are undecided. Using these statements, I create a new battery of questions designed to assess one's loyalty towards a constitutional charter. Question wording is provided in Table 1, along with descriptive statistics for each. While original responses were on a five-point Likert scale, each question was recoded into three-categories (agree, undecided, and disagree), with the disagree category representing supportive answers (and, therefore, greater constitutional loyalty). Using this recoded variable, I

\footnotetext{
${ }^{2}$ The statements are presented in a critical fashion. For instance: "If the U.S. Supreme Court started making a lot of decisions that most people disagree with, it might be better to do away with the Supreme Court altogether." Respondents answering "disagree" or "strongly disagree" would be considered "supportive" of the institution.
} 
create a "constitutional loyalty scale" that provides the mean response for a subject across all four statements (i.e. the "row average"). This scale becomes my dependent measure for subsequent analyses (each subject has two; one for federal loyalty and the other for loyalty towards the Michigan state constitution). ${ }^{3}$

Several observations can be made regarding constitutional loyalty for both the federal and Michigan state constitutions among college students. At the federal level, there appears to be a well-spring of diffuse support, but it is somewhat tempered. A large majority notes that it does matter if the Constitution were rewritten/amended (58 percent), while a slight majority disagrees that the Constitution is too controversial to be useful (52 percent). ${ }^{4}$ Importantly, however, a majority (54 percent) believes the Constitution favors some groups more than others, while only a plurality (46 percent) would not support doing away with the Constitution if it prevented actions popularly supported. Taken together, these findings note that American college students view their national charter with a supportive yet critical eye. Many balk at replacing it or viewing it as too controversial to be useful, yet a substantial portion consider the Constitution biased and would consider doing away with it if it continually frustrates popular decision-making. Further indicating this trend is the fact that, across all four statements, the average number of supportive replies is 1.7 , with 26 percent of subjects expressing no support

\footnotetext{
${ }^{3}$ There are several different scales used in the larger literature to produce a summary measure of diffuse support. I report here using the arithmetic mean of the four statements since the results are more intuitive to interpret. Other scale measures I created for constitutional loyalty (both federal and Michigan) include: the number of supportive statements (i.e. Gibson's 2012 preferred method); creating a factor score using principal component factor analysis (see Gibson and Caldeira 1992); and proportion support (i.e. the number of supportive responses divided by total statements). Substantive findings do not differ significantly from those reported here. See also Chapter 5.

${ }^{4}$ All percentages reported herein are rounded to the nearest whole number, meaning that percentages may not sum to 100 .
} 
at all for the constitution (i.e. zero supportive statements), and 10 percent providing supportive statements for all questions. A majority (54 percent), though, issued two or more supportive statements.

Table 1.

Constitutional Loyalty Towards the U.S. and Michigan State Constitutions

Level of Diffuse Support

\begin{tabular}{|c|c|c|c|c|c|c|c|}
\hline \multirow[b]{2}{*}{ Item } & \multicolumn{3}{|c|}{ Percentage } & \multirow[b]{2}{*}{ Mean } & \multirow[b]{2}{*}{ Std. Dev. } & \multirow[b]{2}{*}{$N$} & \multirow[b]{2}{*}{$\begin{array}{c}\text { Factor } \\
\text { Loading }^{a}\end{array}$} \\
\hline & Agree & Disagree & Undecided & & & & \\
\hline \multicolumn{8}{|c|}{ No difference if rewritten } \\
\hline Federal & 18 & 58 & 24 & 3.5 & 1.1 & 250 & 0.60 \\
\hline State & 19 & 35 & 46 & 3.2 & 0.9 & 246 & 0.72 \\
\hline \multicolumn{8}{|c|}{ Constitution favors some groups } \\
\hline Federal & 54 & 17 & 29 & 2.5 & 1.1 & 250 & 0.66 \\
\hline State & 27 & 8 & 64 & 2.8 & 0.7 & 246 & 0.58 \\
\hline \multicolumn{8}{|c|}{ Do away with the Constitution } \\
\hline Federal & 21 & 46 & 33 & 3.4 & 1.1 & 249 & 0.83 \\
\hline State & 18 & 30 & 52 & 3.1 & 0.9 & 246 & 0.80 \\
\hline \multicolumn{8}{|c|}{ Constitution is too controversial } \\
\hline Federal & 17 & 52 & 31 & 3.5 & 1.0 & 250 & 0.87 \\
\hline State & 7 & 32 & 61 & 3.3 & 0.7 & 245 & 0.83 \\
\hline
\end{tabular}

Note: Data taken from pre-test measures. Percentages are calculated using the collapsed variables (i.e. "strongly agree" and "agree" responses are combined). Due to rounding, percentages may not sum to 100 . Agree category corresponds with low constitutional loyalty while disagree connotes high constitutional loyalty since questions are written in the negative (see below). Means and standard deviations are calculated using the uncollapsed distributions (i.e. scale is 1-5). Higher mean scores indicate greater constitutional loyalty.

a Loadings come from the first factor from the unrotated solution of a principal-components factor analysis (one each for federal and Michigan). No rotation was necessary due to additional factors having trivial eigenvalues.

Question wording is as follows (with "Michigan state" substituting federal in the state-level battery):

1. No difference if rewritten. "It would not make much difference to me if the federal constitution were rewritten or amended."

2. Constitution favors some groups. "The federal constitution favors some groups more than others."

3. Do away with the Constitution. "If the federal constitution continually prevents decisions that the people agree with, it might be better to do away with the Constitution altogether."

4. Constitution is too controversial. "The federal constitution is too controversial to be useful today."

A different story is painted by the Michigan state data. Majorities are undecided across three of the four statements, while a sizable plurality (46 percent) remains undecided if it would make a substantive difference if the Michigan state constitution were rewritten or amended. Excluding the undecideds suggest supportive replies on all questions save whether the Michigan 
constitution is biased towards groups (74 percent believe it is), a finding paralleling the federal results. Counting across all four statements provides further evidence of this trend: Across all four statements, the average number of supportive replies is only one (1), while 46 percent express no support at all for the Michigan constitution. Only three (3) percent responded with a supportive response for all four questions. ${ }^{5}$

At face value, these findings suggest that loyalty towards Michigan's constitution is low, especially given the loyalty scale results. However, the large number of undecided responses suggests an alternative interpretation: there is a great degree of ignorance of the Michigan state constitution, enough that respondents chose the noncommittal response (i.e. undecided/neither agree or disagree). This explanation is made more plausible when one ignores the undecideds: Large majorities (greater than 60 percent) gave supportive responses to all questions save whether they thought the Michigan state constitution favored some groups. Thus, for those who did choose a category other than undecided, they were more likely to express loyalty towards it.

Why the greater loyalty baseline for the federal constitution? There are two likely factors:

First, college students generally know more about the federal charter given its significance in secondary and collegiate civic courses. This may explain why subjects gave fewer undecided responses to the federal questions than on the state battery. The relationship between knowledge about a constitution and loyalty towards is worthy of further examination at both levels. I build upon these observations and provide an empirical test of this proposition in Chapter 6. Second, and relatedly, the U.S. Constitution does enjoy a "protected status" of sorts given the innate constitutional status quo bias Americans are likely to express regarding it (Zink and Dawes

\footnotetext{
${ }^{5}$ Only 31 percent of the sample gave two or more supportive answers.
} 
2016). The status quo bias, though, seems to be weaker at the state level given the default: undecided rather than simply disagree. There remains a potential third factor as well: Given the likely low familiarity with the Michigan constitution, subjects simply "transferred" their feelings on the federal constitution to the Michigan charter. I further evaluate this proposition below.

While these statistics are illuminating, there is still the question about whether combining these four statements into a formal scale validly captures constitutional loyalty. Each battery of questions was analyzed using principal-components factor analysis (PCF, using Stata). If the four statements are collectively measuring constitutional loyalty, only one factor should explain a substantial amount of the variance. For federal constitutional loyalty, only one factor achieved an eigenvalue greater than one, indicating that the four statements are measuring a common concept. About 56 percent of the federal variance is explained by this single factor. As indicated

in Table 1, all statements also have factor loadings greater than 0.4 , again suggesting these statements are good indicators of constitutional loyalty. Similar results are observed for the Michigan battery. While not reported here, the Cronbach's Alpha for test scales (using means) are high ( 0.72 for federal and 0.71 for Michigan). Collectively, these tests suggest that both batteries are validly and reliably capturing subjects' constitutional loyalty levels.

\section{Does Constitutional Loyalty Vary Between Individuals?}

Prior works on institutional support and loyalty suggest four broad dimensions that may influence one's support for an institution. These dimensions are also found in the extant work on constitutional support more broadly (see Blake and Levinson 2016; Stephanopoulos and Versteeg 2016). These four dimensions are: personal/demographic attributes; political affiliations; civic 
knowledge; and institutional attitudes. ${ }^{6}$ The only prior study to address individual determinants of constitutional loyalty is Blake and Levinson (2016), albeit through the guise of asking whether a respondent would favor holding a federal constitutional convention or not. While this question does examine constitutional loyalty, it is but one facet. Blake and Levinson (2016) found that approximately one-third of Americans support holding a constitutional convention, but the likelihood of support varied among different dimensions. For my purposes here, I discuss each dimension below, with the exception of civic knowledge that I leave for Chapter 6 (and, therefore, expand upon the results presented here). I present descriptive statistics for the various factors within each dimension, using primarily Blake and Levinson's (2016) results as a guide. ${ }^{7}$

\section{Demographic Attributes}

First, personal/demographic attributes, including race, gender, and income. Given my sample population, I drop educational attainment and age from my analyses; this is because I am dealing with only "young" persons by most studies' standards ${ }^{8}$ and all subjects have a similar educational attainment (i.e. some college). For the remaining factors, Blake and Levinson (2016) found: (1) African Americans and Hispanics are more likely to support holding a constitutional convention than other minorities and whites; (2) females were less likely to support holding a convention than males; and (3) that persons with higher incomes were less likely to support a

\footnotetext{
${ }^{6}$ I follow Gibson's (2012) taxonomy here. Some scholars combine the demographic and political affiliations dimensions, while others often add other factors that are arguably their own dimensions while ignoring others. For example, Blake and Levinson (2016) discuss constitutional interpretative philosophies in their work in addition to the other dimensions.

${ }^{7}$ In many respects, the findings on generators of constitutional approval mirror the factors influencing constitutional loyalty. Compare Stephanopoulos and Versteeg (2016) with Blake and Levinson (2016); both studies use the larger literature on institutional legitimacy to determine which dimensions to include in their surveys (see also Chapter 2).

${ }^{8}$ Subjects range in age from 18 to 40 years old. The bulk of the sample (93 percent) are 25 years old or younger. Prior studies on constitutional support (e.g. Blake and Levinson 2016; Stephanopoulos and Versteeg 2016) pool those younger than 35 years old into one category, meaning only five of my subjects would fall outside this bin.
} 
convention. I expect similar patterns here: minorities, women, and working-class persons with lower mean loyalty scores.

Table 2.

Mean U.S. Constitutional Loyalty by Demographic Attributes

\begin{tabular}{|c|c|c|c|c|c|c|}
\hline \multirow[b]{3}{*}{ Item } & \multicolumn{6}{|c|}{ Level of Diffuse Support } \\
\hline & \multicolumn{3}{|c|}{ Federal } & \multicolumn{3}{|c|}{ Michigan } \\
\hline & Mean & Std. Dev. & $N$ & Mean & Std. Dev. & $N$ \\
\hline \multicolumn{7}{|l|}{ Race/Ethnicity } \\
\hline Caucasian & 3.4 & 0.8 & 123 & 3.2 & 0.6 & 119 \\
\hline Black & 3.0 & 0.8 & 55 & 3.0 & 0.7 & 55 \\
\hline Asian Am. & 3.0 & 0.4 & 26 & 3.0 & 0.5 & 26 \\
\hline Hispanic & 2.9 & 0.6 & 11 & 3.0 & 0.4 & 11 \\
\hline Arabic & 3.3 & 0.8 & 15 & 2.8 & 0.5 & 15 \\
\hline \multicolumn{7}{|l|}{ Gender } \\
\hline Male & 3.2 & 0.9 & 112 & 3.0 & 0.7 & 112 \\
\hline Female & 3.2 & 0.7 & 131 & 3.1 & 0.5 & 127 \\
\hline \multicolumn{7}{|l|}{ SES } \\
\hline Working Class & 3.0 & 0.7 & 70 & 3.0 & 0.6 & 69 \\
\hline Middle Class & 3.4 & 0.8 & 130 & 3.2 & 0.6 & 128 \\
\hline Upper Class & 3.1 & 0.9 & 47 & 3.0 & 0.6 & 46 \\
\hline
\end{tabular}

Note: Data taken from pre-test measures. Statistics calculated using dependent measure for constitutional loyalty (i.e. the average response to all four statements).

Table 2 shows how mean constitutional loyalty differs by these factors (note the side-byside comparison between federal and Michigan constitutional loyalty for each attribute). For federal loyalty, African Americans and Hispanics have lower mean scores than whites, although these differences are somewhat trivial. Men and women, meantime, do not differ at all in their federal loyalty. Socioeconomic status appears to matter, albeit, again, only marginally: the middle and upper classes express greater loyalty than their working-class brethren, with middle-class persons expressing the greatest loyalty. Switching to Michigan mean constitutional loyalty, a larger pattern between whites and minorities emerges, although Arab Americans express the lowest loyalty. Indeed, Arab Americans are the only group that varies between their federal and state loyalty scores; Arab Americans are more supportive of the federal constitution (3.3) than 
the Michigan charter (2.8). Turning to gender, men and women, again, do not drastically differ in their state mean constitutional loyalty, while there are only marginal differences among socioeconomic status. These results are somewhat different from Blake and Levinson (2016): while minorities are more likely to express lower loyalty towards the U.S. and Michigan state constitutions, the differences appear trivial. Moreover, men and women hold similar loyalty scores while socioeconomic status appears to only make a difference at the federal level.

\section{Political Affiliations}

Having explored the (ostensibly) limited role of demography in differentiating constitutional loyalty, I now turn to two likelier culprits: partisan affiliation and ideological persuasion. Previous legitimacy studies, broadly, support the idea that persons sharing ideological and partisan proximity with a governmental institution are more likely to support it (see, e.g., Durr, Martin, and Wolbrecht 2000). Concerning constitutions, Blake and Levinson (2016) find that Republicans and conservatives were less likely to support holding a federal constitutional convention than Democrats and liberals. This may be due to the constitutional veneration that the Republican Party and conservative ideology broadly favor and impress upon its adherents. Univariate distributions are illustrated in Figure 1 for both partisanship and ideology. As witnessed, the expected pattern emerges: Republicans and conservatives have significantly higher loyalty averages than their Democratic and liberal counterparts. 
Figure 1.

Mean Federal and Michigan Constitutional Loyalty by Partisanship and Ideology
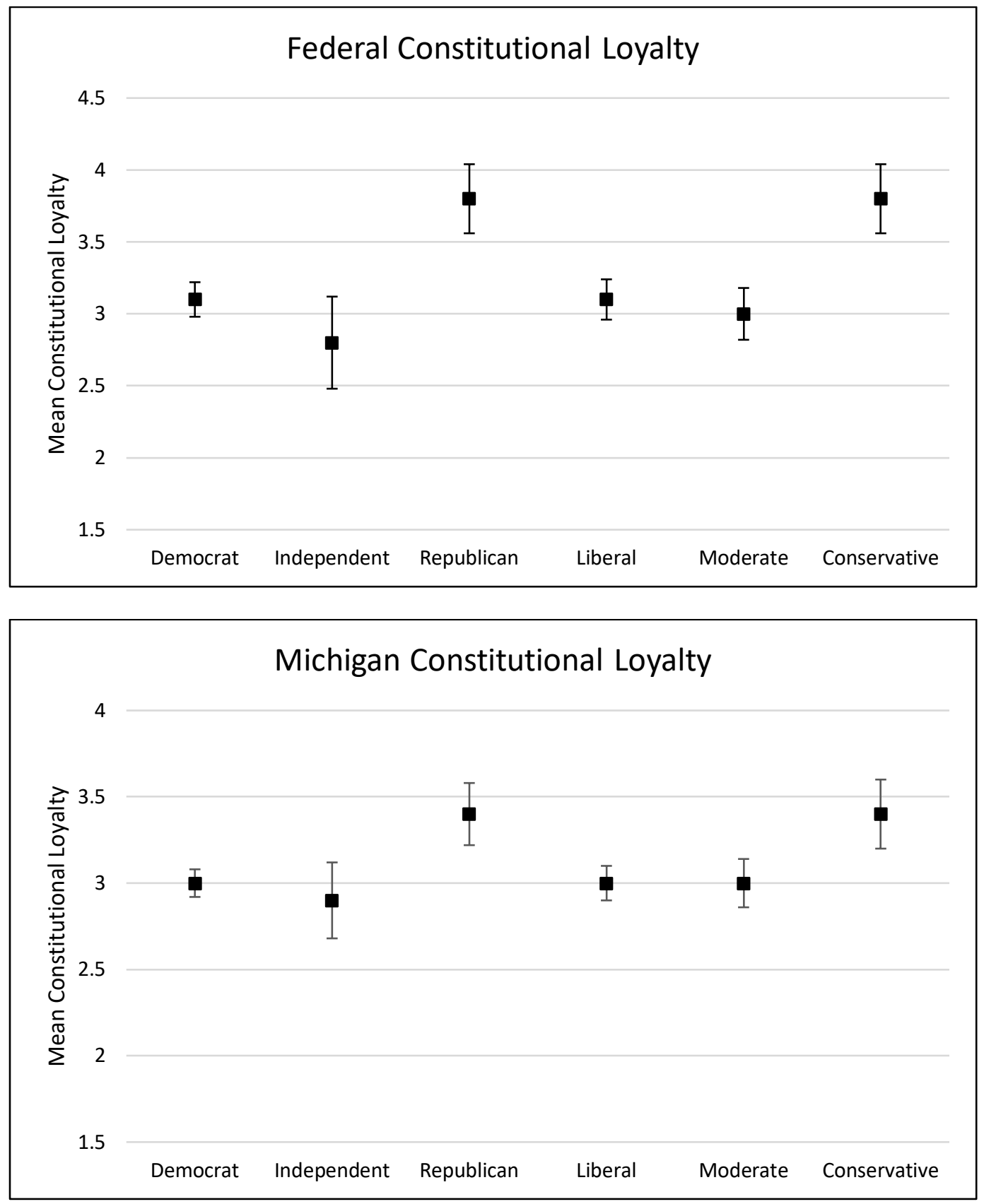

Note: Data based on pre-test measures. Loyalty scores presented as group mean. Partisanship is presented as a collapsed three-category variable (with "strong" and "weak" partisans pooled together, and pure and leaning independents combined). Ideology is similarly collapsed by merging "weak" and "strong" ideological affinities together. Error bars represent the 95 percent confidence interval around the mean. 
Institutional Attitudes

There is mixed evidence in the empirical literature about whether support for one governmental institution or branch influences support for the others. For example, some studies find a link between presidential and Congressional approval ratings (Jones and McDermott 2002; Lebo 2008; Mondak et al., 2007), whereas others find no linkage (Chanley, Rudolph, and Rahn 2000; Patterson, Ripley, and Quinlan 1992) or that some branches are unaffected (see, e.g., Durr, Martin, and Wolbrecht 2000). Importantly, though, these works are analyzing the relationship among institutions' specific support, not their diffuse support. Blake and Levinson (2016) consider these institutional attitudes and whether they influence a person's constitutional loyalty (diffuse support). From a descriptive standpoint, they find that higher approval ratings for federal institutions (president, Congress, and the U.S. Supreme Court) correspond with higher constitutional loyalty (i.e. a lower likelihood of supporting a constitutional convention). Although this relationship is qualified in their regression analyses (see below), Blake and Levinson's (2016) findings suggest a positive relationship between institutional attitudes and constitutional loyalty. 
Figure 2.

Mean Federal and Michigan Constitutional Loyalty by Institutional Attitudes
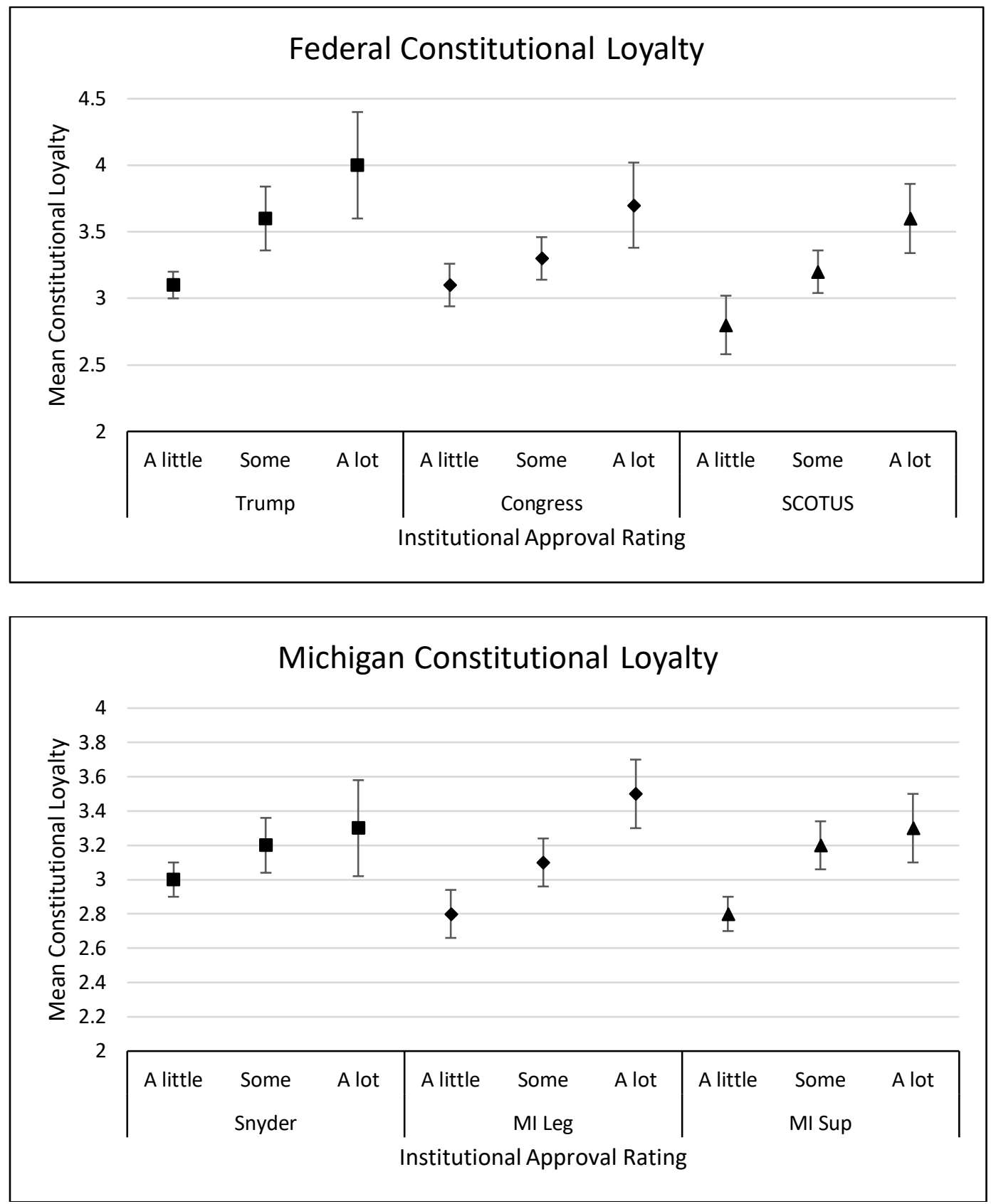

Note: Data from pre-test measures. Loyalty scores presented as group mean. Approval ratings originally captured as a five-category variable (anchored by "Not at all" and "A lot"). Results were collapsed into three categories: A little (combining "Not at all" and "A little" responses), Some (no change), and A lot (combining "A lot" and "A great deal").

Given the debate in the literature, I examine federal and Michigan mean constitutional loyalty by other institutional attitudes. For federal constitutional loyalty, I ask subjects their 
approval ratings (i.e. specific support) of three federal institutions: President Trump, the U.S. Congress, and the U.S. Supreme Court (SCOTUS). For Michigan constitutional loyalty, I inquire about the state-level counterparts: Governor Rick Snyder, the Michigan State Legislature, and the Michigan Supreme Court. ${ }^{9}$ Results are presented in Figure 2. At the federal level, it appears that increasing support for governmental institutions corresponds with an increase in mean constitutional loyalty. This is true, and pronounced, across all three branches, although the magnitude is greater between those with low and high approval. A similar pattern occurs between state institutions and Michigan constitutional loyalty, although it is less pronounced with gubernatorial approval; mean constitutional loyalty scores are approximately equal across levels of approval for Governor Rick Snyder. Overall, though, a person's general attitudes towards other governmental institutions appears to be reflected in their constitutional loyalty.

\section{Generators of Constitutional Loyalty}

Descriptive data, however, do not offer definitive answers to whether constitutional loyalty is grounded in these dimensions or not. Patterns of loyalty varying across factors in isolation does not account for the interrelated nature of these variables. As the literature on institutional support and loyalty suggest, many of these factors appear substantial in isolation (e.g. demography) but become trivial once other controls are included (e.g. partisan affiliations).

\footnotetext{
${ }^{9}$ Readers may note that measuring executive branch institutional support is inquired via subject's opinion on the present incumbent. This is because the dimension here aims to capture a person's specific support for governmental institutions, or institutional approval (and see if these short-term assessments have a larger impact). This is standard practice in the literature, since inquiring about the presidency generally would invoke a measure more akin to institutional loyalty rather than specific support. (Ironically, the literature considers general approval questions about the U.S. Congress and the SCOTUS, as asked here, to be reflections of specific support.) This question wording also permits a test for whether a specific officeholder (e.g. President Trump) is influencing results (see regression analysis, below).
} 
Blake and Levinson (2016) provide an illustrative example of how several dimensional factors become unrelated to constitutional loyalty when all factors are considered. ${ }^{10}$ In their unified regression modeling accounting for all four dimensions (demography, political affiliations, institutional attitudes, and civic knowledge), Blake and Levinson found that while race and age remained significant, the influence of other personal attributes (namely socioeconomic status and gender) had no discernible effect on constitutional convention support. Moreover, both partisanship and ideology matter little in explaining a person's support for holding a constitutional convention. Indeed, the influences of demographic attributes, partisan affiliation, and ideological persuasion disappeared after controlling for institutional attitudes, civic knowledge, and preferred method of constitutional interpretation. Comparing these results with the predictors of constitutional approval (Stephanopoulos and Versteeg 2016), a similar pattern emerges - although partisanship and ideology remained significant even after controlling for institutional attitudes and civic knowledge.

The suggestion from the literature, therefore, is that the four dimensions interact with each other albeit in different ways for specific and diffuse support. Given my better approximation of constitutional loyalty, I proceed to test the various dimensions empirically, controlling for multiple factors to determine whether they serve as predictors or not. I mimic the estimation procedure (OLS regression) of prior constitutional support studies (namely Blake and Levinson 2016 and Stephanopoulos and Versteeg 2016) by estimating a base model of constitutional loyalty using only demographic/personal attributes (model 1 ). From there, I estimate a further two models: one incorporating political affiliations (model 2), and another

\footnotetext{
${ }^{10} \mathrm{See}$, below, for a similar discussion regarding constitutional approval (Stephanopoulos and Versteeg 2016).
} 
including institutional attitudes (model 3). These procedures are replicated twice: one for federal constitutional loyalty (see Table 3) and one for Michigan constitutional loyalty (see Table 4). I also consider the importance of constitutional knowledge in a fourth model, which is presented in Chapter 6. For now, I consider the importance of demography, political affiliations, and institutional attitudes.

Before doing so, I briefly discuss the choice of simple linear (OLS) regression rather than ordered logit/probit techniques. Despite the ordinal nature of the dependent variable, OLS is used because it is easier to interpret and present OLS coefficients (despite the non-plausible numbers produced). Moreover, there is debate concerning whether the estimation differences between OLS and ordered logit are consequential enough and outweigh OLS's simplicity (see, e.g., Angrist and Pischke 2009) despite the technical violation of OLS regression assumptions. Additionally, the works on constitutional support opt to use OLS regression for interpretation purposes. I opt to use OLS for these reasons, but also because I am less interested in the specific point estimates than in identifying the causal relationship and its strength. 
Table 3.

Regression Modeling of Federal Constitutional Loyalty

\begin{tabular}{|c|c|c|c|}
\hline & Model 1 & Model 2 & Model 3 \\
\hline \multirow[t]{2}{*}{ Female } & -0.032 & -0.018 & 0.092 \\
\hline & (0.104) & (0.115) & $(0.126)$ \\
\hline \multirow[t]{2}{*}{ Age } & $0.028^{\wedge}$ & 0.019 & 0.022 \\
\hline & $(0.015)$ & $(0.016)$ & $(0.017)$ \\
\hline \multirow[t]{2}{*}{ African American } & $-0.547 * * *$ & $-0.445^{* *}$ & -0.148 \\
\hline & $(0.137)$ & $(0.155)$ & $(0.166)$ \\
\hline \multirow[t]{2}{*}{ Other Minority } & $-0.431 * * *$ & $-0.339 *$ & -0.18 \\
\hline & $(0.125)$ & $(0.143)$ & $(0.142)$ \\
\hline \multirow[t]{2}{*}{ SES } & 0.001 & -0.038 & $-0.194 *$ \\
\hline & (0.079) & $(0.087)$ & $(0.089)$ \\
\hline \multirow[t]{2}{*}{ Partisanship } & & 0.069 & 0.056 \\
\hline & & $(0.047)$ & $(0.054)$ \\
\hline \multirow[t]{2}{*}{ Ideology } & & 0.044 & -0.053 \\
\hline & & $(0.065)$ & $(0.07)$ \\
\hline \multirow[t]{2}{*}{ Trump Approval } & & & $0.19 *$ \\
\hline & & & $(0.086)$ \\
\hline \multirow[t]{2}{*}{ Congress Approval } & & & -0.141 \\
\hline & & & $(0.086)$ \\
\hline \multirow[t]{2}{*}{ SCOTUS Approval } & & & $0.448 * * *$ \\
\hline & & & $(0.077)$ \\
\hline \multirow[t]{2}{*}{ Constant } & $2.913 * * *$ & $2.811 * * *$ & $2.35 * * *$ \\
\hline & $(0.371)$ & $(0.412)$ & $(0.45)$ \\
\hline$N$ & 226 & 198 & 151 \\
\hline Adjusted $\mathrm{R}^{2}$ & 0.083 & 0.097 & 0.296 \\
\hline
\end{tabular}

Note: Data taken from pre-test measures. Standard errors in parentheses.

$* * * p<0.001, * * p<0.01, * p<0.05, \wedge p<0.10$

Federal Predictors

I consider federal constitutional loyalty first. The dependent variable for all models is the index of constitutional loyalty discussed prior, or the mean response for a subject across all four federal diffuse support statements. Values range from one to five, with higher scores indicating greater mean constitutional loyalty. ${ }^{11}$ In the first model, I include only demographic variables: a

\footnotetext{
${ }^{11}$ As discussed prior, I created several alternative dependent variables in addition to the mean index: a factor score, proportion support, and a simple additive index of number of supportive replies. Regression analyses were replicated for all alternative dependent variables, yielding no significant or substantial differences from the results presented here.
} 
binary measure for gender; the subject's age; two dummy variables to capture race, with one noting if the subject was African American and the other indicating if the subject was part of another minority group (i.e. Hispanic, Native American, Asian American, Pacific Islander, Arab American, or mixed-race); and, finally, an ordinal variable capturing the subject's socioeconomic status (SES) (working, middle, and upper-class are the categories). As the findings indicate, gender and income class have no significant effect on constitutional loyalty, but race and age do. Being African American reduces one's mean constitutional loyalty by approximately a half-point on the five-point loyalty scale, while being a member of another minority ethnicity reduces loyalty by a smaller, yet still significant, magnitude. This pattern holds across all models, except in model 3 (see below). These findings are similar to prior work on constitutional loyalty and approval specifically, and diffuse support more generally: African Americans are less likely to express institutional loyalty or approval than other minorities and whites likely given their historical experience relative these other groups (Blake and Levinson 2016; Stephanopoulos and Versteeg 2016; see also Gibson and Caldeira 1992). While not significant at conventional levels, the age variable reaches significance at the .10 level in the demography model; an additional year in age increases the subject's mean constitutional loyalty by .028 points. This finding - that older subjects have greater loyalty than younger persons - squares with the literature on constitutional approval and loyalty, and the marginal significance is more likely a result of the sampling frame: college students reduces age variability considerably. ${ }^{12}$

\footnotetext{
12 While not reported here, regression diagnostics (i.e. influential observations, or DFbeta, and standardized residuals analysis) confirm that the age coefficient is being heavily influenced by older subjects (those 25 years and older). This is also true in the remaining models.
} 
However, demographic variables may share a complex and interrelated relationship with a subject's partisan and ideological affiliations. Given the increasing polarization of American politics at both the federal and state levels, it could be that constitutional loyalty is explained more by how one identifies politically than what one's ascribed attributes would suggest. For example, the Republican Party and conservatives increasingly emphasize the U.S. Constitution as sacrosanct, with characterizations of opponents "shredding" or "ignoring" the Constitution a potent and common political attack. Model 2 explores this relationship by adding two additional variables: partisanship captures a subject's political party identification on the typical seven-point scale (anchored by "strong Democrat" and "strong Republican"), while ideology is a five-point scale anchored by "strong" liberal at the low end and "strong" conservative at the high pole.

While prior institutional support studies (especially those on Congress and the president) have found that one's partisanship and ideology matter, works examining constitutions find that these variables matter little in explaining a person's constitutional approval or loyalty. That pattern is true here: neither partisanship or ideology reaches statistical significance in model $2 .{ }^{13}$ Instead, only race remains significant and negatively related to mean constitutional loyalty. Age is no longer even marginally significant (but see footnote 12 , above). While somewhat surprising given the larger institutional support literature, in the context of constitutions it is not. Diffuse support is meant to be resilient and based more on belief in the underlying system's or institution's legitimacy, or right to govern. Specific support, meantime, is more of a short-term appraisal, and is more likely to be affected by ideology and partisanship. For the U.S. Constitution, though, belief in it is concomitant with belief in America's civic creed (Smith 1993), a belief that

\footnotetext{
${ }^{13}$ Collinearity diagnostics do not indicate a problem in any model with running both partisanship and ideology.
} 
should transcend political attributes (and demography, for that matter). Lending credence to this theory is the fact that race remains significant across models 1 and 2: those persons considered to be outside "the true meaning of Americanism" (Smith 1993, 549; emphasis in original) are less likely to express approval and loyalty towards the Constitution. Thus, African Americans and other racial minorities - all of whom found their disapparate treatment justified on constitutional grounds at one time or another - do not express the same level of loyalty as white Americans. This relationship transcends the partisan and ideological forces that are otherwise more influential for the institutions the Constitution establishes.

Relatedly, there may be a relationship between the specific support enjoyed by the institutions of government created by the U.S. Constitution and a subject's loyalty towards the charter itself. Moreover, and as aforementioned, there is a debate in the literature if institutional support for one institution affects another's. To test for this interactive effect, model 3 includes three approval variables: one for the president (specifically President Donald J. Trump), the U.S. Congress, and the SCOTUS. These variables are measured on a five-point scale on how well the subject approves of the way the institution is handling its job, with higher scores indicating greater approval.

As the results show, institutional attitudes matter a great deal in determining one's mean constitutional loyalty. While congressional approval does not reach significance, approval of the president and the SCOTUS are positively related with mean constitutional loyalty. A one-unit increase in presidential rating corresponds with approximately a 0.2-point increase in mean loyalty, while a corresponding increase in the SCOTUS's approval increases mean loyalty by roughly half a point. These results suggest two, interdependent explanations: First, the role of 
the SCOTUS in interpreting the Constitution and resolving constitutional issues likely factors into constitutional loyalty. Since the SCOTUS enjoys a high degree of public support generally and given its role as "guardian" of the Constitution, support for the Court likely transfers to the charter itself. However, Blake and Levinson (2016) found a null-finding for the SCOTUS's approval and likelihood of supporting a federal constitutional convention. They attribute this null finding to the SCOTUS's high diffuse support, meaning there was already limited opposition expressed towards the Court. Yet, my findings suggest the opposite: the SCOTUS's approval substantially matters.

My interpretation is that today's political context may be influencing results. Since institutional approval is a specific support measure, recent decisions of the Court and the judiciary more generally striking down Trump administration actions may be causing a positive feedback: a common refrain from the Left and Trump critics is that the courts are "protecting" the Constitution with these decisions. Thus, agreement with the SCOTUS's decisions are often a reflection of agreement with the Constitution itself. Importantly, the question of whether one approves of the SCOTUS's present job handling is not inducing the subjects to consider the SCOTUS's diffuse support; they are not being asked if they would eliminate the Court or curtail its power. Rather, they are simply asked if they agree with its present job performance. As Gibson and his colleagues have found, this kind of question wording matters. Therefore, in thinking about the Court's actions (i.e. its opinions), individuals are consequently reflecting on the Constitution itself - with those opinions reflected in the relationship between the SCOTUS's job approval and one's constitutional loyalty. 
A second, related explanation also presents itself: presidential approval, specifically of Trump's approval, may be skewing the results. Unlike prior administrations, the Trump presidency has encountered (triggered?) more constitutional conflicts that may influence one's constitutional loyalty to a greater degree than previously. To control for this possible confounder, I run a modified version of model 3 (results not reported here) without Trump's approval rating included. The results do modify somewhat, but not unexpectedly: in addition to the SCOTUS's approval rating, partisanship now becomes significant and in a positive direction (i.e. Republicans express greater loyalty than Democrats) and one race variable (minority other than African American) reaches significance at the .10 level $(p=.078)$. These findings suggest that Trump's approval rating does have some leverage on one's mean constitutional loyalty, enough that it subsumes the influence of partisanship and racial minority status.

What these findings on institutional attitudes suggest is that when institutions of government engage in constitutional-level politics (e.g. debates over what the constitution requires) their job performance matters in influencing one's constitutional loyalty. This finding is somewhat troubling given that a general dislike of government could potentially pervade into the civic creed of the nation. It could also mean that loyalty towards the Constitution changes with the political winds, a byproduct of partisan polarization and the increasing tribal nature of American politics. These findings parallel the relationship explored by Stephanopoulos and Versteeg (2016) where other institutional attitudes were positively related with constitutional approval, again suggesting that the U.S. Constitution's institutional support is related to other institutions' support. 
Interestingly, model 3 also indicates that socioeconomic status has a negative relationship: being from a higher socioeconomic class (i.e. middle and upper class) depresses average loyalty. This is somewhat surprising, given the general null findings in prior works on income. Furthermore, it becomes significant only in model 3. One tentative explanation is that this finding, again, has something to do with the current political context; those from the upper classes may perceive American politics as dysfunctional, ameliorated with structural changes achieved only via constitutional alterations.

\section{Michigan Predictors}

Turning to Michigan constitutional loyalty, I repeat the analyses using Michigan-level data. In estimating these models, I use the Michigan scale of constitutional loyalty constructed above using the mean response to the four Michigan diffuse support questions. ${ }^{14}$ All independent variables used in the federal analyses are the same unless otherwise noted. Finally, the Michigan models are run using robust standard errors to correct for heteroskedasticity present in the normal OLS regression. ${ }^{15}$

\footnotetext{
${ }^{14}$ Like in the federal regressions, I repeat the analysis here for the alternative dependent variables, which yielded no substantial differences. See note 11, above.

${ }^{15}$ Analysis of the residuals for each Michigan model indicated non-normal distributions, including significant skewness and kurtosis scores. Analysis of the federal models detected no heteroskedasticity.
} 
Table 4.

Regression Modeling of Michigan Constitutional Loyalty

\begin{tabular}{|c|c|c|c|}
\hline & Model 1 & Model 2 & Model 3 \\
\hline \multirow[t]{2}{*}{ Female } & 0.088 & 0.127 & 0.207 \\
\hline & (0.081) & $(0.085)$ & $(0.128)$ \\
\hline \multirow[t]{2}{*}{ Age } & 0.01 & 0.001 & 0.021 \\
\hline & $(0.012)$ & (0.014) & $(0.014)$ \\
\hline \multirow[t]{2}{*}{ African American } & $-0.228 *$ & -0.17 & -0.12 \\
\hline & $(0.114)$ & (0.128) & (0.167) \\
\hline \multirow[t]{2}{*}{ Other Minority } & $-0.276 * * *$ & $-0.27^{* *}$ & -0.203 \\
\hline & $(0.082)$ & (0.09) & $(0.126)$ \\
\hline \multirow[t]{2}{*}{ SES } & 0.009 & 0.027 & -0.01 \\
\hline & (0.058) & $(0.063)$ & (0.094) \\
\hline \multirow[t]{2}{*}{ Partisanship } & & 0.035 & 0.022 \\
\hline & & $(0.034)$ & (0.039) \\
\hline \multirow[t]{2}{*}{ Ideology } & & 0.03 & 0.071 \\
\hline & & (0.052) & (0.071) \\
\hline \multirow[t]{2}{*}{ Snyder Approval } & & & -0.055 \\
\hline & & & $(0.071)$ \\
\hline \multirow[t]{2}{*}{ Legislature Approval } & & & 0.037 \\
\hline & & & (0.184) \\
\hline Michigan Sup. Ct. & & & 0.235 \\
\hline Approval & & & $(0.172)$ \\
\hline \multirow[t]{2}{*}{ Constant } & $2.98 * * *$ & $2.913 * * *$ & $1.1^{* * *}$ \\
\hline & $(0.284)$ & $(0.316)$ & $(0.417)$ \\
\hline$N$ & 222 & 195 & 116 \\
\hline $\mathrm{R}^{2}$ & 0.053 & 0.082 & 0.211 \\
\hline
\end{tabular}

Note: Data taken from pre-test measures. Robust standard errors in parentheses.

$* * * p<0.001, * * p<0.01, * p<0.05, \wedge p<0.10$

As presented in Table 4, predictors of Michigan constitutional loyalty are similar to federal factors, albeit with some crucial differences concerning institutional attitudes. First, demography does not appear to be destiny (again). Only the racial variables (African American and other racial minority) are statistically significant in model 1. Being an African American reduces one's Michigan mean constitutional loyalty by about 0.2 points, while other racial minorities see their mean loyalty reduced by a similar magnitude ( 0.27 points). Socioeconomic status, age, and income are all non-significant (although I caution that the sample may be disguising age's effect; 
see footnote 12, above). Expanding the modeling to include partisanship and ideology does little; neither factor is significant, while only other racial minority status remains statistically significant in the expanded model (model 2). It would appear that similar patterns of behavior at the federal level concerning personal and political attributes are replicated at the state level.

The influence of other institutional attitudes, however, is markedly different at the statelevel. Subjects were asked their job approval for state-level institutions created by the Michigan constitution, including the state governor (designated as Governor Rick Snyder), the Michigan State Legislature, and the Michigan Supreme Court. These variables were measured the same way as their federal counterparts. Whereas greater approval of President Trump and the SCOTUS were positively related to federal mean constitutional loyalty, there exists no similar relationship at the state level. Indeed, no variable achieves significance in model 3, including the race variables.

How to explain these findings? First, the general ignorance of the Michigan constitution and state governmental actors may be confounding the results. In Chapter 6, I control for knowledge about the Michigan constitution and report those findings there. Another possibility is that state-level institutional attitudes matter less in generating Michigan constitutional loyalty than their federal counterparts. Second, and related, it may be that Michigan constitutional loyalty suffers from what Zink and Dawes (2016) call a "warmglow" effect: federal-level attitudes diffuse down into state-level feelings. Consequently, I re-estimate model 3 (results not reported here) but with federal institutional attitudes rather than state. The results provide some partial evidence of this "warmglow:" while Trump's and Congress's approval do not achieve statistical significance, the SCOTUS's approval does $(p=0.008)$. The model also suggests two other factors 
that become significant: other minority status is negatively associated with mean loyalty while gender achieves significance at the 0.10 level $(p=0.099)$, with females expressing greater loyalty than males.

As Zink and Dawes (2016) opine, the federal "warmglow" likely explains individuals' attachments to their state constitutions, connoting that state constitutional loyalty may be dependent on federal loyalty. Put another way, federal and state constitutional loyalty are strongly correlated with each other. A simple crosstabulation suggest this is the case ( $r=0.61)$. To further control (and test) for this possibility, I re-ran Michigan model 3 but with an added control: mean federal constitutional loyalty. Two differences are worthy of note: First, the explained variation $\left(R^{2}\right)$ in the new estimate is substantially larger than the original model 3 ( 0.53 versus 0.21). Second, no variables (again) reach traditional levels of statistical significance except for federal constitutional loyalty; the latter is highly significant $(p=.000)$ and positively related to Michigan constitutional loyalty. A one-unit increase in federal mean constitutional loyalty corresponds with a 0.53 -point increase in state mean constitutional loyalty.

\section{Summary}

Collectively, these findings suggest two preliminary conclusions. First, the predictors of constitutional loyalty are very similar to the generators of constitutional approval, save for institutional attitudes in the case of Michigan constitutional loyalty. Demography and political affiliations are considerably un-influential when it comes to explaining a person's constitutional support. This is not that unsurprising but raises concerns about how constitutional loyalty may be driven more by the performance of the institutions the charter creates. Indeed, a person's attitudes towards the SCOTUS is intriguing, especially given the SCOTUS's interpretative role to 
say what the U.S. Constitution (and to a lesser extent state charters) is, indirectly influencing the charter's underlying support. Second, Michigan constitutional loyalty appears dependent on federal constitutional loyalty. This "warmglow" is not unexpected given the widespread exposure to the symbolism attached to the U.S. Constitution. Most citizens have limited engagement with their state constitutions in civics courses relative to the federal charter, suggesting that subjects are transferring analogous feelings to a lesser known entity but nonetheless still carrying the title of "constitution."

There remain two questions: First, how does familiarity with a constitution influence one's loyalty? As Gibson and Caldeira (2009a) note in examining the SCOTUS's diffuse support, "To know it is to love it." Thus, positivity bias may further explain loyalty scores. I examine this proposition in the coming chapters (especially Chapter 6). Second, is there a relationship between constitutional loyalty and constitutional approval? The literature on institutional support suggests that while specific support does play a role in generating diffuse support, the two are distinct concepts. In the next section, I consider the role of constitutional approval and its predictive influence on one's constitutional loyalty.

\section{What About Constitutional Approval?}

While the focus of this study is on constitutional loyalty, I do analyze constitutional approval (i.e. specific support) to (1) see if a relationship exists between approval and loyalty, (2) if my subjects' approval patterns mirror prior work, and (3) if periodic conventions influence subjects' approvals of their constitutions (see Chapter 5). The most comprehensive work on constitutional approval to date is Stephanopoulos and Versteeg's (2016). In general, these authors found a high degree of constitutional approval for both the federal and respondents' 
state constitutions, although the former was stronger than the latter. As discussed above, I capture a subject's constitutional approval by using a numbered approval scale, which asks respondents to assess how strongly they approve of the federal or Michigan state constitution. ${ }^{16}$ Given my subject pool is college students, my findings are somewhat different: the average approval score for the federal constitution is 3.4 , while the average is 3.2 for the Michigan state constitution. At face value, two conclusions can be drawn. First, the Michigan state constitution enjoys less approval than its federal counterpart, but by a somewhat trivial (albeit statistically significant; $p=0.002$ ) margin. Second, it appears that college students are far "cooler" in their orientations towards the federal and Michigan constitutions than what Stephanopoulos and Versteeg (2016) found. This may be indicative of the fact that younger persons are less likely to express high institutional support more generally (e.g. towards courts and legislatures) than older persons, with the same pattern found in support for holding a federal constitutional convention (Blake and Levinson 2016).

Nonetheless, differences do emerge below the surface. Stephanopoulos and Versteeg (2016) found that African Americans exhibited lower approval ratings than other racial minorities and whites; men were more supportive than women of constitutions; those from upper-income brackets demonstrated higher approval; and older persons (especially those over 55) expressed greater approval. However, these differences become insignificant when pooled into regression models, with other political and knowledge variables explaining the variation, although there are two exceptions: age and race.

\footnotetext{
${ }^{16}$ Subjects were asked to circle their approval on a five-point number line, with five being "strongly approve." This measure is adapted from Stephanopoulos and Versteeg (2016), albeit I reduce the scale from ten to five points for more intuitive interpretation.
} 
My results here echo these findings, with some differences. On federal approval, African Americans rate the Constitution lower than other groups, especially whites; men have higher approval ratings than women; and those coming from the middle- and upper-income classes express greater approval than those coming from the working class. Political affiliations also differed, although these are reversed from Stephanopoulos and Versteeg (perhaps reflecting a change in political control at the federal level): Republicans and conservatives were more likely to rate the Constitution higher than liberals. Finally, other institutional attitudes (i.e. towards other federal governmental branches and officials) do influence constitutional approval: subjects whom strongly approved of President Trump, the U.S. Congress, and the SCTOUS rated the Constitution higher than those with more negative attitudes. The Michigan results are similar to the federal findings, ${ }^{17}$ except on the matter of gender: both men and women rate the Michigan constitution on average a 3.2 .

Two questions persist: First, how does familiarity/knowledge of the constitution influence approval? I consider this question in Chapter 6 but highlight what prior works have found here: persons more attentive to political news and expressing greater self-knowledge of a constitution are more likely to support it. Second, what is the relationship between constitutional approval and constitutional loyalty? The literature suggests that specific and diffuse support should, theoretically and conceptually, not be closely related; specific support represents current satisfaction with the institution's outputs, which waxes and wanes. Diffuse support, meantime, is more durable and represents a commitment to the institution that should be independent of

\footnotetext{
${ }^{17}$ Rather than measuring institutional attitudes towards federal institutions, I replace the three federal institutions with state-level equivalents (e.g. Governor Rick Snyder, the Michigan State Legislature, and the Michigan Supreme Court). See also footnote 9 , above.
} 
present satisfaction. Thus, the theories hypothesize no empirical relationship between specific and diffuse support.

Actual empirics, however, tend to disprove this theoretical assumption, demonstrating a great degree of relationship between specific and diffuse support. The literature is widespread on the degree of correlation between the two (see Gibson and Caldeira 1992), with some scholars arguing that it is too difficult to effectively disentangle the two concepts empirically-speaking (see, e.g., Davidson and Parker 1972). Concerning my data, bivariate correlations between constitutional approval and loyalty yield mixed results: there is a weak-to-moderate positive relationship between Michigan constitutional approval and loyalty $(r=0.34)$, whereas the correlation is somewhat stronger between federal constitutional approval and loyalty ( $r=0.52)$. Keeping with the "warmglow" effect, federal constitutional approval is moderately correlated with Michigan constitutional approval $(r=0.50)$.

While I do not try to adjudicate the empirical debate in the literature here, I do note that there should be some relationship between specific and diffuse support. For instance, Gibson and Caldeira $(1992,1127)$ note that most literature on the SCOTUS's institutional support indicate a strong correlation between the Court's specific and diffuse support. This is not unsurprising in the sense that specific support should help to generate diffuse support over the long-term. An analogy helps: Marital relationships include both specific and diffuse support elements. Specific support refers to a partner's current feelings toward her spouse, which are context dependent and will likely wax and wane depending on the spouse's outputs (e.g. forgetting to take the garbage out). However, marital diffuse support is the long-term commitment to the institution of marriage; while she may express dissatisfaction that he has not taken the garbage out, she 
nonetheless remains committed to the marriage. However, if he continually causes displeasure, the long-term effect (i.e. low specific support) may generate a decline in diffuse support (and, ultimately, dissolve the underlying marriage).

Correlations, though, do not help us determine causation. In the face of other demographic characteristics, political attributes, and institutional attitudes, constitutional approval's influence may diminish. To test for this possibility, I control for one's constitutional approval alongside the other three dimensions (demographics, political affiliations, and institutional attitudes) in two new regression models, one each for federal and state constitutional loyalty. Readers will note the reduced Ns compared to the prior regression models; this is due to several subjects missing (i.e. non-answers) constitutional approval scores, especially in the Michigan model. ${ }^{18}$ Results are provided in Table 5.

\footnotetext{
${ }^{18}$ Analysis determined that non-answers are random and do not systemically vary.
} 
Table 5.

Regression Modeling with Constitutional Approval

\begin{tabular}{lcc}
\hline & Federal & Michigan \\
\hline Female & 0.128 & 0.19 \\
Age & $(0.117)$ & $(0.136)$ \\
& 0.009 & $0.043^{* * *}$ \\
African American & $(0.016)$ & $(0.013)$ \\
& -0.08 & 0.022 \\
Other Minority & $(0.156)$ & $(0.177)$ \\
& -0.057 & -0.171 \\
SES & $(0.134)$ & $(0.139)$ \\
& $-0.182^{*}$ & -0.056 \\
Partisanship & $(0.084)$ & $(0.11)$ \\
& 0.071 & 0.045 \\
Ideology & $(0.05)$ & $(0.043)$ \\
& -0.074 & 0.035 \\
Executive Approval & $(0.064)$ & $(0.063)$ \\
& $0.16^{*}$ & -0.076 \\
Legislature Approval & $(0.08)$ & $(0.074)$ \\
& $-0.147^{\wedge}$ & 0.06 \\
Supreme Court & $(0.08)$ & $(0.192)$ \\
Approval & $0.287^{* * *}$ & 0.176 \\
Constitutional Approval & $(0.078)$ & $(0.174)$ \\
& $0.38^{* * *}$ & $0.242^{*}$ \\
Constant & $(0.069)$ & $(0.098)$ \\
& $1.55^{* * *}$ & $0.948^{\wedge}$ \\
$\mathrm{N}$ & $(0.442)$ & $(0.499)$ \\
Adjusted-R & & 100 \\
$\mathrm{R}^{2}$ & 147 & 0.284 \\
\hline
\end{tabular}

Note: Data taken from pre-test measures. Standard errors in parentheses for federal model; robust standard errors for Michigan model.

$* * * p<0.001, * * p<0.01, * p<0.05, \wedge p<0.10$

In general, constitutional approval is indeed a significant and positive predictor of federal and Michigan mean constitutional loyalty. In the federal model, a one-unit increase in constitutional approval corresponds with an increase of 0.38-points in mean loyalty. Therefore, a person rating the federal Constitution a "five" on the approval scale would be 1.9-points higher in average loyalty than a person rating the U.S. Constitution a "one." Compared with model 3 (see Table 3), institutional attitudes and socioeconomic status remain significantly related and in 
the same direction as prior. The one new significant factor in this model is Congressional approval, which is significant $(p=0.067)$ at the 0.10 level. Higher satisfaction with Congress, however, reduces mean constitutional loyalty. This is somewhat surprising but may reflect a preference for popular decision-making undertaken by Congress (as the deliberative body of the country) unencumbered by constitutional limits. Michigan constitutional loyalty is also significantly influenced by one's specific support for the state charter. A one-unit increase in Michigan constitutional approval corresponds with a 0.24 -point increase in mean loyalty. Therefore, a person expressing a high degree of job satisfaction with the Michigan constitution (scoring a "five" on approval) would see approximately a 1.22-point increase in mean loyalty. The only other factor that reaches significance is age, but the effect is inconsequential at best (this effectively null finding is, again, likely caused by the limitation of the college student sample; see footnote 12 , above).

While not presented here, I estimate another Michigan model that controls for federal constitutional loyalty, given the "warmglow" effect. The results do not substantially differ, excepting that federal constitutional loyalty is significant and provides a substantial increase in mean Michigan constitutional loyalty $(b=0.483 ; p=0.000)$. Michigan constitutional approval's coefficient is somewhat reduced $(b=0.139)$ and is marginally insignificant at traditional levels $(p=0.066)$. However, this is likely due to the "warmglow" effect; minimal familiarity with the Michigan constitution likely means that one's federal loyalty is substituting for both specific and diffuse support of the Michigan constitution, thus explaining the insignificant result. 


\section{Discussion}

Overall, these results present a clearer picture about how college students evaluate the federal and Michigan state constitutions. Both documents enjoy a degree of diffuse support, or loyalty, although it is a qualified loyalty in many respects. For example, while majorities believe the federal charter is not too controversial and expressed skepticism at rewriting it, a majority does believe the document favors some groups over others and only a plurality explicitly rejected eliminating the Constitution entirely. These college students, though, express a great degree of undecidedness towards the Michigan charter, although large majorities demonstrate support for the document once the undecideds were removed. This is likely a function of the mass ignorance of the state charter.

Like other institutional loyalties, constitutional loyalty follows similar, predicted patterns for college students. Demography does not appear to meaningfully influence one's federal or Michigan constitutional loyalty, with partisanship and ideology also noninfluential. Institutional attitudes, or the specific support for other governmental institutions, does appear to predict one's average constitutional loyalty. However, this is likely a result of the political context of the time (e.g. the Trump administration), while the SCOTUS's roles as constitutional arbiter and interpreter indirectly influence one's constitutional attitudes; agreement with the Court's decisions on major constitutional questions reflects one's underlying loyalty to the charter. The influence of federal attitudes is also apparent at the state-level, with Michigan constitutional loyalty depended on how one feels about federal institutions and the U.S. Constitution. Finally, one's constitutional approval (specific support) influences his/her loyalty to the charter. 
Importantly, these findings reflect more of the expectations of the literature than not. While a more comprehensive examination of diffuse support predictors (borrowing from the larger literatures on constitutional approval and the courts' institutional support), the relationships observed here follow the patterns elsewhere. What is surprising is the extent that institutional attitudes appear, at least in these preliminary analyses, to be driving college students' mean constitutional loyalties. It appears that constitutions are, indirectly, being evaluated via their own outputs - namely, the performance of their created institutions (i.e. the executive, legislature, and judiciary). Thus, how well a constitution's institutions perform helps to determine its own loyalty and approval. If these institutions are not doing well, individuals may find that structural changes to the charter are necessary - necessitating a lower loyalty to countenance fundamental changes.

But there is a key dimension that is unaccounted: What about constitutional knowledge? Do persons with greater familiarity of their constitutional charters behave the same? Does knowledge thwart the influence of institutional attitudes? I consider these propositions in Chapter 6. In the next chapter, however, I explore the dissertation's primary focus: What role do periodic conventions play in generating constitutional loyalty? 


\section{CHAPTER 5 - PERIODIC CONVENTIONS \& CONSTITUTIONAL LOYALTY}

Having discussed overall levels and the predictors of constitutional loyalty, I now turn to examining my dissertation's experimental results. In this chapter, I first restate my central research question and theory, noting my expectations and formal hypotheses. My primary focus is addressing the role that periodic conventions play in generating or undermining constitutional loyalty. Next, I summarize my methods and discuss my subject sample. Following these preliminaries, I discuss the experiment's results and evaluate my hypothetical predictions. Finally, I conclude with a discussion on the experiment's limitations and implications.

\section{How Do Periodic Conventions Influence Constitutional Loyalty?}

Research Questions and Theory

As detailed above (see Chapter 2), Thomas Jefferson was not a fan of permanent constitutional charters. Jefferson feared that blind support for a constitution may have negative consequences, including saddling the polity with suboptimal institutions. Instead, succeeding generations should have the opportunity to effect "periodic repairs," or constitutional revisions

- including wholescale replacement of the current charter. In modern parlance, Jefferson's criticism is a call for periodic constitutional conventions, or opportunities for the public to modify or replace their existing constitution, a process more fundamentally involved than simply amending it. James Madison, among others, feared that periodic conventions would reduce the constitution's legitimacy; to make the constitution subject to a sunset provision would reduce its habitual obedience, reducing its long-term effectiveness by eviscerating popular support. However, Madison did concede that periodic conventions may bolster support: in Federalist 49, he wrote that if succeeding generations knew prior conventions were rejected, then respect for 
the present charter may increase given the deliberate choice expressed by the people (Madison [1788] 1961). Put another way, knowing that prior generations could have replaced the constitution but chose not to would increase loyalty towards it.

This debate yields two mechanisms by which constitutional loyalty may be influenced. First, the notion that habit breeds obedience; a preference for the status quo generates further satisfaction and loyalty with a constitution simply because it is the default. The longer the status quo exists, moreover, the stronger its support. An alternative mechanism is the one Jefferson and Madison quibble over: the constitution's susceptibility to change may reinforce its loyalty. Periodic conventions represent an existential threat; the charter could be fundamentally altered or even replaced by a convened convention. Studies on risk aversion (see Chapter 2 for a review), for instance, note that people prefer options that mimic the status quo's characteristics or otherwise avoid alternatives that carry risks. Highlighting what periodic conventions could do may be enough to reinforce a person's constitutional loyalty.

Several questions can be distilled from this philosophical debate and empirical literatures. Is constitutional loyalty reinforced or undermined by periodic conventions? Literature on risk aversion and constitutional status quo bias suggests that once voters are aware of the potentiality that a periodic convention represents (i.e. replacing a constitution), voters are less inclined to support it. Thus, I would expect constitutional loyalty to increase due to periodic conventions since conventions represent a threat to the constitution's integrity. Madison's contention, though, remains: Does knowing that prior periodic conventions were rejected by voters (or were approved) affect constitutional loyalty? If the proposition is valid, then constitutional loyalty should increase among voters who know a constitution was successfully 
retained in prior elections. Voters informed that prior conventions were approved, though, may express weakened loyalty.

\section{Expectations}

Importantly, Madison's contention directs us to consider one's loyalty towards constitutions, or that an individual's diffuse support should increase. The more a subject is primed to think about changing a constitution, the more likely she will not support proposed modifications (see also Zink and Dawes 2016). As such:

Hypothesis 1a: Subjects exposed to more information about periodic conventions will exhibit higher constitutional loyalty.

Yet, the literature on diffuse support would seem to discount this possibility, given its long-term, and resilient, nature. Periodic conventions, though, may influence a person's constitutional approval, or specific support. The contextual, ephemeral nature of specific support would be far more susceptible to periodic conventions and priming surrounding them than diffuse support. Therefore:

Hypothesis 1b: Subjects exposed to more information about periodic conventions will exhibit higher constitutional approval.

It is important to tease out this possibility; a person's constitutional loyalty may be unaffected (especially given constitutional status quo bias), but her constitutional approval may respond to the stimuli represented by periodic conventions. Nonetheless, I still proceed with Madison's expectations (i.e. Hypothesis 1a) given the dissertation's focus.

A second set of hypotheses moves beyond this general relationship between periodic conventions and constitutional loyalty and examines different primes. Federalist 49 suggests one 
such prime: knowledge of prior conventions being rejected promotes greater constitutional loyalty. This could also be true of constitutional approval; knowing that prior generations kept the document wholescale may additionally bolster its specific support. Therefore, I expect:

Hypothesis 2a: Subjects informed about prior periodic conventions being rejected by voters will have higher constitutional loyalty than those told prior periodic conventions were approved.

Hypothesis 2b: Subjects informed about prior periodic conventions being rejected by voters will have higher constitutional approval than those told prior periodic conventions were approved.

Again, the nature of diffuse support should argue against Madison's contention in Hypothesis 2a, but I assume its potentiality here given my dissertation's goal of empirically testing Madison's proposition.

A third hypothesis also presents itself: Knowledge about periodic conventions may manifest electorally, to the degree that a subject would vote to hold a periodic convention. My experiment tests for this possibility (see below), and I proceed with the assumption that a subject's constitutional status quo bias will undercut their electoral support irrespective of whether their constitutional loyalty or approval is affected.

Hypothesis 3: Subjects exposed to more information about a periodic convention will indicate lower likelihoods of voting to hold a convention.

I leave open my expectations about whether a particular prime (i.e. being informed that prior conventions were approved versus rejected) will have a differential effect on a convention's electoral support (see results section, below). 
Finally, I note that the experimental nature of this study requires a degree of post-hoc control. Subjects who are unaware of what periodic conventions represent may respond differently to the treatments than subjects already acquainted.

Hypothesis 4: Subjects less familiar with periodic conventions will be more susceptible to the treatment than subjects with greater familiarity.

My expectation, therefore, is that any significant results detected will likely be driven by subjects who were previously ignorant of periodic conventions. Subjects more familiar with periodic conventions likely did not respond to the treatment, seeing no significant change in their mean constitutional loyalty and/or constitutional approval scores. (See Table 6, below, for a summary of hypotheses and results.)

\section{Methods and Data ${ }^{1}$}

\section{Survey Instrument}

I test these hypotheses using a between-subjects survey experiment. Subjects were first given a pre-test measuring their demographic characteristics (e.g. age, race, and socioeconomic status), sociopolitical variables (e.g. ideology, partisanship, and political orientations), and initial specific and diffuse support for the federal and Michigan state constitutions. ${ }^{2}$ Subjects were then randomly assigned to one of four experimental conditions (see below). Depending on condition assigned, participants encountered varying information concerning Michigan's 2010 periodic convention and its powers via a mock newspaper article. After reading the experimental vignette,

\footnotetext{
${ }^{1}$ Greater elaboration of these methods (including justifications) can be found in Chapter 3 . This section serves as both a quick primer and reminder.

${ }^{2}$ See Appendix A for the complete survey instrument, including pre-test, manipulations, and post-test. See also Chapter 3 for variable operationalizations not discussed below.
} 
subjects completed a post-test with three tasks: (1) two questions on how likely they are to support a constitutional convention at the federal and state levels; ${ }^{3}$ (2) two short question batteries on federal and Michigan state constitutional knowledge; and (3) complete, again, the specific and diffuse support batteries from the pre-test.

\section{Measurement and Manipulations}

My main dependent variable is the index of constitutional loyalty (one each for federal and Michigan). Briefly, this measure is the average response across all four diffuse support statements from the post-test (and used in the prior chapter). I also measure the treatment's effect on a subject's constitutional approval (scores range from $1=$ "strongly disapprove" to 5 = "strongly approve") and the two constitutional convention support questions (scores range from $1=$ "very unlikely" to 5 = "very likely"). Finally, to investigate whether effects differ by a subject's prior knowledge about periodic conventions, I use three pre-test measures to create a summary scale of prior knowledge. These three true/false questions include: (1) whether Michigan has a state constitution (true); ${ }^{4}(2)$ if Michigan voters are asked every 16 years if they would like to hold a constitutional convention (true); and (3) if the current state constitution can be revised by a periodic convention (true). The resultant "prior knowledge" scale ranges in scores from zero (no correct answers) to three (all questions correctly answered). For simplicity, I recoded this variable into a binary measure, with subjects answering zero or a single question correctly as

\footnotetext{
${ }^{3}$ I do not include the convention support questions on the pre-test for two reasons: (1) I do not want to potentially alert subjects to the treatment and (2) subjects may not be aware what a constitutional convention is, thus biasing initial measures and yielding invalid comparisons with post-treatment scores (Gerber and Green 2012).

${ }^{4}$ This is a legitimate question given the general ignorance of state government (Roeder 1994; see also Armaly and Black 2016) and that one national survey found that 54 percent of respondents incorrectly identified that their state had no constitution (Lyons, Jaeger, and Wolak 2012).
} 
"low prior knowledge" and those answering two or three questions correctly as "high prior knowledge." ${ }^{5}$ Experimental results were reanalyzed using this grouping variable.

The experimental treatment is a mock newspaper article covering the 2010 Michigan periodic convention ballot question (the last time the ballot question appeared). In composing the article, I used John Minnis's (2010) article published in the Oakland Legal News as a model (predominately borrowing phrasing), although my instruments differ significantly from his original piece. ${ }^{6}$ Subjects assigned to Condition 0 ("control") received a "plain" article on the 2010 convention question. The article did not frame, prime, or otherwise emphasize features of a periodic convention (specifically that it can wholescale replace the present charter) and balances discussion by providing an affirmative and negative position on holding the convention. (See Appendix A for full wording for each condition.) The control (Condition 0) will serve as the baseline for subsequent analysis.

The remaining conditions received altered articles. Subjects assigned to Condition 1 ("more information") received the "control" article but with an added paragraph describing how a seated convention could fundamentally alter or replace the current constitution. Condition 1 effectively measures whether a constitutional status quo bias exists by inducing the subject to consider replacing the charter (see also Zink and Dawes 2016). However, this treatment does not

\footnotetext{
${ }^{5}$ Each statement also included a "Don't Know" option. I recoded these variables into simply binary measures with respondents coded as having known the correct answer ("True" responses) versus not knowing the correct answer ("False" and "Don't Know" responses). Binary recodes were used to construct the original additive index.

${ }^{6}$ I selected Minnis's piece as a model given his comprehensive account of the Michigan convention ballot question in 2010. The article includes direct quotes from various organizations and officials supporting and opposing the ballot question, as well as positive and negative justifications for why a convention is (un)necessary. While I do not use the entire piece as originally published, various paragraphs are lifted, edited, and reorganized in a manner that approximates the article I sought. Moreover, the mundane realism here is heightened given usage of an actual article on the convention question rather than a purely artificial one.
} 
address the priming nature described in Federalist 49 by Madison: knowing that prior convention questions were defeated bolsters one's support (approval and/or loyalty) for the constitution. Conditions 2 and 3 test for this prime: Condition 2 ("negative prime") presents the article found in Condition 1 but with a new paragraph near the end highlighting how past convention referenda were rejected by voters (using the actual vote margins). Conversely, Condition 3 ("positive prime") emphasizes a series of past referenda that were approved by voters, suggesting that voters in the past have been critical of the state's constitution, albeit earlier versions. Knowledge that voters have voted to fundamentally review the state constitution may work against the document's institutional approval and loyalty.

\section{Subjects}

Subjects were 251 undergraduates at Wayne State University recruited through introductory American government courses (1000 level). Students were asked to participate in an anonymous survey exploring students' knowledge and feelings towards the federal and Michigan state constitutions. Participation was voluntary; students wishing to participate completed an in-person survey during regular class time. Persons opting to not participate were free to sit quietly during the survey's administration. (For more information on selection procedures and safeguards, see the relevant discussion in Chapter 3.) Steps were taken to ensure that students did not take the survey twice, nor were they alerted to the experimental randomization process (i.e. students received a survey "packet" that already included a random treatment condition). In my sample, 46 percent were male, and 54 percent were female (with 7 invalid or missing responses). The average age was 20 years (15 missing). Politically, 67 percent identified as Democrats, 12 percent as independents, and 21 percent as Republicans (18 missing). 
Ideologically, the sample tilts leftwards on a five-point ideology scale, with a two (2) as the median ideology score (24 missing). Finally, 50 percent of the sample identifies as Caucasian, 22 percent as African American, 11 percent as Asian American, 4 percent as Latinx, 6 percent as Arabic/Middle Eastern, and 6 percent reporting other (5 missing). ${ }^{7}$

\section{Analysis and Results}

\section{Randomization Checks}

While a convenience sample, random assignment should produce groups that are equivalent on initial measures of the dependent and relevant independent factors. The latter included demographic and sociopolitical characteristics, as well as prior knowledge on Michigan's periodic conventions and institutional attitudes towards federal and state institutions. Preliminary tests suggest that randomization worked: ANOVAs (for ratio-level variables), KruskalWallis $\mathrm{H}$ tests (for ordinal-level variables), and chi-squares (for nominal-level variables) revealed no significant differences for any pre-test measure across all four conditions. This includes initial measures of constitutional approval and loyalty, where all conditions reported similar pre-test measures. ${ }^{8}$ Finally, of the 251 subjects, 62 were assigned to Condition 0 ("control"); 79 to Condition 1 ("more information"); 55 to Condition 2 ("negative prime"); and 55 to Condition 3 ("positive prime").

\footnotetext{
${ }^{7}$ Subjects coded as "other" include those identifying as Native American, Pacific Islander, or mixed race. Only four subjects identified as Native American or Pacific Islander, explaining why I report them here with other categories. Note that all percentages reported here may not sum to 100 due to rounding.

${ }^{8}$ Analysis of missing data on dependent and independent factors by experimental condition also yielded nonsignificant results.
} 


\section{Michigan Results}

Having established equal groups, I now test my hypotheses (see Table 6 for a summary of hypotheses and results). There are three dependent variables of interest: how likely one supports a federal or state constitutional convention, constitutional approval, and constitutional loyalty. ${ }^{9}$ I first examine Michigan-level findings before considering whether the experiment (aimed primarily at Michigan constitutional support) also affected federal constitutional feelings. In conducting my analysis, I run one-way ANOVAs to ascertain whether the dependent variables varied among the conditions. ANOVAs, or a one-way analysis of variance, permits researchers to determine if three or more independent (unrelated) groups differ significantly on an outcome variable by examining the variance among group means. As used here, ANOVA provides a statistical test for whether the group means are equal, noting if the means are significantly different from one another. Should significant differences be found, post-hoc tests are used to identify which groups significantly differ from one another (using a pairwise comparison of means). While there exists multiple post-hoc methods, I use the Bonferroni method since I have four conditions (control, more information, negative prime, and positive prime) and each condition varies in sample size (see above) (thus, I opt for a post-hoc test that is more conservative in correcting for Type I errors). I also report effect sizes (Eta-squares, $\eta^{2}$ ) where appropriate. ${ }^{10}$

\footnotetext{
${ }^{9}$ Constitutional loyalty is, again, measured using the subject's average response to all four diffuse support statements. As noted in Chapter 4 (footnote 3), I created alternative measures to capture one's constitutional loyalty. While the findings reported herein are based on the mean response, other analyses conducted using the alternative measures yielded no substantial differences. This is true for both federal and state-level findings. ${ }^{10}$ Effect size indicates how strong the difference is between means. Eta-squares are a measure of explained variation, or how much of the variance in the group mean (dependent variable) is explained by the independent variable.
} 
Table 6.

Hypotheses: Summary and Results

\begin{tabular}{|c|c|c|}
\hline Hypothesis & Expectation & Results \\
\hline Hypothesis 1a & $\begin{array}{c}\text { More information about periodic conventions increases } \\
\text { subject's mean constitutional loyalty }\end{array}$ & No significant differences \\
\hline Hypothesis 1b & $\begin{array}{c}\text { More information about periodic conventions increases } \\
\text { subject's constitutional approval score }\end{array}$ & No significant differences \\
\hline Hypothesis 2a & $\begin{array}{c}\text { Informed periodic conventions rejected by voters } \\
\text { increases subject's mean constitutional loyalty }\end{array}$ & No significant differences \\
\hline Hypothesis 2b & $\begin{array}{c}\text { Informed periodic conventions rejected by voters } \\
\text { increases subject's constitutional approval score }\end{array}$ & Yes, but scores decreased \\
\hline Hypothesis 3 & $\begin{array}{c}\text { More information about periodic conventions decreases } \\
\text { subject's likelihood of voting for a convention }\end{array}$ & $\begin{array}{c}\text { No significant differences } \\
\text { Hypothesis 4 }\end{array}$ \\
$\begin{array}{c}\text { Subjects less familiar with periodic conventions will be } \\
\text { more susceptible to treatments than subjects with } \\
\text { greater familiarity }\end{array}$ & $\begin{array}{c}\text { No significant differences } \\
\text { among subjects with } \\
\text { greater familiarity, but } \\
\text { only for constitutional } \\
\text { approval }\end{array}$ \\
\hline
\end{tabular}

Concerning Michigan, the experiment produced mixed results. For constitutional loyalty, the one-way ANOVA did not indicate significant differences between the groups $(F(3234)=0.15$, $p=0.927) .{ }^{11}$ Constitutional loyalty scores did not significantly vary between any of the conditions. These results cast doubt that more information about periodic conventions (specifically that a convention can replace the constitution) increases one's loyalty towards the charter itself (Hypothesis 1a). Moreover, priming voters about past periodic conventions (whether approved or rejected) does not seem to matter (Hypothesis 2a); subjects informed that prior conventions

\footnotetext{
${ }^{11}$ It is not standard practice within the literature to illustratively report ANOVA tables, and I adhere to this practice throughout the dissertation. Formal ANOVA tables are available upon request.
} 
had been rejected ("negative prime") did not differ in their mean constitutional loyalty from subjects told that prior conventions had been approved ("positive prime").

However, a different picture is painted for constitutional approval. The results of a oneway ANOVA show a significant difference between the conditions $(F(3,222)=3.06, p=0.029)$, indicating constitutional approval scores differed. Bonferroni post-hoc tests revealed that subjects informed that prior conventions were approved (Condition $3, \bar{y}=3.43 ; s=0.84$ ) had significantly larger mean constitutional approval scores than those told that prior conventions were rejected by voters (Condition $2, \bar{y}=2.96 ; s=0.81 ; \mathrm{p}=0.019$ ). However, there were no statistically significant differences between the other conditions. Results are graphically illustrated in Figure $3 .^{12}$

\footnotetext{
${ }^{12}$ I opt to not visually report non-significant findings. Therefore, only significant findings are illustrated here and for the remainder of the chapter.
} 


\section{Figure 3.}

Michigan Constitutional Approval Scores by Experimental Condition

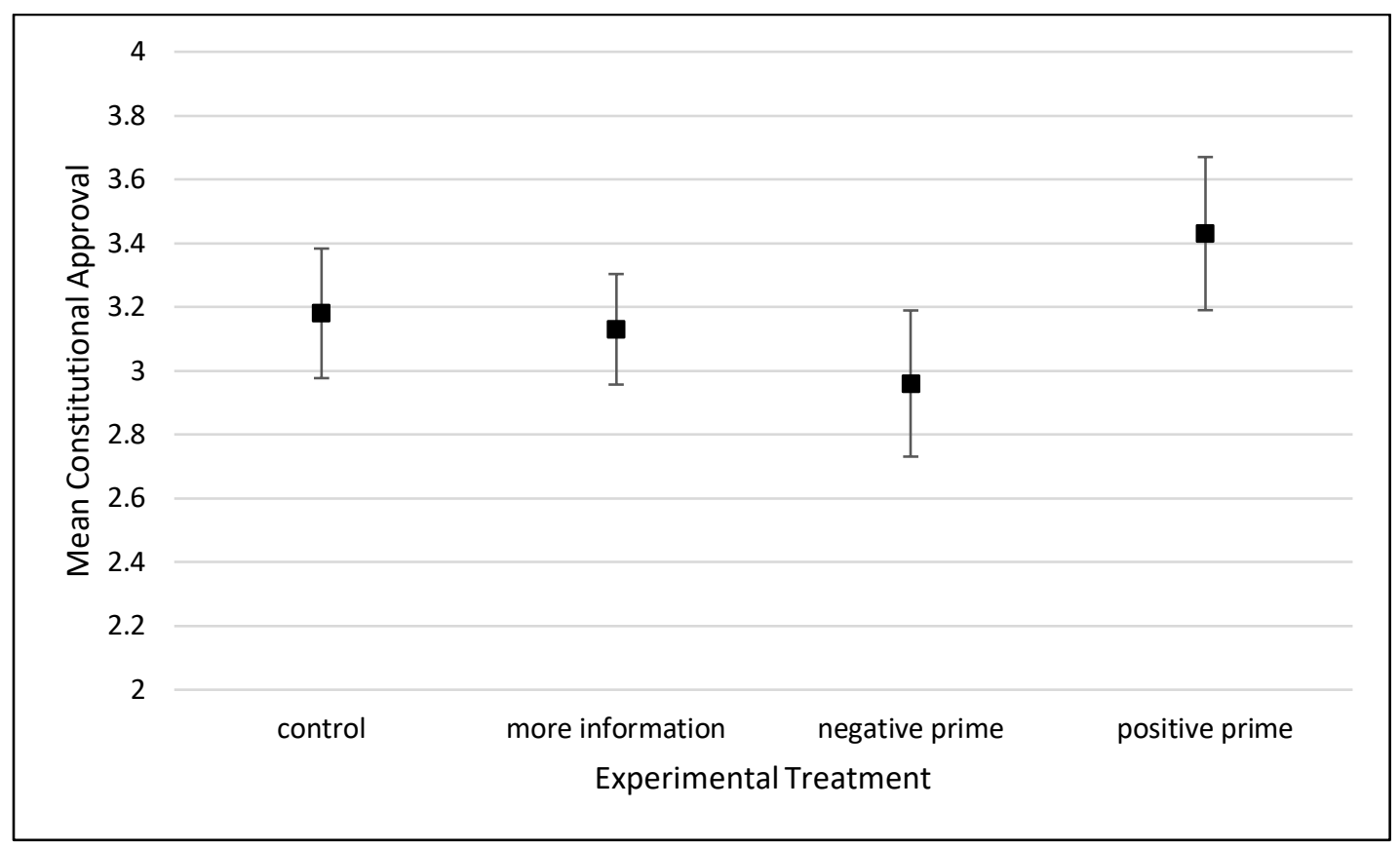

Note: Data based on post-test measures. Constitutional approval score presented on five-point scale, with higher numbers indicating greater approval. Error bars represent the 95 percent confidence interval.

These results are somewhat intriguing, and do not square with my hypothetical expectations. The lack of significant findings except between the differing primes discounts Hypothesis $1 b^{\prime}$ s expectation that subjects exposed to more information about a periodic convention will express greater constitutional approval. Instead, the significant difference between Conditions 2 and 3 illustrates how additional information about a periodic convention is only meaningful if it includes a prime: knowing how other conventions were decided by voters and that a convention can replace the constitution induces changes in constitutional approval, although the effect size is small $\left(\eta^{2}=0.04\right)$. However, I hypothesized (Hypothesis $2 b$ ) that the negative prime (Condition 2, i.e. prior conventions were rejected) would galvanize support for the current charter relative those told that prior conventions had been approved (Condition 3). This is also in line with Madison's assertion in Federalist 49: voters would provide further support 
for charters they knew were previously upheld rather than subject to a convention. Results here point to the opposite conclusion: knowing that prior conventions were approved - and thus subjected the charter to revision and, ultimately, replacement - induced greater constitutional approval in subjects. I further discuss this finding, below.

I also examine whether subjects' likelihood of voting for a periodic convention was different among the treatments. My general expectation (Hypothesis 3 ) is that subjects exposed to more information about a periodic convention will express lower likelihoods of electorally supporting a periodic convention. A one-way ANOVA suggests this is not the case; there are no statistically significant differences between conditions $(F(3,244)=1.14, p=0.333)$. This is not terribly unsurprising given the null findings for constitutional loyalty; constitutional status quo bias likely serves as a considerable barrier already, and the treatment was not enough to overcome it. Madison would certainly take comfort here!

However, there is a further possibility that those with prior knowledge about Michigan's periodic convention mechanism may react differently than those more ignorant (Hypothesis 4). As Langton and Jennings (1968) found, students less familiar with political information and events found their civics courses in high school more meaningful compared to students who had prior exposure. For example, African American students' political knowledge, political efficacy, and tolerance levels increased at greater rates compared to their more informed and experienced white peers. A similar "redundancy" effect may be at work here; subjects with a better understanding of periodic conventions will be less influenced by the treatment. ${ }^{13}$ To test for this potentiality, I use the "prior knowledge" scale described above to re-estimate my ANOVAs.

\footnotetext{
${ }^{13}$ Level of constitutional knowledge may work in a similar fashion, a proposition I explore in Chapter 6.
} 
Summary statistics suggest that there is a great degree of ignorance on Michigan's periodic conventions. Approximately 64 percent of subjects correctly identified that Michigan has a state constitution, although 34 percent were unsure (only 2 percent incorrectly identified Michigan as having no charter). ${ }^{14}$ Concerning the frequency of periodic conventions, only 16 percent correctly noted it was true; 13 percent indicated it was false, with the vast majority of subjects (71 percent) unsure. Finally, about a quarter (24 percent) knew that a periodic convention could revise and replace the present Michigan constitution; a small percentage (4) thought it could not, while 71 percent were unsure. The resulting additive index of correct answers ranged from 0 correct answers (33 percent of subjects) to 3 (all) correct answers (only 9 percent). Most subjects (72 percent) had one or no correct answers (ostensibly many only correctly noting that Michigan had a state constitution), providing motivation for replicating the above analyses controlling for prior periodic convention knowledge.

In replicating my ANOVAs, I recode the additive index of prior periodic convention knowledge into a dichotomous measure, pooling incorrect and "Don't Know" responses together (see footnote 5, above). Those with one or no correct answers were coded as "low prior knowledge" with subjects providing two or three correct answers labeled as "high prior knowledge." I re-run the above analyses using the prior convention knowledge dummy as a grouping variable (i.e. ANOVAs are produced for each level of prior knowledge). No significant differences among levels of prior knowledge emerges in these new ANOVAs, keeping with prior findings, except for constitutional approval. Like before, significant differences in constitutional

\footnotetext{
${ }^{14}$ Relative prior work (Lyons, Jaeger, and Wolak 2012, where 54 percent of respondents incorrectly identified their state as not having a constitution), this is a better-than-expected result!
} 
approval scores emerges between Conditions 2 ("negative prime") and 3 ("positive prime"), but only for those with low prior periodic convention knowledge $(F(3,158)=3.53, p=0.016) .{ }^{15}$ Bonferroni post-hoc tests indicate that subjects exposed to the negative prime $(\bar{y}=2.75 ; s=0.77)$ had lower approval scores than the positive prime group $(\bar{y}=3.35 ; s=0.92 ; \mathrm{p}=0.01)$. The effect is also stronger than observed in the original run $\left(\eta^{2}=0.06\right)$. Results are graphically presented in Figure 4.

Figure 4.

Michigan Constitutional Approval Scores by Prior Knowledge

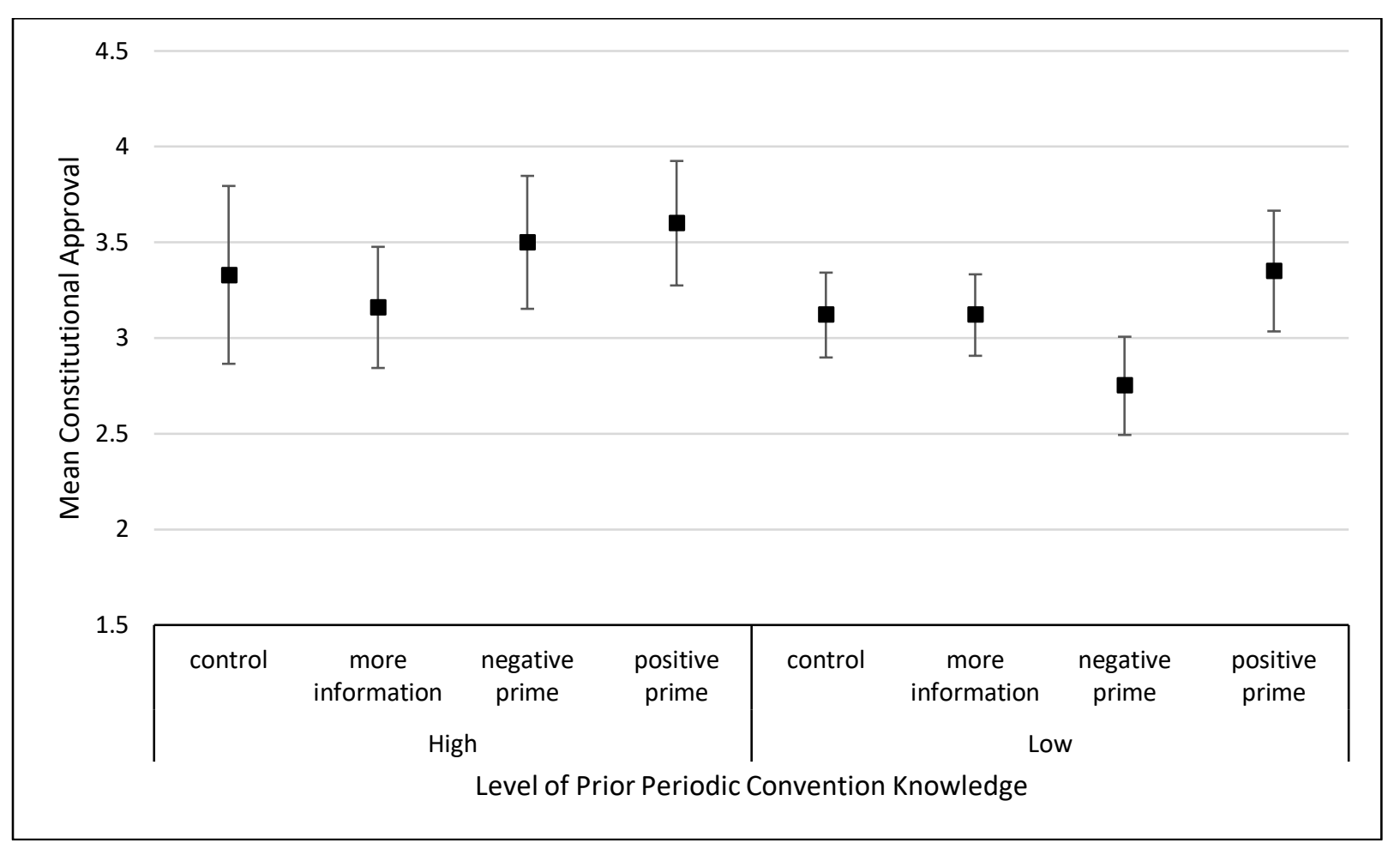

Note: Data based on post-test measures. Constitutional approval score presented on a five-point scale, with higher numbers indicating greater approval. Error bars represent the 95 percent confidence interval.

What these findings suggest is that, again, more information about a periodic convention must be accompanied by a prime in order to have a meaningful impact. However, the effect

${ }^{15}$ One-way ANOVA results for those with greater prior knowledge were non-significant $(F(3,59)=1.21, p=0.316)$. 
appears to be limited to those unfamiliar with Michigan's periodic convention. The moderate effect size also indicates that the treatment matters more for those uninformed. Yet, the positive prime still induces stronger constitutional approval rather than the hypothesized negative prime. I return to this finding in the discussion section, below, but at least note here that it appears Madison's logic in Federalist 49 was incorrect: knowing that prior generations voted to keep a constitution (by rejecting periodic conventions) does not generate greater support for it. Rather, the opposite is true; knowing prior conventions have been supported (and possibly replaced the constitution) produces greater approval of the present charter.

\section{Federal Results}

I now turn to federal results for the three dependent variables. While the experiment deals with Michigan's periodic convention mechanism, it is prudent to examine whether subjects' federal constitutional feelings change in response to a state-level stimulus. While the federal constitution has no history of periodic conventions (nor being subject to a revising convention), perhaps a "warmglow" effect occurs - or state level feelings on periodic conventions bleed into federal thinking, similar to what Zink and Dawes (2016) find (see also Chapter 4 for a discussion). To this end, I run another series of ANOVAs to test for whether levels of federal constitutional loyalty, constitutional approval, and likelihood of supporting a federal constitutional convention vary with the treatments.

Results paint a mixed picture. On federal constitutional loyalty, the one-way ANOVA did not indicate significant differences between the conditions $(F(3,238)=1.07, p=0.361)$. Similar null findings were observed for likelihood of voting for a federal constitutional convention $(F(3,245)=1.05, p=0.371) ;$ the treatments had no effect on subjects' federal proclivities. These 
findings suggest that, like Michigan, federal constitutional loyalty is unaffected by primes about periodic conventions. Similarly, subjects' electoral support for a federal convention appears unmoved - an expected result given the treatments' inability to move a person's diffuse support. However, federal constitutional approval is affected by the treatments. Per the one-way ANOVA, significant differences among the conditions occur $(F(3,216)=3.55, p=0.015)$. Bonferroni posthoc tests show subjects exposed to a negative prime had lower federal constitutional approval scores $(\bar{y}=3.06 ; s=0.88)$ than those in the positive prime condition $(\bar{y}=3.28 ; s=0.92 ; p=0.027)$, as depicted in Figure 5. This echoes the Michigan constitutional approval findings, suggesting that a reverse "warmglow" is occurring (with a moderate effect size, $\eta^{2}=0.05$ ); subjects informed that prior periodic conventions had been rejected not only rated the Michigan constitution lower but correspondingly offered a frostier evaluation of the federal charter. 


\section{Figure 5.}

Federal Constitutional Approval Scores by Experimental Condition

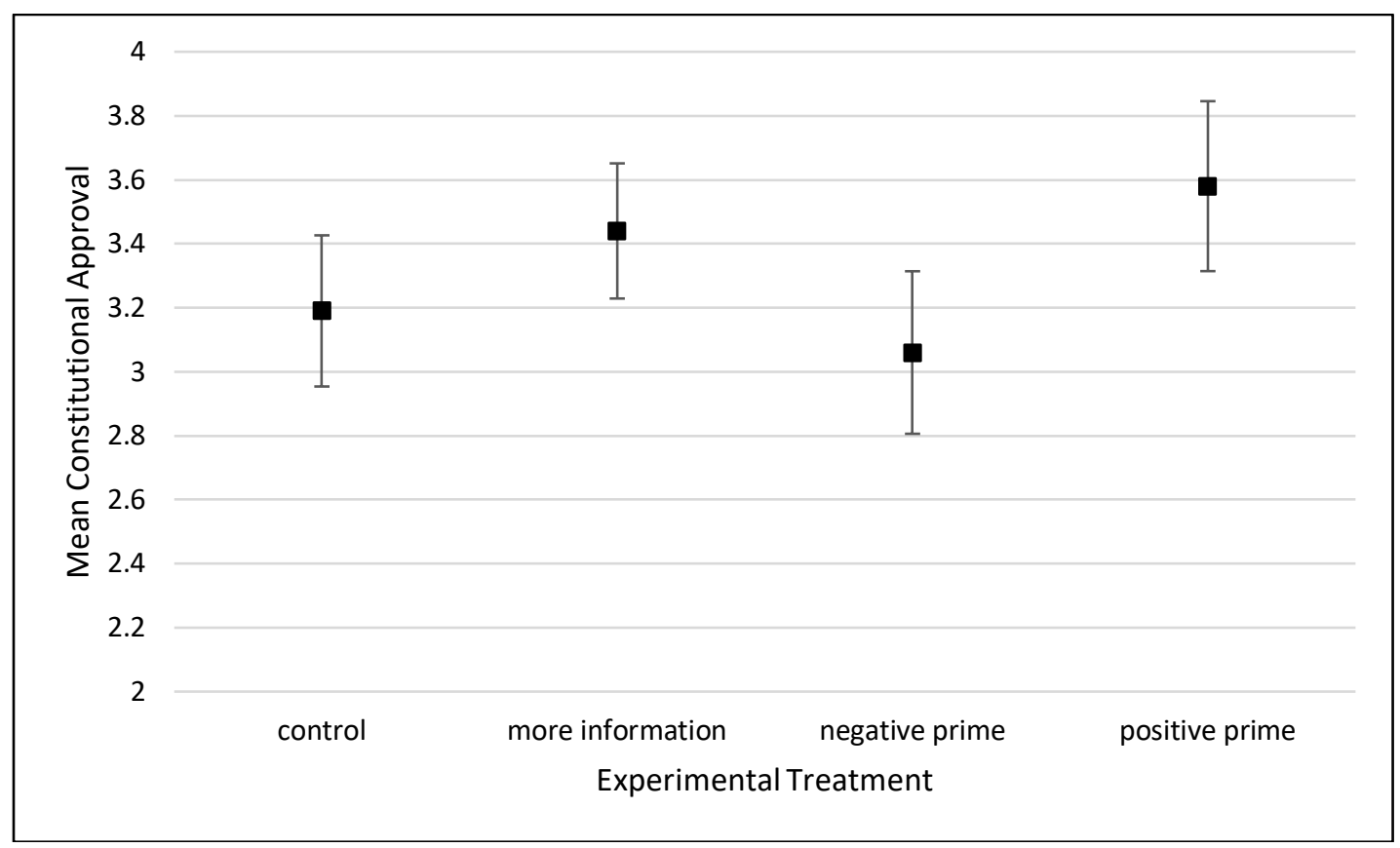

Note: Data based on post-test measures. Constitutional approval score presented on five-point scale, with higher numbers indicating greater approval. Error bars represent the 95 percent confidence interval.

Perhaps these results, though, are different depending on the subject's familiarity with Michigan's periodic convention. Again, I re-run the analyses using the index of prior periodic convention knowledge described above, but this time using federal-level dependent variables. One-way ANOVAs do not find significant differences among the groups for either federal constitutional loyalty or the likelihood of supporting a federal constitutional convention. However, and like in the Michigan re-runs, federal constitutional approval does significantly differ among the conditions for those with low prior periodic convention knowledge $(F(3,156)=5.26$, $\mathrm{p}=0.002) .{ }^{16}$ Bonferroni post-hoc tests determined that subjects in the negative prime $(\bar{y}=2.83$; $s=0.75)$ had significantly lower federal constitutional approval scores than subjects in the

\footnotetext{
${ }^{16}$ Subjects with greater prior knowledge did not significantly differ among conditions $(F(3,55)=1.39, p=0.255)$.
} 
positive prime $(\bar{y}=3.3 .53 ; s=0.93 ; \mathrm{p}=0.004)$, as shown in Figure 6 . Taken together with the former findings on federal constitutional approval, it appears the reverse "warmglow" is moderately occurring among subjects more ignorant of periodic conventions $\left(\eta^{2}=0.09\right)$. This is an unsurprising result given that low prior knowledge subjects were also more susceptible to the negative prime in the Michigan analysis.

\section{Figure 6.}

Federal Constitutional Approval Scores by Prior Knowledge

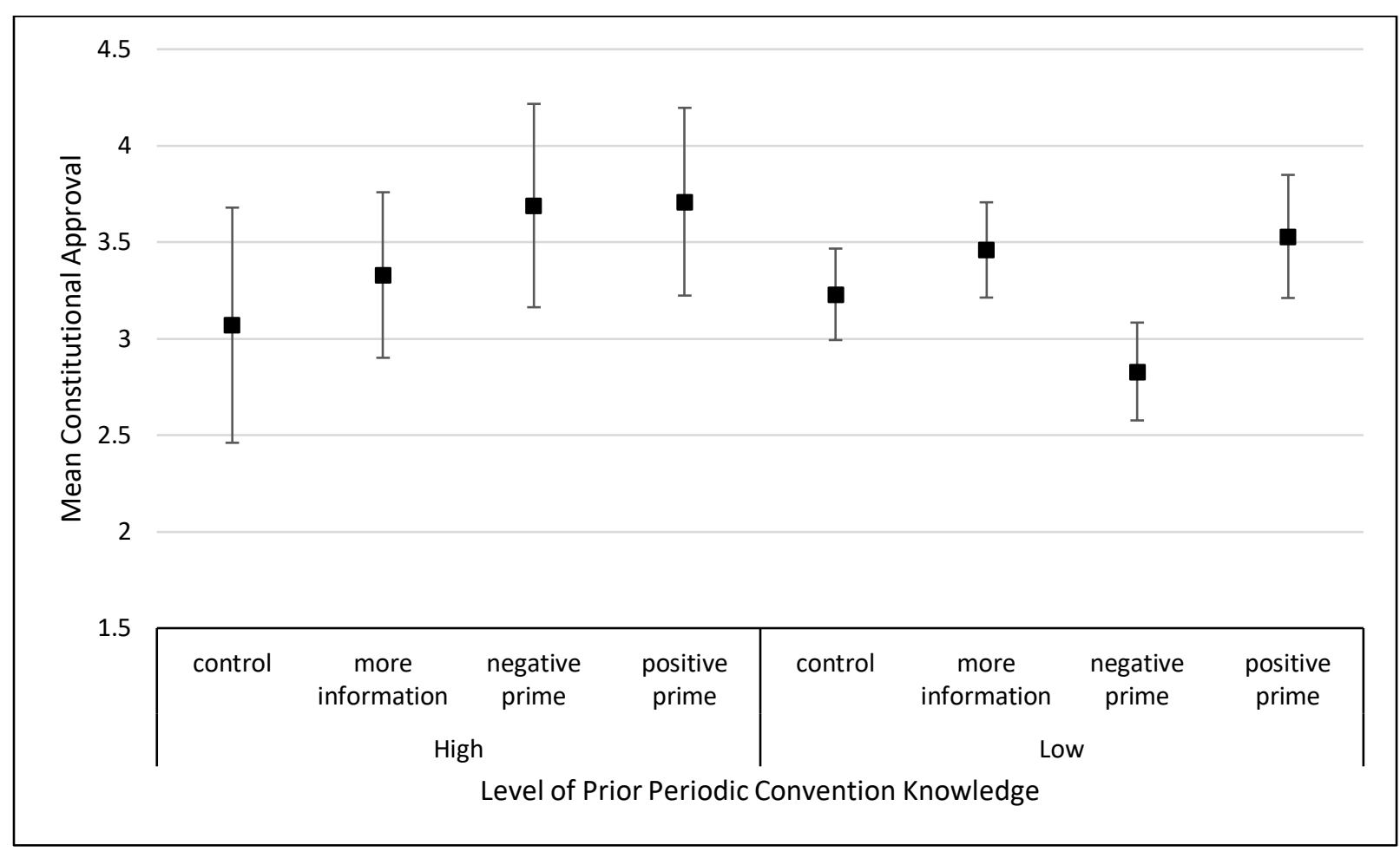

Note: Data based on post-test measures. Constitutional approval score presented on a five-point scale, with higher numbers indicating greater approval. Error bars represent the 95 percent confidence interval.

\section{Discussion}

Collectively, these findings challenge the expectations in the literature and those proffered by Madison and others. Only one hypothesized relationship was fully supported by my analyses (Hypothesis 4; see also Table 6 above); the rest were largely unsupported or countered 
by alternative patterns. Given these results, three, interrelated observations can be made. First, it appears that primes about periodic conventions - noting the existential threat they represent to constitutions - have minimal, if any, effect on either Michigan or federal constitutional loyalty. Providing subjects with additional information about what periodic conventions can do did not result in significant differences in a person's constitutional loyalty. Similarly, priming subjects to think about prior conventions (either those rejected or supported) did not induce greater or lower loyalty. This runs squarely contrary to Madison's argument in Federalist 49 that persons knowing that prior conventions were rejected (i.e. the charter was deliberately kept by previous generations) would exhibit greater loyalty towards the constitution.

This null finding, though, is not entirely unexpected. Institutional loyalty (or diffuse support) is meant to be a reliable well-spring of support for an institution. It should not be influenced by short-term assessments. While periodic conventions represent a fundamental threat to constitutional integrity, they are infrequent. Michigan's periodic convention ballot question, moreover, is relatively a short-term threat, too; it occurs once every 16 years and during only one election that cycle. Given the general status quo bias that exists among Americans (albeit to a lesser extent at the state level; see Zink and Dawes 2016), it is not surprising that constitutional loyalty remained unaffected by the treatments. This also helps explain why the treatments did not generate greater Michigan constitutional loyalty (or bleed into federal constitutional loyalty) among the negative and positive prime conditions: subjects' constitutional loyalties are resilient (as is the nature of diffuse support generally) and designed to counteract negative and positive information that may compromise constitutional integrity. Moreover, this result is replicated when measuring subjects' likelihood of voting for a state or 
federal constitutional convention; the conditions did not significantly vary, again pointing to an entrenched opposition to fundamental constitutional change.

And yet, state constitutions have been replaced and amended (i.e. their integrities violated) far more frequently than the federal charter (Dinan 2009). Perhaps the way constitutional change is presented to voters affects (or rather overcomes) their underlying loyalties. Priming voters to think about how past conventions were rejected (approved), for example, may lead to greater (lower) constitutional support. While this is not the case for constitutional loyalty, it is indeed the case for constitutional approval. This leads me to my second observation: priming does matter for a constitution's specific support, at both the state and federal levels. It appears that periodic conventions induce a short-term reassessment of constitutional satisfaction, as evidenced by the significant differences in approval scores between the negative and positive primes. Thus, just providing greater information about how a convention can wholescale replace a constitution is not enough; a prime makes the statement more meaningful.

What is surprising about the priming, though, is how approval decreases for those exposed to a negative prime. This is somewhat counter-intuitive. The logic of a negative prime is that if prior constitutional conventions were rejected by voters, then there is an implicit message that earlier generations have continuously endorsed the present constitution (see Brennan 2017). Subsequently, subjects in this condition should exhibit higher approval scores; they did not. Instead, those informed that prior conventions had been approved, ultimately replacing the constitution, expressed greater approval for the present charter. Meantime, the implicit assumption in the positive prime is that it is okay to do-away with the constitution. Yet, previous 
studies suggest that primes emphasizing risks (see Eckles and Schaffner 2011; Kam and Simas 2012) should engender opposition to the proposed changes, or, in this example, greater constitutional approval.

I propose two explanations for this finding. On the one hand, my subjects are likelier to express lower constitutional approval given their ages. As Stephanopoulos and Versteeg (2016) found, younger persons have lower constitutional approval scores than older persons. Thus, for a college student who is already likely to express disapproval with a constitution, it is not surprising to see that a negative prime (that the constitution continues to survive) may encourage the individual to express dissatisfaction with it. Yet, merely providing subjects with information about the role of a periodic convention (Condition 1) did not evidence any changes in approval. This suggests that something else with the prime is at work and may be a consequence of the college student sample being afforded an opportunity to express dissatisfaction. Additionally, the positive prime may be working as intended; by priming subjects to believe that it is okay to replace the constitution, subjects' risk aversion may have activated, causing them to express greater approval of the current constitution simply because it is the status quo (see Kim and Simas 2012; Samuelson and Zeckhauser 1988).

Periodic conventions, therefore, influence a constitution's specific and diffuse support differently, and impact at both the state and federal levels. Constitutional approval is affected by relatively short-term events, like periodic conventions, that prompt momentary reconsiderations of the charter. However, one's diffuse support remains unaffected. This can be seen in the significant results between the negative and positive primes: while approval scores decreased in the negative prime condition, the same condition did not see a change in one's constitutional 
loyalty or likelihood of supporting a constitutional convention relative the other conditions. In the larger debate about whether specific and diffuse support empirically differ (see, e.g., Caldeira and Gibson 1992; Davidson and Parker 1972; and Gibson and Caldeira 1992; see also the relevant discussion in Chapter 4), these experimental results would suggest they do. I also note that there appears to be a reverse "warmglow" effect present, at least where it concerns constitutional approval. My findings illustrate that the periodic convention treatments aimed at Michigan also transferred into federal constitutional feelings. Subjects in the negative prime expressed both lower Michigan and federal constitutional approval compared to the positive prime subjects. Where Zink and Dawes (2016) found that federal constitutional feelings underscored state constitutional feelings (serving as a convenient default or foundation), I find a similar phenomenon here, albeit reversed: periodic conventions at the state level also influence the subjects' federal constitutional approval.

Finally, a third observation is that periodic conventions influence subjects differently depending on their prior knowledge of the mechanism. Subjects who expressed greater familiarity with Michigan's periodic convention mechanism were unaffected by the treatments. Instead, the significant differences uncovered between the negative and positive primes concerning constitutional approval were driven by those largely ignorant of periodic conventions. Practically, this suggests that efforts to pass (or defeat) a periodic convention proposal likely turn on low-information voters who, in the face of new information, reevaluate their views. But this is limited to constitutional approval, or the constitution's specific support; there is no difference on constitutional loyalty scores, suggesting that constitutional status quo bias is more universally held. 
Collectively, these findings also point to a more general role played by knowledge in constitutional loyalty and approval. If varying prior knowledge on periodic conventions qualified results, then perhaps greater knowledge about the charter itself will also factor. Prior studies on constitutional approval indicate this is the case, finding that educational attainment, general familiarity with politics (e.g. attentive news consumption), and greater familiarity with a charter produce higher approval (see, e.g., Stephanopoulos and Versteeg 2016). But does this relationship hold for constitutional loyalty? Moreover, prior studies rely on self-described levels of constitutional knowledge rather than an actual measure. It could be that this relationship is non-existent. Since my sample controls for educational attainment automatically, I can measure and test the effect of actual constitutional knowledge as both a predictor of constitutional loyalty and its role in the experiment. I explore these propositions in the next chapter. 


\section{CHAPTER 6 - THE IMPACT OF CONSTITUTIONAL KNOWLEDGE}

I now turn to my final empirical results: What role does constitutional knowledge play in predicting constitutional loyalty? Do more constitutionally knowledgeable persons react differently to periodic conventions than those less informed? In answering these questions, I expand upon the analyses done thus far and revise conclusions tentatively drawn. First, I present a theoretical overview of the interplay between civic knowledge (including news consumption and constitutional knowledge) and constitutional support, drawing upon prior works. Specifically, I note how prior works fail to capture actual constitutional knowledge; instead, the standard operationalization is to ask respondents to self-describe their (alleged) familiarity with a charter. This raises validity concerns that I attempt to remedy with a new measurement scheme for both federal and Michigan constitutional knowledge. After discussing these measures, I re-evaluate the results presented in Chapters 4 and 5, extending my analyses to include controls for two facets of civic knowledge: attentiveness to national/local news and level of constitutional knowledge. Finally, I conclude by discussing implications and limitations.

\section{Civic Knowledge and Its Influence on Constitutional Support}

\section{Theory}

The institutional support literature suggests that knowledge about the institution impacts one's support towards it. However, the relationship varies depending on the institution. Work by Gibson and colleagues find that persons who know more about the U.S. Supreme Court also express greater loyalty towards it (see Gibson and Caldeira 2009a, 2009b; Gibson, Caldeira, and Baird 1998; and Gibson and Nelson 2015), a phenomenon known as "positivity bias." Conversely, Hibbing and Theiss-Morse $(1995,2002)$ found that those who knew the most about Congress 
were also the same persons who liked it the least. Others (Jones and McDermott 2002; Mondak et al., 2007) have found a similar relationship concerning Congress's specific support, or institutional approval, although Mondak et al. (2007) note this is likely due to differences in how high knowledge and low knowledge persons evaluate Congress, not because of knowledge's direct effect. ${ }^{1}$ Thus, institutional knowledge appears to impact an institution's specific and diffuse support.

Prior works on constitutional support indirectly control for levels of constitutional knowledge. Blake and Levinson (2016) and Stephanopoulos and Versteeg (2016) found that better educated subjects (e.g. high school graduates versus bachelor's degree holders) tended to express greater support for the U.S. Constitution and their state charter (or, in the former study's case, less supportive of holding a federal constitutional convention). However, this is a proxy measure; an implicit assumption that greater education corresponds with greater knowledge about governmental institutions generally. In their comprehensive accounting of constitutional approval, Stephanopoulos and Versteeg (2016) ask respondents to assess their own familiarity with their state constitution's content as well as the federal charter's (on a five-point scale, with five indicating greater familiarity). This self-described measure is a better direct approximation of constitutional knowledge. Beyond constitutional knowledge, Stephanopoulos and Versteeg (2016) also test the impact of more general public affairs knowledge on constitutional approval. They ask two questions on news consumption habits, or how often the subject follows national and local news. Collectively, these measures form a common dimension of civic knowledge.

\footnotetext{
${ }^{1}$ Mondak et al. (2007, 42-47) show that high-knowledge persons evaluate Congress's job performance based on whether the institution conforms with their preferred policies (i.e. policy congruence), while low-knowledge individuals make assessments based on their views of the sitting president.
} 
Using these measures, Stephanopoulos and Versteeg (2016) find that civic knowledge matters in predicting constitutional approval. In general, those expressing greater knowledge of the federal constitution rated the document significantly higher than low-knowledge persons. The same relationship held for attentiveness to national news. Similar relationships were observed for state constitutional approval. In the study's unified regression models, moreover, both news consumption and charter knowledge remained highly significant and substantively impactful alongside the significant roles of institutional attitudes, race, and age. These findings, though, address only constitutional approval, or specific support; no study has addressed the impact of charter knowledge (or news consumption) on constitutional loyalty, or diffuse support. $^{2}$

Importantly, two caveats must be acknowledged with these findings on constitutional approval, both noted by Stephanopoulos and Versteeg (2016). First, the measures are selfreported; respondents were not assessed on actual constitutional knowledge or news consumption habits. Thus, the findings offer tentative evidence of a relationship between constitutional approval and civic knowledge. Moreover, participants with greater charter knowledge fared no better on Stephanopoulos and Versteeg's (2016) survey reading comprehension quizzes than low-knowledge respondents, further evidence that self-reported knowledge may differ from genuine familiarity. ${ }^{3}$ Second, it is possible that respondents felt they were more familiar with their constitutions because they approved (or supported) them. Thus,

\footnotetext{
${ }^{2}$ As a reminder, constitutional approval refers to one's current satisfaction with or feelings about the charter. Constitutional loyalty, meantime, reflects the subject's underlying, long-term commitment to the charter and its institutional integrity.

${ }^{3}$ These surveys were designed to assess whether the respondent had actually read and understood the survey's treatment. Coincidentally, they also provided a further test of whether low- and high-knowledge persons differed.
} 
both "support and professed familiarity stem from the same general positive attitude toward the documents" (Stephanopoulos and Versteeg 2016, 145). Little research has addressed this psychological aspect of knowledge, with the literature on political knowledge focusing almost exclusively on actual rather than professed knowledge (for a review, see Delli Carpini and Keeter 1996). Combined, these caveats suggest that a different conceptualization and measurement scheme are needed to better evaluate the impact of civic knowledge generally, and charter knowledge specifically, on constitutional approval and loyalty.

\section{Measuring Actual Constitutional Knowledge}

Measuring actual levels of constitutional knowledge, though, is difficult given that no formal battery or measure exists to do so beyond self-purported questions. This is true at both the federal and, especially, state levels. Yet, actual demonstrations of constitutional knowledge are ostensibly more valid than merely asking if one knows a great deal about a charter. Indeed, social desirability bias (Finkel, Guterbock, and Borg 1991) likely overestimates the degree of familiarity given the importance of the U.S. Constitution as the nation's civic creed; to express little knowledge of it can be construed as unpatriotic (see Blake and Levinson 2016). Instead, asking questions about the constitution's content is a better way to ascertain whether the subject has actual familiarity with the charter's content or not.

To measure actual constitutional knowledge, I look towards the political knowledge and civic education literatures for conceptualization and measurement strategies. While there is disagreement over how best to measure political knowledge, there appears to be "consensus on the central importance of the individual's ability to understand and retain concrete political facts" (Nie, Junn, and Stehlik-Barry 1996, 22). Today, Delli Carpini and Keeter's (1996, 304-306) five- 
question battery is considered the gold standard in political science. The five questions, based off items asked on the American National Election Studies survey, range in difficulty from easy to complex, while measuring different kinds of political knowledge (e.g. knowledge of democratic norms, political officials, and current facts; see also Nie, Junn, and Stehlik-Barry 1996, 22-25 for further elaboration). Questions on the federal constitution appearing in professional and scholastic surveys often follow this conceptualization: factual knowledge on constitutional norms, principles, and/or practices, with many being open-ended. Green and colleagues (2011) provide a convenient example: To operationalize knowledge of constitutional principles, they focus on students' understanding of civil and political rights accorded by the Bill of Rights and other amendments. This approach - operationalizing constitutional knowledge in terms of rights - may be appropriate given the dominance of the Bill of Rights in civics instruction (see Glendon 1993). Nonetheless, the structural principles (e.g. institutional processes and separation of powers) should not be ignored.

I employ two different approaches to capture federal and state constitutional knowledge. For federal constitutional knowledge, I ask six questions designed to assess subjects' factual understanding in three areas: structural factors; principles and norms; and general facts. In line with Gibson and Caldeira's (2009b) critique of political knowledge surveys, I eschew open-ended, recall questions in favor of closed-ended inquiries stressing recognition. Utilized this way, subjects are far likelier to answer questions correctly, demonstrating less ignorance than recall questions would suggest (but see Luskin and Bullock 2011). ${ }^{4}$ My questions are adapted or

\footnotetext{
${ }^{4}$ I also aim for a "humbler" conceptualization of ignorance (Gibson and Caldeira 2009b). Like Lupia (2006), Gibson and Caldeira (2009b) argue that the public's purported ignorance on civic and political issues is significantly
} 
inspired from various surveys, including the Annenberg Public Policy Center's annual Constitution

Day Civics Survey; the National Assessment of Educational Progress (NAEP) civics exam; the American National Election Studies; and prior works on political and civic knowledge (e.g. Delli Carpini and Keeter 1996; Gainous and Martens 2012; Green et al., 2011; and Niemi and Junn 1998). Green et al. (2011) and Niemi and Junn (1998), in particular, provide convenient question verbiage and usefulness in establishing which questions are better for discriminatory power. ${ }^{5}$ Questions selected reflect their high frequency appearing on multiple political knowledge surveys. To discourage guessing and artificially inflating knowledge scores, each question included a "Don't Know" response (DK), with the battery preceded by Delli Caprini and Keeter's (1996) recommended disclaimer informing subjects it is okay to be unsure (see note for Table 7, below). ${ }^{6}$

overstated since political knowledge surveys are biased towards facts that scholars think citizens ought to know, rather than a practical understanding.

${ }^{5}$ Green and colleagues used high school students for their study, signifying that their questions may be especially prudent to use on college students with varying civics backgrounds.

${ }^{6}$ There is debate in the literature about whether DK responses are overestimating, underestimating, or otherwise producing differences in political knowledge among sub-populations, including the genders. For illustrious accounts, compare Mondak and Anderson (2004) and Luskin and Bullock (2011). I opt to encourage DK responses since I conceptualize one as either knowing constitutional content or not. Therefore, if one incorrectly answers a question or expresses uncertainty, the net result is the same: the subject is unfamiliar. 
Table 7.

Federal Constitutional Knowledge Questions

\begin{tabular}{lcccc}
\hline & \multicolumn{3}{c}{ Percentage } & N \\
\cline { 2 - 4 } \multicolumn{1}{c}{ Item } & Correct & Incorrect & Don't Know & 248 \\
\hline U.S. Senator Term of Office & 46 & 44 & 10 & 250 \\
Congress 2/3 Override Veto & 79 & 11 & 10 & 250 \\
Bill of Rights Name & 93 & 6 & 1 & 248 \\
Judicial Review \& SCOTUS & 67 & 25 & 9 & 247 \\
Freedom of Religion & 83 & 11 & 7 & 248 \\
President Nominates Judges & 71 & 13 & 17 & \\
\hline
\end{tabular}

Note: Data taken from post-test battery. Percentages are calculated using collapsed variables (i.e. all incorrect answers were pooled together). Due to rounding, percentages may not sum to 100.

Question wording is as follows (correct response provided in parentheses):

1. U.S. Senator Term of Office: "How long is the term of a U.S. Senator?" (6 years)

2. Congress 2/3 Override Veto: "If Congress passes a law and the President vetoes it, Congress can enact it anyway with a two-thirds majority vote of both houses." (True)

3. Bill of Rights Name: "What are the first ten amendments to the U.S. Constitution called?" (Bill of Rights)

4. Judicial Review \& SCOTUS: "Whose responsibility is it to determine if a law is constitutional or not?" (Supreme Court)

5. Freedom of Religion: "Among the rights guaranteed by the First Amendment is the right to:" (Freedom of Religion)

6. President Nominates Judges: "It is the President's responsibility to nominate federal judges." (True)

All questions included the following disclaimer adapted from Delli Carpini and Keeter (1996, 305): "We are now going to ask you a few questions concerning your knowledge of the FEDERAL Constitution. Many people don't know the answers to these questions, so if there are some you don't know, select 'Don't Know' and move on."

Question wording and descriptive statistics appear in Table 7. In general, there is a high degree of knowledge regarding the federal constitution. Large majorities answered correctly for all questions save one; only 46 percent correctly identified a U.S. Senator's term of office as six years. These results are promising, especially given the college student sample. Since students were exposed to the U.S. Constitution as part of their class's curriculum, it appears many retained a functional understanding of several constitutional features, weeks after when the U.S. Constitution was formally discussed. Thus, this sample can be used to critically test the theory that those with greater knowledge about constitutions have higher levels of constitutional approval and loyalty. To summarize these findings, I create a simple additive index of the number 
of correct answers (range 0-6). Most participants (52 percent) correctly answered at least five questions, with less than ten percent answering two or fewer questions correctly. I use this additive scale in my subsequent analyses.

As an initial test on whether federal constitutional knowledge influences federal constitutional approval and loyalty, I divide subjects into low and high knowledge using the federal constitutional knowledge scale's median score. ${ }^{7}$ I expect to see that low knowledge subjects will approve of the federal constitution at a lower rate than high knowledge subjects, while low knowledge subjects will have lower constitutional loyalty than high knowledge subjects. Simple difference of means tests between low and high knowledge subjects on both constitutional approval and loyalty produce significant results in expected directions. Low knowledge subjects have a mean approval rating of 3.2 compared to 3.6 for high knowledge subjects $(p=0.000)$. Meantime, high knowledge subjects express greater average constitutional loyalty $(\bar{y}=3.4)$ compared to those with lower levels of knowledge $(\bar{y}=2.9)(p=0.000)$. On its face, then, it appears that (actual) constitutional knowledge does influence constitutional approval and loyalty, confirming expectations associated with positivity bias and prior works.

Turning to assessing knowledge of the Michigan Constitution, an altogether different approach is necessary. In general, people's knowledge of their state governments is less than

\footnotetext{
${ }^{7}$ It is difficult to determine an objective "low" and "high" regarding constitutional knowledge, given the difficulties inherent in measuring it - especially Michigan constitutional knowledge. One way could be to set a threshold for a "passing" score (e.g. 80 percent or more correct answers) similar to licensing examinations. I use the median score for two reasons: (1) constitutional knowledge (for both federal and Michigan) is heavily skewed and (2) this provides some objectivity relative the sample itself. Given the goal of trying to determine whether those with greater constitutional familiarity react differently than those who do not, it makes sense to use the underlying sample's properties to determine "low" and "high." Moreover, prior works examining diffuse support (e.g. LaRowe and Hoekstra 2014) use the median as a basis for dividing their samples into high and low categories. I leave it for future research to determine a universal baseline for "high" and "low" constitutional knowledge.
} 
their familiarity with the federal government (Delli Carpini and Keeter 1996; Niemi and Junn 1998; Lyons, Jaeger, and Wolak 2013). This holds true for state constitutional knowledge: A survey by the National Center for State Courts found that 54 percent of respondents incorrectly responded that their state had no constitution (see Lyons, Jaeger, and Wolak 2013, nt. 1). No wonder Roeder $(1994,34)$ has argued that state politics represents an "invisible layer of government" for most citizens. Measurement of state constitutional knowledge, therefore, is difficult; if most individuals are unaware that their state even has a constitution, how can one adequately measure true constitutional knowledge with enough validity?

I propose a recognition measure like the one used by Stephanopoulos and Versteeg $(2016,134)$. These authors asked respondents to identify whether they would like to see a substantive policy provision included in their state's constitution. Provisions presented were based on similar ones present in state charters but did not appear in the federal constitution. I propose a similar exercise to measure the subject's knowledge of the Michigan state constitution: present a substantive or structural provision and inquire whether it is part of the Michigan Constitution of 1963 or not. ${ }^{8}$ Subjects able to correctly identify constituent provisions of the Michigan Constitution are likelier more informed about the document than others.

\footnotetext{
${ }^{8}$ Zackin (2013) also notes how state constitutions are the repositories for positive, substantive rights in American constitutional jurisprudence, suggesting that citizens may be more familiar with their state constitutions when asked about substantive policy provisions. Substantive policy statements or prescriptions, however, are but one feature of state constitutions, and structural features should not be ignored.
} 
Table 8.

Michigan Constitutional Knowledge Questions

\begin{tabular}{lcccc}
\hline & \multicolumn{3}{c}{ Percentage } & N \\
\cline { 2 - 4 } \multicolumn{1}{c}{ Item } & Correct & Incorrect & Don't Know & 247 \\
\hline Judge Term of Office & 20 & 28 & 52 & 247 \\
Legislative Term Limits & 34 & 15 & 51 & 248 \\
Death Penalty Prohibition & 56 & 19 & 25 & 247 \\
Education Mandate & 68 & 9 & 23 & 248 \\
Governor Term of Office & 32 & 25 & 43 & \\
\hline
\end{tabular}

Note: Data taken from post-test battery. Due to rounding, percentages may not sum to 100 .

Question wording is as follows (correct response provided in parentheses):

1. Judge Term of Office: "State judges and supreme court justices serve for life." (Not in the MI Constitution)

2. Legislative Term Limits: "Members of the state legislature serve only a limited number of terms in office before mandatory retirement." (In the MI Constitution)

3. Death Penalty Prohibition: "The death penalty is prohibited." (In the MI Constitution)

4. Education Mandate: "State government is required to provide free, public primary and secondary (5-12) educational institutions for all residents." (In the MI Constitution)

5. Governor Term of Office: "The state governor serves for a two-year term." (Not in the MI Constitution)

All questions included the following disclaimer from Delli Carpini and Keeter $(1996,305)$ and subsequently modified here: "Now we are going to ask you some questions about the MICHIGAN STATE constitution. For each provision, please indicate whether you think this provision is a part of the MICHIGAN STATE constitution or not. If you are unsure, select 'Don't Know' and move on."

These questions and descriptive statistics are presented in Table 8. As one can quickly identify, these data paint a mixed picture regarding Michigan constitutional knowledge. A substantial amount of uncertainty is recorded for each question as evidenced by the Don't Know (DK) category. DK responses represent a majority for questions on whether judges serve life terms (52.2 percent; they do not) and whether Michigan state legislators are term limited (51 percent; yes, they are), while 43.5 percent of subjects are unsure if the state governor serves a two-year term (the Michigan governor serves a four-year term). Only 19.8, 34, and 31.8 percent, respectively, of subjects correctly answered these questions. The general ignorance of judicial, legislative, and executive terms can be explained by a few factors: First, subjects may be confusing federal and state judges, although a more generous interpretation is that subjects did recognize that there may be a difference between the two kinds given the high DK response. 
However, given that incorrect responses (27.9 percent) outnumbered correct responses (19.8 percent), it appears many subjects may simply have transferred federal knowledge onto a corresponding state institution. Second, other Michigan political knowledge surveys have found a high degree of ignorance surrounding Michigan's legislative term limits. Armaly and Black (2016), for example, found that only 45 percent of Michiganders knew that state legislators were subject to term limits. Third, there appears to be general confusion regarding the gubernatorial term; while roughly 32 percent correctly noted that the Michigan Constitution did not create a two-year gubernatorial tenure, about a fourth did, with the rest expressing uncertainty. ${ }^{9}$

Conversely, majorities did correctly identify that the Michigan Constitution prohibits the death penalty (55.6 percent) and requires the state to provide primary and secondary education (68.4 percent). Of the policy provisions presented, these two are likely more commonly highlighted (in the media and elsewhere) than the others. Michigan's death penalty prohibition was the first in the nation, a fact usually shared during death penalty discussions. Moreover, many subjects likely encountered firsthand the state's mandate for primary and secondary education, thus knowing (or at least logically reasoning) that the requirement extends from a constitutional mandate (see also Zackin 2013).

\footnotetext{
${ }^{9}$ There may be an additional issue with how these questions were worded. Both statements on judicial and gubernatorial terms are not only absent in the Michigan constitution but they also are factually incorrect (i.e. Michigan judges serve fixed-terms and the governor has a four-year tenure). Thus, both statements are measuring more than just whether the provision appears in the Michigan charter. This may explain some of the DK responses. I do not drop these questions, though, in constructing the knowledge index because: (1) the already limited amount of questions asked; (2) the importance of including structural features of the constitution; and (3) it is likely that subjects, especially those unfamiliar with the state constitution, were making "double-barred" assessments in terms of identifying whether the provision was true of Michigan generally and if it was included in the constitution or not.
} 
To summarize these findings, I again create a simple additive index of Michigan constitutional knowledge. This scale ranges from zero to five correct answers. Most subjects scored an average of two correct answers out of five, a failing score. The bulk of respondents (approximately 65 percent) identified two or fewer provisions correctly. Perfect scores were rare (1.2 percent), while a sizable amount (13 percent) identified zero provisions correctly. Collectively, these findings suggest subjects are far less familiar with their state charter than the federal. I use this additive scale in the below analyses.

However, I provide an initial test here on whether Michigan constitutional approval and loyalty differ based on level of Michigan constitutional knowledge. Like above, I divide subjects into low and high knowledge by using the Michigan constitutional knowledge scale's median score. ${ }^{10}$ Again, l expect that low knowledge subjects will disapprove of the Michigan constitution more than high knowledge subjects, while also expressing lower constitutional loyalty. Difference of means tests produce trivial and insignificant differences. For constitutional approval, low knowledge subjects have a lower mean (3.1) than those with greater knowledge (3.2), but these means are not significantly different from each other $(p=0.699)$. Likewise, there is no difference in Michigan constitutional loyalty: low and high knowledge subjects express the same average loyalty for the Michigan charter $(3.1 ; p=0.271)$. These findings differ from the federal pattern noted above and run contrary to the expectations in the literature. However, this is just a descriptive inquiry; regression analyses, below, help to better estimate the causal effect.

One final observation: It should be noted that these batteries (both federal and state) are likely to produce rough approximations of citizen constitutional knowledge. For federal

\footnotetext{
${ }^{10}$ See footnote 7 (above).
} 
constitutional knowledge, the emphasis on "rights rhetoric" (Glendon 1991) in most constitutional curricula suggests that subjects will perform better on questions geared towards Bill of Rights knowledge rather than the Constitution's structural and institutional features (e.g. office terms, separation of powers, and the like). My sample, however, is composed of college students in American government courses, explaining the high accuracy rate; compared to the general American population, my scale measure may be overestimating actual federal constitutional knowledge. Concerning Michigan constitutional knowledge, citizens tend to perform poorly on measures assessing state politics and government generally (see, e.g., Patterson, Ripley, and Quinlan 1992 and Lyons, Jaeger, and Wolak 2013), and are also unable to transfer conceptual knowledge of national institutions to corresponding state constitutions (Niemi and Junn 1998). ${ }^{11}$ As evidenced, it is likely that general knowledge of one's state charter is likewise missing from most citizens' minds. While I believe these batteries represent valid first attempts at establishing actual, rather than self-professed, constitutional knowledge, they are not perfect; in Chapter 7, I explore the limitations associated with these measures further, and task future research with improving the scheme developed here.

The Other Factor: Measuring News Consumption

Constitutional knowledge, though, is but one factor within the civic knowledge dimension; the other concerns national and local news consumption. Individuals more attentive to national or local news may be more informed about the federal and their state charters from media exposure to the documents. I test for this possibility by using Stephanopoulos and

\footnotetext{
${ }^{11}$ For instance, National Assessment of Educational Progress (NAEP) civics examinees were able to correctly identify Congress as the national legislative branch but could not do so regarding their state's equivalent legislative assembly.
} 
Versteeg's (2016) approach; subjects are asked (on the pre-test) how closely they follow national and local news, with responses ranging from "never" to "almost daily." ${ }^{12}$ Most subjects do not closely follow the news; 51 percent indicated they followed national news only 3 or 4 times a month or less, while about 55 percent said the same for local news. These findings are somewhat surprising, given that college-educated persons are usually more attentive to national and local news (Delli Carpini and Keeter 1996), but may simply be an artifact of my college student sample. ${ }^{13} \mathrm{I}$ use both scales in my analyses below.

I provide here, though, an initial examination of whether constitutional approval and loyalty differ by news consumption habits alone. Using each measure's median score (each range from 0-5), I divide subjects into those that closely follow national/local news and those that do not. Subjects more attentive to national/local news should express greater constitutional approval and loyalty than those less attentive. Results, however, run contrary to expectations (running difference in means tests): For federal constitutional approval, there is no difference in average approval $(\bar{y}=3.4 ; p=0.671)$ between those who closely follow the news and those who do not. Similar findings are observed for federal constitutional loyalty $(\bar{y}=3.2 ; p=0.643)$. This pattern is replicated at the state level using local news attentiveness: Michigan constitutional approval does not differ among low and high local news watchers $(\bar{y}=3.2 ; p=0.743)$; the same goes for Michigan constitutional loyalty $(\bar{y}=3.1 ; p=0.472)$. On its own, then, news consumption habits do not yield apparent differences in constitutional approval or loyalty, but they may in

\footnotetext{
${ }^{12}$ The full ordinal response set is: never; hardly ever; a few times a year; 3 or 4 times a month; 2 or 3 times a week; and almost daily.

${ }^{13}$ Given that most young persons get their news through social media exposure (see Bialik and Matsa 2017), subjects may have misinterpreted the question to mean overt exposure (i.e. reading a physical newspaper, watching a news program, etc.). However, the questions asked how "closely do you follow" national/local news, meaning subjects may have answered based on how well they keep tabs on issues versus simple exposure to them.
} 
conjunction with other factors. I further examine the causal knowledge of the civic knowledge dimension (both news consumption and constitutional knowledge) in the next section.

\section{Does Civic Knowledge Predict Constitutional Loyalty?}

In Chapter 4, I tested three dimensions, or predictors, of constitutional loyalty: demography, political affiliations, and institutional attitudes. I briefly review those findings here. First, predictors of constitutional loyalty are similar generators of constitutional approval, namely institutional attitudes; how one thinks about the constitution's created institutions (e.g. the President, Congress, or Supreme Court) influences one's loyalty towards the charter. This is not true, however, at the state level, where attitudes toward Michigan-level political institutions matter little in generating Michigan constitutional loyalty. Second, Michigan constitutional loyalty is influenced by a federal "warmglow" effect (Zink and Dawes 2016), where level of federal constitutional loyalty influences Michigan constitutional loyalty. It appears that subjects are transferring analogous feelings at the federal level to a lesser known entity (but still called a "constitution") at the state level. Third, and finally, it appears that an individual's degree of constitutional approval influences her level of constitutional loyalty; thus, a constitution's specific support causally influences its diffuse support.

A key dimension, though, remains unaddressed: What about civic knowledge? Do persons with greater constitutional familiarity and news attentiveness exhibit similar patterns? In their comprehensive study on constitutional approval, Stephanopoulos and Versteeg $(2016,113)$ found that self-reported familiarity with the federal charter and national news consumption frequency were significantly and positively associated with constitutional approval. The same occurred with state-level variables; greater knowledge of a state charter and being more 
attentive to local news caused state constitutional approval scores to increase. Civic knowledge and approval "appear to go hand in hand no matter which constitution is at issue" (Stephanopoulos and Versteeg 2016, 158).

\section{Analysis}

To analyze whether civic knowledge influences constitutional loyalty, I continue my estimation procedures found in Chapter 4. I add two additional factors onto the current base model incorporating demographic attributes, political affiliations, and institutional attitudes (i.e. Chapter 4's model 3): level of (actual) constitutional knowledge and national/local news consumption. I replicate these procedures twice: once for federal constitutional loyalty (see Table 9) and again for Michigan constitutional loyalty (see Table 10). In each model, only appropriate-level factors are incorporated (i.e. the federal model controls for federal constitutional knowledge and national news attentiveness). The dependent variable for all models is the index of constitutional loyalty used in prior chapters, or the mean response for a subject across all four federal (or state) diffuse support statements. Values range from one to five, with higher scores indicating greater constitutional loyalty. ${ }^{14}$

\section{Federal Results}

I start with federal constitutional loyalty. For ease of comparison, Table 9 includes model 3 from Chapter 4 alongside the new models. In this former model, institutional attitudes, particularly on President Trump and the United States Supreme Court (SCOTUS), appear to be

\footnotetext{
${ }^{14}$ As noted in former chapters, I replicate my regression analyses using alternative dependent variables beyond this mean score index. These include a factor score, proportion support, and a simple additive index of number of supportive replies. No significant or substantial differences were found in these alternate estimates for both federal and state modeling relative the findings reported herein.
} 
driving federal constitutional loyalty. Model 4 continues controlling for these institutional attitudes, alongside demographic attributes and political affiliations, while adding new variables on federal constitutional knowledge and national news attentiveness. As the results show, constitutional loyalty significantly differs among those with varying levels of constitutional familiarity $(p=0.006)$. For each additional correct answer on federal constitutional knowledge, a subject's mean constitutional loyalty increases by approximately 0.4-points while controlling for other factors. Attentiveness to national news, however, was highly insignificant ( $p=0.207)$. Concerning the other dimensions, demography and political affiliations remained insignificant, including race and age. Institutional attitudes, however, remained significant; subjects approving of President Trump's and the SCOTUS's job performance expressed higher mean loyalty than those who did not. ${ }^{15}$

\footnotetext{
${ }^{15}$ As discussed in Chapter 4, I use OLS regression rather than ordered probit techniques despite the ordinal nature of the dependent variable because: (1) OLS coefficients are easier to interpret and (2) prior works on constitutional support use OLS regression coefficients despite the technical violations.
} 
Table 9.

Predictors of Federal Constitutional Loyalty

\begin{tabular}{|c|c|c|c|}
\hline & Model 3 & Model 4 & Model 5 \\
\hline \multirow[t]{2}{*}{ Female } & 0.092 & 0.056 & 0.1 \\
\hline & $(0.126)$ & $(0.127)$ & $(0.12)$ \\
\hline \multirow[t]{2}{*}{ Age } & 0.022 & 0.019 & 0.007 \\
\hline & (0.017) & (0.017) & $(0.016)$ \\
\hline \multirow[t]{2}{*}{ African American } & -0.148 & -0.15 & -0.077 \\
\hline & (0.166) & (0.163) & (0.155) \\
\hline \multirow[t]{2}{*}{ Other Minority } & -0.18 & -0.129 & -0.031 \\
\hline & $(0.142)$ & $(0.14)$ & $(0.134)$ \\
\hline \multirow[t]{2}{*}{ SES } & $-0.194^{*}$ & $-0.157^{\wedge}$ & $-0.165^{\wedge}$ \\
\hline & $(0.089)$ & (0.089) & $(0.085)$ \\
\hline \multirow[t]{2}{*}{ Partisanship } & 0.056 & 0.031 & 0.059 \\
\hline & (0.054) & $(0.053)$ & (0.051) \\
\hline \multirow[t]{2}{*}{ Ideology } & -0.053 & -0.029 & -0.058 \\
\hline & (0.07) & (0.069) & (0.065) \\
\hline \multirow[t]{2}{*}{ Trump Approval } & $0.19 *$ & $0.17^{*}$ & $0.14^{\wedge}$ \\
\hline & $(0.086)$ & (0.085) & $(0.08)$ \\
\hline \multirow[t]{2}{*}{ Congress Approval } & -0.141 & -0.086 & -0.121 \\
\hline & $(0.086)$ & $(0.087)$ & $(0.083)$ \\
\hline \multirow[t]{2}{*}{ SCOTUS Approval } & $0.448 * * *$ & $0.366 * * *$ & $0.257^{* *}$ \\
\hline & (0.077) & $(0.081)$ & $(0.08)$ \\
\hline \multirow[t]{2}{*}{ Const. Knowledge } & & $0.137^{* *}$ & 0.067 \\
\hline & & $(0.049)$ & $(0.049)$ \\
\hline News Attentiveness & & $\begin{array}{c}-0.06 \\
(0.047)\end{array}$ & $\begin{array}{c}-0.05 \\
(0.045)\end{array}$ \\
\hline Const. Approval & & & $\begin{array}{c}0.355^{* * *} \\
(0.073)\end{array}$ \\
\hline \multirow[t]{2}{*}{ Constant } & $2.35^{* * *}$ & $2.02 * * *$ & $1.54^{* *}$ \\
\hline & $(0.45)$ & $(0.493)$ & $(0.474)$ \\
\hline $\mathrm{N}$ & 151 & 149 & 145 \\
\hline Adjusted $\mathrm{R}^{2}$ & 0.296 & 0.313 & 0.409 \\
\hline
\end{tabular}

Note: Data taken from pre-test measures, excepting constitutional knowledge that was derived from the post-test. Standard errors in parentheses. ${ }^{* * *} p<0.001,{ }^{* *} p<0.01,{ }^{*} p<0.05, \wedge p<0.10$

These findings are interesting for several reasons. First, institutional attitudes continue to positively, and strongly, affect one's average constitutional loyalty. This is especially true of the SCOTUS's specific support; a one-unit increase in SCOTUS's job approval results in a 0.366-point increase in the subject's mean constitutional loyalty. Trump's job performance provides a more modest 0.17-point increase, but still a significant bump. The results again reinforce the conclusion 
that constitutions are being evaluated on the performance of its created governmental institutions, a logical fact given the role of constitutions in creating governments and establishing the rulebook. Second, constitutional knowledge is positively related to constitutional loyalty, providing evidence of Gibson and Caldeira's (2009a) positivity bias; to know the constitution is to love it. While the magnitude is substantially smaller than what Stephanopoulos and Versteeg (2016) observed (they found that a one-unit increase in self-described constitutional knowledge corresponded with a one-point increase in approval), one would expect this is due to the selfdescribed nature of their variable; my measure is a better estimate of actual knowledge of constitutional topics. Therefore, the relationship between constitutional familiarity and support is indeed positive but the magnitude is likely more modest than previously found.

Another interesting observation is the null finding for national news attentiveness. Stephanopoulos and Versteeg (2016) found that federal constitutional approval increased for respondents more attentive to national news. My analysis casts doubt on this relationship, at least when it concerns constitutional loyalty and college students. It could be that attentiveness to national news influences specific support for the constitution but not its underlying diffuse support given that news reports on constitution-related issues are momentary and contextual, influencing specific support more so than diffuse support. I test this proposition by running a regression on federal constitutional approval controlling for national news attentiveness (results not reported here). I find that while federal constitutional knowledge is significantly and positively related with constitutional approval, attentiveness to national news fails to reach significance. While these findings do suggest that national news consumption matters less for constitutional loyalty, it may also be a construct of my sample; college students generally have 
lower news watching habits (see The Media Insight Project 2015a, 2015b) explaining the null finding. ${ }^{16}$

As discussed in Chapter 4, constitutional approval may be influencing, indeed generating, constitutional loyalty. While the literature debates whether this should theoretically be possible (i.e. specific and diffuse support should be conceptually different), empirically a relationship exists between the two (see Gibson and Caldeira 1992 for a review). Bivariate correlations indicate a moderate relationship between federal constitutional approval and loyalty ( $r=0.52)$. Prior regression modeling in Chapter 4 also found that constitutional approval is a significant and positive predictor of federal constitutional loyalty; a one-unit increase in constitutional approval corresponds with an increase of 0.38-points in mean loyalty. To control for this possible confounder, therefore, I estimate another model (model 5) that adds the subject's federal constitutional approval score alongside all four dimensions: demography, political affiliations, institutional attitudes, and civic knowledge. Results are presented in Table 9, above.

Several observations can be made. First, the explained variation in model 5 is substantially larger than the prior models. Constitutional approval and the other dimensions collectively explain approximately 41 percent of the variation in federal mean constitutional loyalty, a full ten percent more than model 3 . Second, constitutional approval provides a substantial boost in one's constitutional loyalty; a one-point increase in constitutional approval increases a subject's average constitutional loyalty by 0.355 -points, all other factors constant. Third, previously significant factors lose their significance in this new model. SCOTUS approval remains highly significant $(p=0.002)$, but its effect is somewhat diminished, while President Trump's approval no

\footnotetext{
${ }^{16}$ See also footnote 12 (above).
} 
longer reaches traditional levels of significance $(p=0.085)$. Socioeconomic status, however, is insignificant by traditional levels $(p=0.054)$ and inversely related to constitutional loyalty; a oneunit increase in socioeconomic class (e.g. middle to upper-class) decreases mean loyalty by roughly 0.165 -points. Finally, demography and political affiliations remain insignificant, including the race variables.

What to make of these findings? On the one hand, the empirical connection between constitutional approval and loyalty is unmistakable at the federal level; subjects' approval rating of the U.S. Constitution significantly influences their expressed loyalty towards it, but this finding may be attributable to the college student sample. Since college students are predisposed to have lower diffuse support levels across institutions, it is likely that constitutions fare no better. Thus, the connection between specific and diffuse support is more meaningful for this subpopulation; how a college student approves of the constitution influences constitutional loyalty more so than other groups. This may also help explain the mixed findings discussed in Chapter 4 on the individual constitutional loyalty questions: many subjects expressed support for the federal charter's continued operation, but it was tempered by the belief that the document was biased towards certain groups. This can also be seen in how the SCOTUS approval remains significant and influential; since the SCOTUS often engages in constitutional-level politics, agreement with the SCOTUS's decisions (i.e. evaluating its job performance) likely serves as a proxy for constitutional support (see Chapter 4 for further elaboration). I further explore these findings, and their implications, below. 


\section{Michigan Results}

A different relationship emerges for Michigan constitutional loyalty. In estimating these models, I use Michigan-level data for institutional attitudes, constitutional knowledge, and (local) news attentiveness. These models are also run using robust standard errors to correct for heteroskedasticity present in the normal OLS regressions. ${ }^{17}$ Results are presented in Table 10. Again, I use Chapter 4's state-level model 3 as a basis, with model 4 adding the new civic knowledge factors. As illustrated, no variable achieves significance in model 4, including the civic knowledge factors. Only age is significant at the 0.10 level $(p=0.079)$, with trivial effect: an additional year of age increases a subject's Michigan mean constitutional loyalty by 0.023-points controlling for all other factors. These findings mirror those observed in Chapter 4's modeling, where similar relationships at the federal level were not replicated at the state-level.

\footnotetext{
${ }^{17}$ See Chapter 4, footnote 15 for explanation regarding Michigan models' residuals analyses.
} 
Table 10.

Predictors of Michigan Constitutional Loyalty

\begin{tabular}{|c|c|c|c|}
\hline & Model 4 & Model 5 & Model 6 \\
\hline \multirow[t]{2}{*}{ Female } & 0.155 & 0.13 & 0.083 \\
\hline & $(0.124)$ & $(0.133)$ & (0.119) \\
\hline \multirow[t]{2}{*}{ Age } & $0.023^{\wedge}$ & $0.042 * *$ & 0.015 \\
\hline & $(0.013)$ & $(0.013)$ & $(0.012)$ \\
\hline \multirow[t]{2}{*}{ African American } & -0.124 & 0.018 & 0.134 \\
\hline & $(0.166)$ & $(0.174)$ & $(0.147)$ \\
\hline \multirow[t]{2}{*}{ Other Minority } & -0.173 & -0.127 & 0.013 \\
\hline & $(0.121)$ & $(0.132)$ & $(0.124)$ \\
\hline \multirow[t]{2}{*}{ SES } & -0.0001 & -0.033 & 0.041 \\
\hline & $(0.093)$ & $(0.103)$ & $(0.077)$ \\
\hline \multirow[t]{2}{*}{ Partisanship } & 0.008 & 0.028 & -0.006 \\
\hline & $(0.038)$ & $(0.042)$ & $(0.037)$ \\
\hline \multirow[t]{2}{*}{ Ideology } & 0.074 & 0.035 & 0.014 \\
\hline & $(0.071)$ & $(0.064)$ & $(0.053)$ \\
\hline \multirow[t]{2}{*}{ Snyder Approval } & -0.06 & -0.08 & -0.072 \\
\hline & $(0.072)$ & $(0.074)$ & $(0.065)$ \\
\hline \multirow[t]{2}{*}{ Legislature Approval } & 0.203 & 0.238 & $0.238^{*}$ \\
\hline & (0.159) & (0.169) & $(0.11)$ \\
\hline \multirow[t]{2}{*}{ State Sup. Ct. Approval } & 0.069 & 0.002 & -0.054 \\
\hline & $(0.149)$ & $(0.146)$ & $(0.1)$ \\
\hline \multirow[t]{2}{*}{ Const. Knowledge } & -0.005 & -0.028 & 0.024 \\
\hline & $(0.051)$ & $(0.056)$ & $(0.052)$ \\
\hline \multirow[t]{2}{*}{ News Attentiveness } & 0.01 & -0.18 & 0.012 \\
\hline & $(0.042)$ & $(0.048)$ & $(0.032)$ \\
\hline \multirow[t]{2}{*}{ Const. Approval } & & $0.246^{*}$ & 0.123 \\
\hline & & $(0.101)$ & $(0.079)$ \\
\hline \multirow[t]{2}{*}{ Federal Const. Loyalty } & & & $0.487 * * *$ \\
\hline & & & $(0.102)$ \\
\hline \multirow[t]{2}{*}{ Constant } & $2.01 * * *$ & $1.14^{*}$ & 0.381 \\
\hline & $(0.403)$ & $(0.513)$ & $(0.407)$ \\
\hline $\mathrm{N}$ & 115 & 99 & 99 \\
\hline$R^{2}$ & 0.192 & 0.267 & 0.533 \\
\hline
\end{tabular}

Note: Data taken from pre-test measures, excepting constitutional knowledge that was derived from the post-test. Robust standard errors in parentheses. ${ }^{* * *} p<0.001,{ }^{* *} p<0.01,{ }^{*} p<0.05, \wedge p<0.10$

As previously mentioned, these null findings likely result from both the general ignorance of the Michigan state constitution and governmental actors and the federal "warmglow" effect (Zink and Dawes 2016): Given the general ignorance of Michigan state government, federal symbolism and feelings diffuse down upon state-level, analogous institutions. This "warmglow" 
suggests, therefore, that federal and state constitutional loyalty are strongly correlated with each other. Controlling for federal constitutional loyalty may help better estimate the causal relationship. There is also the potential connection between Michigan constitutional approval and loyalty, or whether specific support is influencing diffuse support. A subject's approval rating of the Michigan constitution may similarly influence her loyalty towards it, like in the federal model above.

To test for these possibilities, I run two additional models. First, I include an additional variable measuring subjects' Michigan constitutional approval; results are presented in model 5 in Table 10, above. As displayed, a subject's approval of the Michigan constitution is significantly $(p=0.017)$ and positively related to mean constitutional loyalty. A one-unit increase in constitutional approval increases a subject's average constitutional loyalty by 0.246 -points, holding all other factors constant. In this new model, as well, only one other variable reaches significance: a subject's age is positively related, with one additional year of age increasing average loyalty by 0.042 -points, a somewhat inconsequential effect (although is likely due to the limited age variability within the sample). Importantly, the explained variation in this new model improves considerably relative model 4 , suggesting that a subject's specific support figures prominently in underlying diffuse support. However, these relationships disappear when federal constitutional loyalty - the federal "warmglow" - is taken into account (model 6). Subjects' loyalty towards the federal charter significantly $(p=0.000)$ and substantially influences their Michigan constitutional loyalty. A one-unit increase in average federal constitutional loyalty increases Michigan mean constitutional loyalty by nearly a half point, holding all other factors constant. This is a substantial effect, one further indicated by the overall model's explained 
variation: approximately 53 percent of the variation in Michigan constitutional loyalty is explained by these factors alone.

Two important conclusions can be drawn here: First, Michigan constitutional loyalty is heavily tied with federal constitutional loyalty. Those who express greater federal charter fealty likewise espouse a state level loyalty, although the effect is not a one-to-one. This is in line with the expectations of the "warmglow" described by Zink and Dawes (2016), where greater exposure to federal constitutional symbolism instills in all Americans a general sense of constitutional veneration that diffuses down upon state charters, although loyalty to state charters is observably weaker. My findings mirror this pattern. Second, Michigan constitutional loyalty appears unaffected by a subject's civic knowledge. This is not too surprising given the general ignorance of the Michigan constitution and the charter's general lack of media attention (although that may change during years when the state constitution is in the news, such as during hotly contested constitutional amendment referenda). ${ }^{18}$ Thus, how one feels about the U.S. Constitution appears to be a good proxy for Michigan's constitutional support.

\section{Discussion and Implications}

I can now revise the preliminary conclusions made in Chapter 4 about constitutional loyalty predictors. Like other institutional loyalties, constitutional loyalty follows some similar patterns: demography, partisanship, and ideology are insignificant, while institutional attitudes

\footnotetext{
${ }^{18}$ Michigan constitutional approval, though, does appear to follow the expectations established in the larger literature (see, e.g., Stephanopoulos and Versteeg 2016). I estimate a model that controls for all four dimensions and federal constitutional approval, finding that Michigan constitutional approval is significantly and positively influenced by subjects' Michigan constitutional knowledge $(b=0.112, p=0.031)$ and federal constitutional approval $(b=0.369, p=0.000)$. No other variables reach traditional levels of significance, keeping with prior findings in Chapter 4 and other studies on institutional support (save for the null finding regarding state institutional attitudes).
} 
(especially on the SCOTUS's job performance) matter. However, college students' news attentiveness and constitutional knowledge do not significantly predict their loyalty to the charter, diverging from the larger literature's expectations of positivity bias. Instead, these findings suggest that college students have weaker federal constitutional loyalty than other groups - a loyalty that is influenced heavily by short-term assessments of other governmental institutions and how well one approves of the constitution's performance. While I cannot definitively say this is the case with these data here, I can conjecture that the SCOTUS's role as constitutional arbiter and interpreter indirectly influences college students' constitutional attitudes explaining its significance here; (dis)agreement with the Court's decisions on major constitutional questions may (weaken) solidify one's underlying loyalty to the charter.

Additionally, there is a strong connection between a constitution's specific and diffuse support. Put another way, a person who has high constitutional approval likewise espouses greater loyalty. This suggests there may not be much observable difference between specific and diffuse support, at least where constitutions are concerned, or that it is empirically difficult to separate the distinct concepts (see Davidson and Parker 1972). Both federal and Michigan constitutional support exhibit this relationship. For college students, though, this may be simply a byproduct of the connection noted above: judging constitutional performance based on the outputs of its created institutions, such as the courts. The implication, therefore, is that shortterm outputs of governmental institutions, potentially colored by partisanship and polarization, can indirectly influence college students' constitutional support.

Furthermore, Michigan constitutional loyalty is highly dependent on attitudes toward the federal constitution. The federal "warmglow" noted by Zink and Dawes (2016) occurs here, with 
modeling illustrating the substantial effect that federal constitutional loyalty has upon subsequent loyalty expressed toward the Michigan state charter. Again, this is not surprising given the minimal familiarity with the Michigan state constitution; federal attitudes are substituting for state constitutional support. Consequently, changes in federal attitudes will also affect state level feelings - a potentially problematic development if one considers that the two levels are not mutually exclusive. Approval and loyalty towards the Michigan constitution, therefore, could be influenced by federal constitutional politics that may not have any direct, substantive connection with the Michigan charter. The "warmglow," therefore, may not be entirely benign; it does help generate a basis of support for the Michigan constitution, but it could also reduce it.

However, these findings are limited in two crucial aspects. First, they speak only to college students' behaviors on constitutional loyalty and may not completely generalize to the general American adult population. Future research should use representative samples to test whether the observed patterns happen population-wide. I hasten to add, though, there is no evidence suggesting college students systemically differ from the rest of the American adult population regarding constitutional loyalty predictors, meaning the use of the college sample may not undermine external validity (Druckman and Kam 2011). Nonetheless, these findings do suggest fruitful avenues that scholars can explore regarding constitutional loyalty predictors and the relationship between constitutional approval and loyalty. Second, the null findings between Michigan constitutional loyalty and Michigan constitutional knowledge may be explained by my measurement of Michigan constitutional knowledge (see also footnote 9, above). This battery should be considered a rough approximation, but I would argue that recognition of constituent 
provisions of the Michigan Constitution is a better approximation of constitutional familiarity than self-professed measures. Thus, it could be that positivity bias does exist at the federal level because college students are indeed more familiar with that charter than they are of Michigan's; the insignificant result at the state level simply reflects that most Michigan college students do not have actual familiarity with their state's constitution - and, therefore, the models do not have enough variability to accurately estimate whether a relationship does exist between charter knowledge and loyalty.

\section{Periodic Conventions, Constitutional Knowledge, and Constitutional Loyalty}

Foregoing sections have offered tentative conclusions on the predictors of constitutional loyalty among college students. These findings can provide the basis for future research avenues assessing whether the general population of Americans exhibit similar behaviors. My dissertation's main focus, however, concerns testing the threat of periodic convention referenda upon constitutional loyalty. Briefly, my experimental analysis in Chapter 5 found that: (1) primes about periodic conventions, emphasizing the threat they represent to constitutional integrity, have minimal effect on either Michigan or federal constitutional loyalty; (2) priming subjects that past convention questions were rejected (versus approved) does matter in modifying a constitution's specific support, or constitutional approval, with those informed that prior conventions were rejected having lower federal and Michigan constitutional approval scores than those told prior conventions had been approved; and (3) subjects less familiar with Michigan's periodic convention mechanism were the persons affected most by the priming treatment. 
I further explore this latter finding, which offers evidence of positivity bias at work. Difference in means tests (pooling all subjects together) indicate general differences between those more and less familiar with Michigan's periodic convention mechanism and how they evaluate Michigan's constitution. As illustrated in Figure 7, subjects less familiar express significantly lower average Michigan constitutional approval and loyalty than those more familiar. Subjects more familiar have average approval scores of 3.43 compared to those less familiar with average approval scores of $3.07(p=0.003)$, although the magnitude difference is somewhat small. Greater difference, though, is observed on average constitutional loyalty scores, with more familiar subjects averaging a score of 1.65 compared to less familiar subjects whom average $0.83(p=0.000)$. These differences offer evidence that positivity bias is at play.

\section{Figure 7.}

Michigan Constitutional Support by Prior Periodic Convention Knowledge

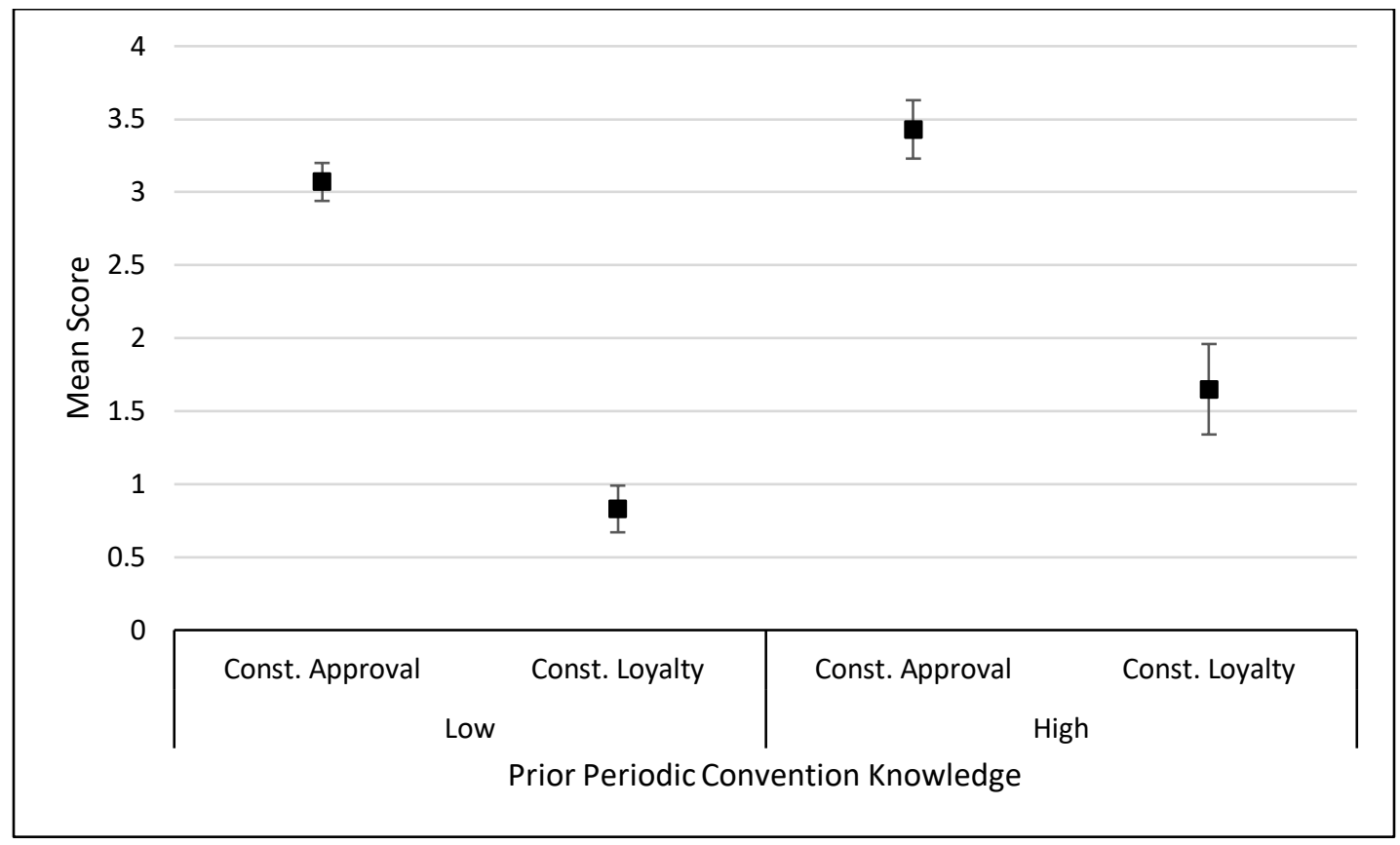

Note: Dependent measures based on pre-test data. Prior periodic convention based on post-test data. Constitutional approval and loyalty presented on five-point scales, with higher numbers indicating greater approval and loyalty. Error bars represent the 95 percent confidence interval. 


\section{Expectations and Analysis}

Similarly, level of constitutional knowledge may also impact the experimental results. Just how those persons less familiar with Michigan's periodic convention acted differently to the treatment, so to may subjects with low knowledge of Michigan's constitution. Therefore:

Hypothesis 5: Subjects possessing less constitutional knowledge will be more susceptible to the treatment than subjects with greater constitutional knowledge.

Again, and like in Chapter 5's analysis, my expectation is that any significant differences among conditions will likely be driven by subjects lacking constitutional familiarity. To test for this possibility, I run one-way ANOVAs using level of federal/Michigan constitutional knowledge as a grouping variable. The latter are the re-coded binary measures (i.e. low and high) of the scale measures used in the prior section, meaning that ANOVAs are produced for each level of constitutional knowledge. There are three dependent variables of interest: likelihood of supporting a federal or state constitutional convention, constitutional approval, and constitutional loyalty. ${ }^{19}$ Bonferroni post-hoc tests were used to identify statistically significant differences between conditions, and I also report effect sizes where appropriate. ${ }^{20}$

Results

I begin with Michigan constitutional support. Like Chapter 5, one-way ANOVAs do not find significant differences among the groups for either Michigan constitutional loyalty or likelihood of supporting a Michigan constitutional convention. However, there are significant differences

\footnotetext{
${ }^{19}$ Constitutional loyalty is, again, measured using the subject's average response to all four diffuse support statements. Analyses reported here were re-ran using the alternative dependent measures noted in infra-note 9 (above), yielding no substantial differences.

${ }^{20}$ See Chapter 5 for a discussion about the use of ANOVA and the Bonferroni method. Formal ANOVA tables available upon request.
} 
among low and high knowledge persons on Michigan constitutional approval, but only among those in the negative (Condition 2) and positive prime (Condition 3) groups. Results are graphically presented in Figure 8. As expected, these differences occur only for those with low Michigan constitutional knowledge $(F(3,142)=3.06, p=0.03) \cdot{ }^{21}$ Bonferroni post-hoc tests indicate that subjects exposed to the negative prime $(\bar{y}=2.83 ; \mathrm{s}=0.82)$ had lower approval scores than the positive prime group $(\bar{y}=3.38 ; s=0.75 ; p=0.041)$, a moderate effect size $\left(\eta^{2}=0.06\right)$. These findings mirror those found in Chapter 5: information about a periodic convention must both be (1) accompanied by a prime to have a meaningful effect and (2) influences those with lower (constitutional) knowledge more than others.

\section{Figure 8.}

Michigan Constitutional Approval Scores by Constitutional Knowledge

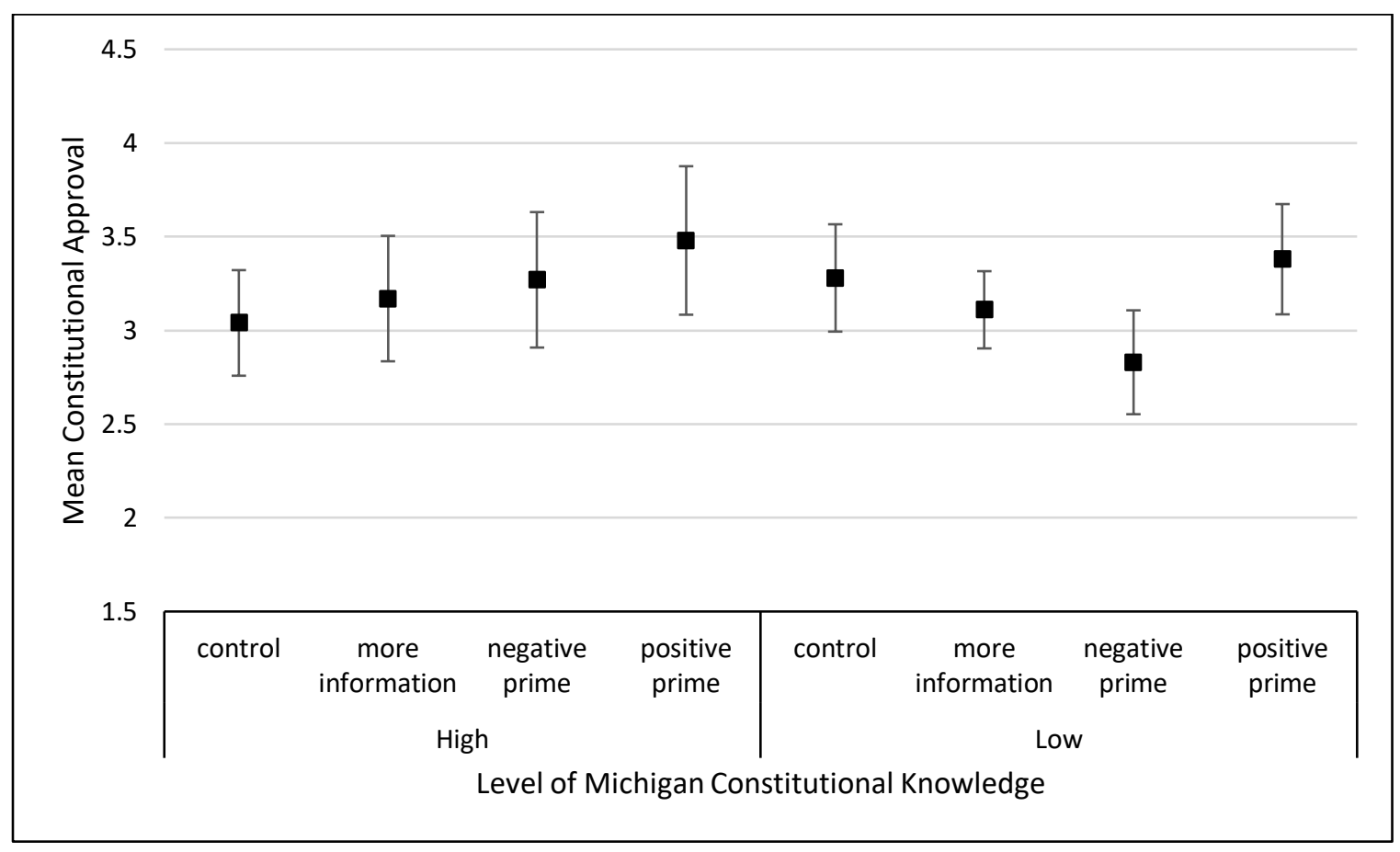

Note: Data based on post-test measures. Constitutional approval presented on a five-point scale, with higher numbers indicating greater approval. Error bars represent the 95 percent confidence interval.

${ }^{21}$ One-way ANOVA results for those with high constitutional knowledge were non-significant $(F(3,76)=1.29, p=$ $0.283)$. 
Alongside these findings, Chapter 5 also noted that a reverse "warmglow" (Zink and Dawes 2016) appeared to be influencing federal constitutional approval. Put another way, subjects informed that prior periodic conventions had been rejected (the negative prime) not only rated the Michigan constitution lower but correspondingly offered a frostier evaluation of the U.S. Constitution. Further analysis confirmed this reverse "warmglow" occurred among those with lower prior knowledge about Michigan's periodic convention mechanism (see Chapter 5 for elaboration). Therefore, it stands to reason those with lower Michigan constitutional knowledge and those with lower federal constitutional knowledge may also exhibit similar tendencies.

Figure 9.

Federal Constitutional Approval and the Reverse "Warmglow" Effect

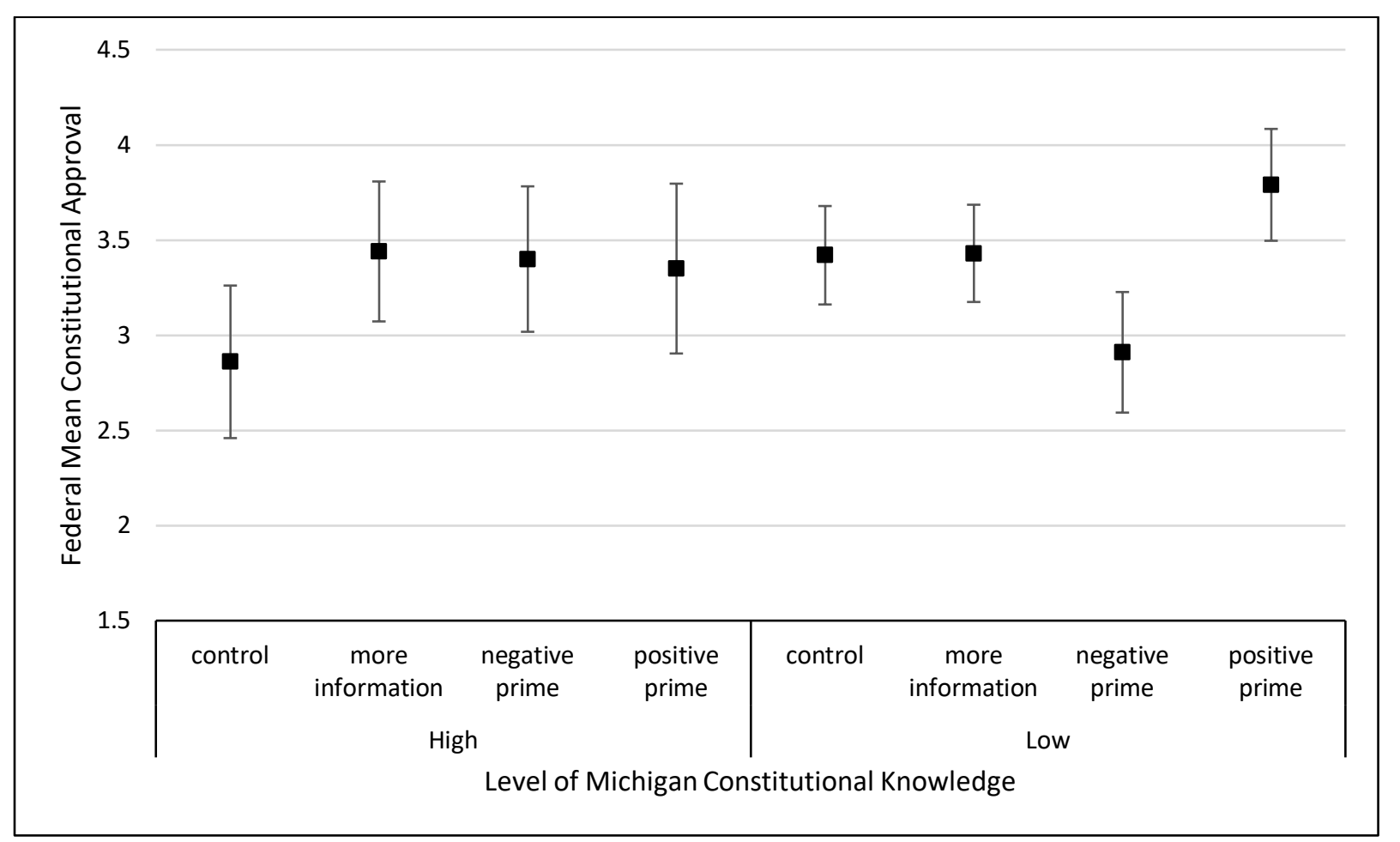

Note: Data based on post-test measures. Constitutional approval presented on a five-point scale, with higher numbers indicating greater approval. Error bars represent the 95 percent confidence interval. 
I test both propositions here. First, I re-run the one-way ANOVAs above using federal dependent variables. No significant differences among experimental conditions by levels of Michigan constitutional knowledge emerge for either federal constitutional loyalty or the likelihood of supporting a federal constitutional convention. However, and like in the Michigan results above, federal constitutional approval does significantly differ among the conditions for those with low Michigan constitutional knowledge $(F(3,137)=5.32, p=0.002) .{ }^{22}$ Bonferroni posthoc tests determined that subjects in the negative prime $(\bar{x}=2.91 ; s=0.91)$ had significantly lower federal constitutional approval scores than subjects in the positive prime $(\bar{x}=3.79 ; \mathrm{s}=$ $0.72 ; p=0.001)$, as shown in Figure 9. This is a moderately strong effect $\left(\eta^{2}=0.104\right)$, resulting in almost a full point difference in federal constitutional approval. Taken together, these findings indicate that a reverse "warmglow" is occurring: subjects more ignorant of the Michigan constitution and periodic conventions are also more susceptible to the negative prime. The same, however, cannot be said about federal constitutional knowledge levels, the second proposition. One-way ANOVAs for all three dependent variables yield null findings. Thus, it is the differences among Michigan constitutional knowledge that determine susceptibility to the treatment.

\section{Discussion and Implications}

These findings, coupled with those of Chapter 5, further qualify the conclusion that periodic conventions influence subjects differently depending on their prior knowledge. Differences on Michigan constitutional approval are driven by subjects who (1) are not familiar with periodic conventions and (2) have low constitutional knowledge scores, but these

\footnotetext{
22 One-way ANOVA results for those with high constitutional knowledge were non-significant $(F(3,74)=1.80, p=$ $0.154)$.
} 
differences occur only between the negative and positive primes. Put another way, subjects informed that prior periodic conventions had been rejected expressed lower constitutional approval, but this difference occurred among those with low Michigan constitutional knowledge and not previously familiar with periodic conventions. Positivity bias leads us to think there should be differences among those groups with greater familiarity of an institution than not, an expectation confirmed by these results. Practically speaking, therefore, campaigners will want to focus on low-information voters. ${ }^{23}$

There remains, however, the unexpected direction of the negative and positive prime conditions. To review, the negative prime (subjects informed that prior conventions were rejected) sends an implicit assumption that the constitution has been supported by past generations who refused to fundamentally alter it. Conversely, the positive prime (subjects informed that prior conventions were approved) communicates an implicit message that it may be okay to replace or alter the charter because it has been done before (see Brennan 2017; see also Chapter 5 for elaboration). Instead, results here still confirm what was observed in Chapter 5: negative prime subjects expressed higher average constitutional approval scores than those in the positive prime, opposite of expectations. However, I believe my prior explanations still fit: Younger persons, including my sample, already have lower approval scores generally, which may have been accentuated by the negative prime that afforded college students opportunities to express dissatisfaction. More likely, though, is the positive prime is working as intended; priming

\footnotetext{
${ }^{23}$ Although these voters are less likely to vote/participate, a fact that also explains why opponents of constitutional change have an easier time defeating ballot initiatives and periodic conventions.
} 
subjects to believe it is okay to replace a constitution activates subjects' risk aversion, bolstering their support for the current constitution.

Additionally, the null findings on Michigan and federal constitutional loyalty, even among differing constitutional knowledge levels, provide evidence that specific and diffuse support empirically differ. Given that periodic conventions influence specific support, or constitutional approval, more than diffuse support, it would suggest that periodic conventions are prompting relatively short-term reassessments that do not affect the subjects' underlying constitutional orientations. However, this assertion must be squared with the regression analyses above; specific support for the constitution appeared to be heavily predicting one's constitutional loyalty even amongst other controls. At least among college students, my findings would seem to indicate that the debate in the larger literature on specific and diffuse support is far from settled.

Finally, I note the (still) occurring reverse "warmglow" among subjects. Whereas Zink and Dawes (2016) found that federal constitutional feelings underscored state constitutional feelings, a reversed phenomenon continues to occur here: negative and positive priming on periodic conventions influenced subjects' Michigan and federal constitutional approval. I posit that the "warmglow," regardless of its direction, is more a manifestation of the constitutional status quo bias that pervades the nation's constitutional feelings - at both the state and federal levels.

\section{Summary}

Constitutional knowledge has a qualified relationship with constitutional loyalty. On the one hand, higher levels of constitutional knowledge engender a positivity bias among college students, increasing average constitutional loyalty. But there are significant caveats, least among them that the relationship holds at the federal level only; Michigan constitutional loyalty is 
unaffected by one's actual familiarity with the charter's content, instead influenced more by the subject's federal constitutional attitudes (i.e. the "warmglow"). More importantly is that subjects' constitutional approval appears to heavily inform their loyalty; if one approves of the constitution, then you less willing to alter or do away with the charter. This is true for both Michigan and federal constitutional support. Yet, constitutional knowledge does matter; those unfamiliar with their constitutional charters respond differently to periodic conventions than those who have better understandings. Proponents and opponents of periodic conventions, therefore, would do well to focus their energies on these kinds of individuals. 


\section{CHAPTER 7 - CONCLUSIONS, IMPLICATIONS \& FUTURE WORK}

Having reviewed my findings, I now turn to a larger discussion about how these results square with prior works and political reality. The scholarly literature on institutional support indicates that my results - particularly the null findings on primes about periodic conventions influencing a person's constitutional loyalty - are not entirely unexpected, but also may be welcomed; if a person's constitutional loyalty is not influenced by primes emphasizing the existential threat periodic conventions represent to constitutional charters, then proponents of constitutional veneration can breathe a sigh of relief. However, there still remains the political reality: people do express disapproval with the constitutional system of government and its outputs, and primes about periodic conventions do influence a person's approval of their constitutions, albeit in unanticipated ways. Below, I discuss my findings and their implications, including where future research should focus in further exploring constitutional loyalty and periodic conventions.

\section{Lessons \& Implications: Constitutional Loyalty, Periodic Conventions, and the Big Picture} Opinions on Political Institutions (and System) Drive Constitutional Loyalty

Constitutional scholar Sandford Levinson often describes the U.S. Constitution as our nation's "sacred text" (see, e.g., Levinson 2006, 2012, \& 2018). And we do, indeed, venerate the document, or at least are risk averse about fundamentally altering it (Zink and Dawes 2016). My findings detailed in the prior chapters reinforce this belief (the U.S. Constitution enjoys a deep wellspring of loyalty) but it also offers some cautionary notes. For example, while my subjects expressed skepticism at rewriting the Constitution, less than a majority explicitly rejected the idea of eliminating the Constitution altogether (see Table 1). These findings are not out of the 
mainstream; the Pew Research Center (2018) found that 61 percent of the country believes significant changes are needed in the fundamental design and structure of American government - both of which are created by the Constitution itself. Thus, a paradox of sorts: Americans express support for their federal constitutional charter, yet also are underwhelmed with the political system that charter creates.

The paradox is also reflected in how attitudes towards the U.S. Constitution's created institutions matter in predicting one's federal constitutional loyalty. This is particularly true with feelings toward the U.S. Supreme Court (SCOTUS) and President Trump. When institutions of government engage in constitutional-level politics (e.g. debates over what the constitution requires, whether a governmental branch's actions are constitutional, etc.) their job performance matters in determining one's constitutional loyalty. This finding is somewhat troubling given that a general dislike of government could potentially pervade into the civic creed of the nation. It could also mean that loyalty towards the Constitution changes with the political winds, a byproduct of partisan polarization and the increasing tribal nature of American politics. It may already be happening, too: in this context, the Pew survey above (finding that a majority of Americans favoring fundamental system-wide changes to the constitutional system) could be read to signal that constitutional loyalty has taken a significant hit (see Pew Research Center 2018 for a comparison with prior years).

Although this may not be all doom-and-gloom; partisanship may certainly weigh on people's feelings toward the political system, but it is another question if those feelings about requiring fundamental change extend to the constitutional system itself (i.e. the general design 
of government). Hibbing and Theiss-Morse (1995) argue that the public is critical of governmental institutions but not the system's design per se:

People actually see two quite different political systems.... [A]nything associated with the constitutional system elicits a positive response.... To the extent there are problems with the political system it is because we have deviated from what was outlined in the Constitution, not because that outline was flawed. (104)

The problem, though, is that the Pew survey did differentiate between feelings on governmental institutions and the general design of government. Respondents not only dislike specific institutions (especially Congress), but they also feel that the larger, governmental design requires significant, fundamental changes.

My findings would suggest that these feelings, moreover, are taking aim at the Constitution itself. People no longer are keeping the Constitution separate from criticism, or attributing blame to the created institutions. Instead, the Constitution itself is seen as "flawed" (see, e.g., Levinson 2006 \& 2018). My subjects may not have been overtly willing to do away with the U.S. Constitution completely, but they did express skepticism regarding its fairness and only a plurality agreed that fundamentally altering it would not matter (see Table 1). Likewise, if other institutional attitudes - on the SCOTUS and president - are influencing constitutional loyalty, it suggests that our hyperpartisan polarization may actually be harming our underlying faith in the constitutional system. My findings on the positive relationship between constitutional approval and loyalty (i.e. high constitutional specific support predicts high constitutional diffuse support) also reaffirms the assertion that short-term assessments do influence long-term dispositions.

State constitutions are not immune, either. While my results did not indicate that statelevel institutional attitudes predict state constitutional loyalty, my regression analysis did demonstrate the existence of a "warmglow" effect. As Zink and Dawes (2016) find, a 
constitutional status quo bias at the federal level diffuses down into the states, although some "strength" is lost (i.e. the status quo bias is less resilient and easier to overcome). The implicit assumption, therefore, is that Americans tap into a shared and underlying schema when evaluating their federal and state constitutional charters. My findings provide further evidence of the warmglow: federal constitutional institutional feelings, particularly on the SCOTUS and President Trump, influence state constitutional loyalties. This is further exacerbated given the limited engagement (and knowledge) that citizens have with their state charters; when evaluating an unknown, we turn to familiar schemas for help. As my subjects demonstrated, feelings on the federal Constitution and government provide a convenient proxy.

\section{Periodic Conventions: Influencing Constitutional Approval}

Periodic conventions also have a role to play here, albeit in unexpected ways. While periodic conventions do not influence constitutional loyalty (a finding that is not entirely unexpected given the theorized durability of diffuse support), they do influence one's specific support, or constitutional approval. However, this is a qualified support; those told that prior conventions were rejected by voters had decreased approval scores relative those subjects told that prior conventions had been approved. This stands contrary to Madison's expectations in Federalist 49 and are somewhat counter-intuitive, although it could be that informing voters that prior conventions had been approved (the "positive prime") activated their risk aversion and constitutional status quo biases (i.e. the warmglow). More importantly, though, was how both Michigan and federal constitutional approval were affected by these primes.

Collectively, my findings suggest that changes to our constitutional evaluative criteria can occur at the state level and cascade into federal-level effects, a "reverse" warmglow. Since the 
federal Constitution has no history of periodic conventions, testing for convention effects at the state level is the more realistic and appropriate option. Given the influence, though, of federallevel feelings on state constitutional loyalty (and constitutional support more generally), it is not surprising that a state-level interaction would cause feedback. However, the relationship between constitutional approval and loyalty raises concerns regarding this feedback loop; low constitutional approval is correlated with low constitutional loyalty. In one respect, then, Madison's advice actually leads to reduced constitutional loyalty (and, in his eyes, veneration): telling voters that prior conventions have been rejected overrides their constitutional status quo biases, inducing support to amend/alter/replace a charter. At least one prominent constitutional critic echoes this sentiment: Levinson (2018) calls for us to reflect "about whether our $18^{\text {th }}$ century Constitution serves us well today." His method of doing so? Noting how various constitutional reforms (ones that many contemporary Americans ostensibly favor today) have been rejected over the past 200 plus years.

Constitutional Ignorance: The Importance of Reading the Manual

Importantly, though, there is an "ignorance gap" when it comes to these findings. Those unfamiliar with periodic conventions are the subjects more susceptible to the primes, and thus driving the results. The same relationship holds for constitutional knowledge/familiarity: persons more knowledgeable about a constitution express greater loyalty/approval/support towards it, reflecting a "positivity bias" common in institutional support: to know it is to love it (see Gibson and Caldeira 2009a). Thus, one way to generate constitutional loyalty - or counteract more negative political aspects, including hyperpartisanship - is to teach constitutional processes (e.g. periodic conventions) and about constitutions generally. 
Michigan constitutional loyalty illustrates the negative effects of constitutional ignorance. Persons less familiar with Michigan's periodic convention mechanism were the subjects responding to the treatments; those already familiar did not differ in their mean constitutional loyalties nor constitutional approval scores. There is also no evidence of a positivity bias at the Michigan level, and is likely the result of the low level of Michigan constitutional knowledge exhibited across the board. This is not unsurprising given that, generally, periodic conventions are not taught even within states that utilize them, nor do state constitutions feature prominently (if at all) in secondary and collegiate civics curricula (see Snider 2017). What is surprising, though, is how pervasive this ignorance gap can be: if most Americans exhibit low political knowledge (Delli Carpini and Keeter 1996), then it stands to reason they also will display low constitutional knowledge. The net effect is that constitutional support for most of the population could be influenced quite easily (albeit over the long-term).

The efficacy of periodic conventions should also be considered suspect given these observations. If voters are unaware of periodic conventions generally, then its utility as a citizens' way of reviewing the political system's design and structure is lost (especially in those states with reoccurring periodic convention referenda, including Michigan). In short, Jefferson's charge to replace constitutions every generation does not seem plausible (or reasonable, for that matter) if most citizens are not informed enough to even realize they can replace a constitution. Instead, the better approach may be piecemeal; singular amendments presented as such rather than general revisions. Then again, the latter approach does not achieve great success either: less than half of all legislature-referred and popular initiative amendments to the Michigan constitution since 1964 have been approved, indicating a "general unwillingness of Michigan voters to change 
their constitution" (Zink and Dawes 2016, 555). A further complication concerns how priming voters about periodic conventions can lead to differing results, outcomes driven by the ignorant among the citizenry. Here, both Madison and Jefferson would agree: when it comes to constitutions and revisions, an informed citizenry is not only preferable but a prerequisite.

\section{Future Research}

Armed with these findings, additional avenues of research readily present themselves. First, replication studies should explore whether the experimental results are generalizable to the larger population of American adults. As mentioned before, some scholars (e.g. Druckman and Kam 2011) note that framing/priming experiments do not present generalizability concerns when using college student samples. There is no indication that college students systemically vary in their responses to these primes relative adults (or vice versa). Nonetheless, there may be generational differences that the experiment cannot detect; perhaps Millennials differ in their constitutional support relative their parents and grandparents that may signal a profound shift in how we describe constitutional support more generally. Any difference, therefore, would lead to further questions about why young people differ in how they respond to constitutional primes.

Second, does partisan strength matter in teasing out how periodic conventions influence constitutional loyalty and approval? In his examination of Michigan's constitutional conventions, Thomas (1968) found that partisanship was the deciding factor for voters when supporting (opposing) the 1963 constitution. Similar to how those ignorant of periodic conventions responded the most to the negative and positive primes, it could be that strong partisans may be responding differently to the primes relative more moderate persons. Then again, the null findings concerning partisanship on constitutional loyalty may offer evidence against 
partisanship's influence generally. Future research should more fully control for this possible confounder.

Relatedly, there are questions concerning how policy agreement with the substantive framing of periodic conventions may influence underlying constitutional approval and loyalty (and, ultimately, support for the convention itself). By substantive framing I mean the "purpose" of the periodic convention, such as the revisions prioritized, the themes to discuss, and/or the goals of the convention itself, among others. Put another way, how do proponents of a periodic convention frame their arguments? Do these frames matter in adjudicating whether a convention is approved or not? Do certain characterizations help to overcome entrenched constitutional loyalty and/or approval? Why? My experiment here cannot speak to these questions, but they are certainly pertinent to our greater understanding of the subject. The general decline in periodic conventions described by Snider (2017), moreover, presupposes these questions - what has changed since the 1960s and 70s to precipitate such a drastic decline? While the periodic convention literature does speak to some of these possibilities (see Snider 2017 for a review), none of them address how an individual's underlying constitutional support is influenced (if at all).

Third, the relationship between the SCOTUS's institutional support and constitutional loyalty is worthy of further elaboration. Do people proxy their constitutional attitudes and feelings for how they feel about the Constitution's "guardian?" Are college students different from other Americans in this respect? Given the intricate relationship between courts and constitutions generally, future scholarship may find that diffuse support measures for courts are 
more generally indicators of one's constitutional loyalty. If not, are Americans sophisticated enough to differentiate courts interpreted roles and opinions relative a constitution itself?

Finally, greater exploration into constitutional knowledge is clearly warranted, especially where it concerns state constitutions. Both constitutional knowledge question batteries should be considered first steps. For federal constitutional knowledge, the emphasis on "rights rhetoric" (Glendon 1991) in U.S. Constitution curricula means that people are less familiar with structural and institutional features than questions pertaining to the Bill of Rights. This is somewhat evident in my study, given that the two highest scoring questions concerned the Bill of Rights (see Table 7). Thus, other studies (e.g. Green et al. 2011) focus on measuring respondents' abilities to recall factual info regarding the Bill of Rights when operationalizing constitutional knowledge. I contend, though, that this yields an incomplete picture - noting full well that contemporary constitutional curricula deliberately emphasize only certain aspects of the Constitution. Future research should direct energies here to better tap the full extent of the constitutional knowledge domain but also whether a standard question battery can be created (like the political knowledge battery constructed by Delli Carpini and Keeter 1996; see also Delli Carpini and Keeter 1993).

Measuring Michigan constitutional knowledge certainly requires greater elaboration. This effort is complicated by the absence of the Michigan constitution from virtually all civics curricula within the state, both secondary and collegiate. While I argue that my identification method is a better way to ascertain a subject's effective (and applied) familiarity with the Michigan state charter, it certainly is incomplete (see Chapter 6). Future research needs to establish what the content of Michigan constitutional knowledge ought to entail. Should it correspond with federal themes? Should it be directed more at substantive policy provisions (e.g. positive rights found in 
most state constitutions; see Zackin 2013) rather than governmental design features? Or something else entirely? Greater conceptualization is a necessary first step in better operationalizing state constitutional knowledge.

\section{Afterword: Wither Our Civic Creed?}

What motivated this dissertation was a desire to adjudicate Madison's and Jefferson's dueling contentions about periodic conventions and constitutional loyalty. The major takeaway concerns not the qualifying of these contentions, but rather how constitutional loyalty can be influenced by other institutional attitudes - and how federal constitutional loyalty serves as the foundation for our state constitutional support. There is indeed a more complex relationship concerning constitutional loyalty that extends beyond just a mere constitutional status quo bias. Additionally, and given the role of constitutional approval in generating constitutional loyalty, one wonders if hyperpartisanship and polarization are coloring feelings on our constitutional charters.

The more interesting note, however, concerns the citizenry's abysmal understanding of our constitutional charters, especially the state variety. While my subjects had a relatively strong grasp of federal constitutional knowledge, Michigan constitutional knowledge was virtually nonexistent. Moreover, the use of periodic conventions as a general revision mechanism - a citizen "redo" button, if you will - becomes questionable if the public just does not have enough familiarity to properly understand what a periodic convention is - never mind actually judging on the merits whether the present charter ought to be replaced. There is a pressing need for educating about state constitutional charters at the same rate as the federal Constitution. Federal constitutional knowledge should not be neglected, either; the hyper-focus on the Bill of 
Rights neglects structural and institutional principles that should not be ignored. One wonders if a majority of Americans favor fundamental changes to the "design and structure" of our government (Pew Research Center 2018) because they simply do not understand how our constitutional system actually operates.

If the U.S. Constitution is our national "civic creed" (Smith 1993), we neither fully understand it nor do we really treat it like a creed. The same is even truer for our individual states' constitutions. How can we question a faith that we do not fundamentally grasp? How can we believe a credo without understanding it? Such blind loyalty and woefully inadequate understanding raise the specter of citizens making fundamentally flawed decisions when it concerns constitutional revision, as well as being easily manipulated by political elites and other special interests. Periodic conventions become a hollow hope - as does the larger call for discussing our constitutional design and system. The threat is perhaps bigger at the state level, where federal constitutional attitudes mask genuine need for constitutional revisions - or saddle the state with suboptimal modifications. Here, then, is the biggest takeaway: Our civic creed withers without a renaissance in constitutional education. 


\section{APPENDIX A: SURVEY INSTRUMENT}

\section{Pre-test Instrumentation}

Thank you for taking this voluntary survey. These questions examine how college students think about and understand constitutional charters. All information will be kept completely confidential and anonymous.

First, we would like to ask you a few questions about your political orientations, behaviors, and feelings on federal and state institutions.

1. Generally speaking, do you usually think of yourself as a Democrat, a Republican, or an Independent?

\begin{tabular}{|c|c|c|c|c|c|c|c|}
\hline $\begin{array}{l}\text { Strong } \\
\text { Democrat }\end{array}$ & $\begin{array}{c}\text { Weak } \\
\text { Democrat }\end{array}$ & $\begin{array}{c}\text { Independent } \\
\text { but lean } \\
\text { toward }\end{array}$ & Independent & $\begin{array}{l}\text { Independent } \\
\text { but lean } \\
\text { toward }\end{array}$ & $\begin{array}{c}\text { Weak } \\
\text { Republican }\end{array}$ & $\begin{array}{c}\text { Strong } \\
\text { Republican }\end{array}$ & $\begin{array}{c}\text { Don't } \\
\text { Know/Unsure }\end{array}$ \\
\hline 0 & 0 & 0 & 0 & 0 & 0 & 0 & 0 \\
\hline
\end{tabular}

2. When it comes to politics, how would you describe yourself in terms of liberal or conservative views?

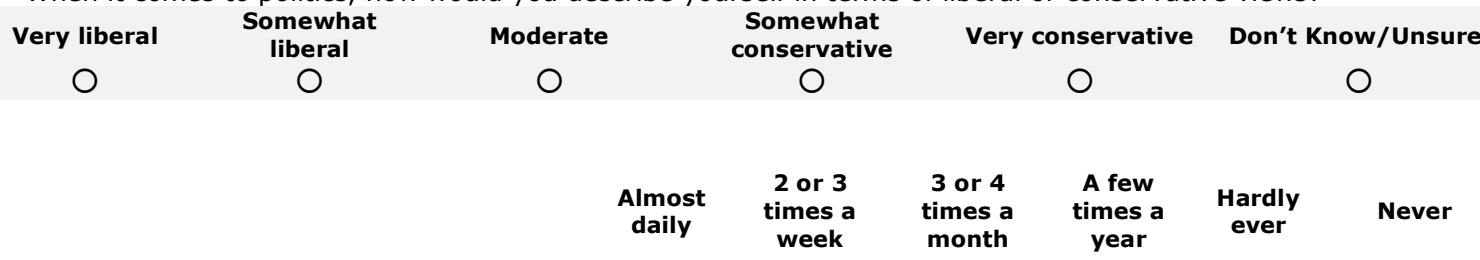

3. How closely do you follow NATIONAL news?

4. How closely do you follow LOCAL news?

$0 \quad 0$

$\bigcirc$

$\bigcirc$

$\bigcirc$

$\bigcirc$

In general, how much do you approve of the way these FEDERAL officials and institutions are handling their jobs?
5. President Donald J. Trump
Not at
all
A little Some
A lot A great Unsure
6. United States Congress
$\mathrm{O}$
O 0
$\mathrm{O}$
7. United States Supreme Court

Now consider the MICHIGAN STATE government. In general, how much do you approve of the way these STATE officials and institutions are handling their jobs?
8. Governor Rick Snyder
Not at
A little Some
A lot
A great Unsure
deal
9. Michigan State Legislature
O
$\bigcirc$
0
$\bigcirc$

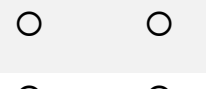
10. Michigan State Supreme Court

\section{APPROVED}
FEB 082018 
Next, we are interested in the extent to which you follow Michigan government. Please answer the following true/false questions. Many people don't know the answers to these questions, so if there are some you don't know, select "Don't Know" and move on.

True False Know/Unsure

1. Michigan has a state constitution.

2. Every 16 years, Michigan voters are asked if they would like to hold a constitutional convention.

3. The current Michigan state constitution, in force since 1964 , can be revised by a periodic convention approved by voters.

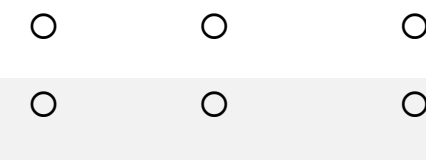

Now we are interested in knowing your feelings on the U.S. FEDERAL Constitution. To what extent do you agree with the following statements?

$\begin{array}{cccc}\begin{array}{c}\text { Strongly } \\ \text { agree }\end{array} \quad \text { Agree } & \begin{array}{c}\text { Neither } \\ \text { agree or } \\ \text { disagree }\end{array} \quad \text { Disagree } & \begin{array}{c}\text { Strongly } \\ \text { disagree }\end{array}\end{array}$

4. It would not make much difference to me if the

0 disagree sagree FEDERAL constitution were rewritten or amended.

5. The FEDERAL constitution favors some groups more than others.

6. If the FEDERAL constitution continually prevents decisions that the people agree with, it might be better to do away with the Constitution altogether.

7. The FEDERAL constitution is too controversial to be useful today.

8. On a scale of 1 to 5 (with 5 being "strongly approve"), how much do you approve of the FEDERAL constitution? Please circle your answer. 
Now we would like to know your feelings on the MICHIGAN STATE constitution. To what extent do you agree with the following statements?

$\begin{array}{ccccc}\begin{array}{c}\text { Strongly } \\ \text { agree }\end{array} & \text { Agree } & \begin{array}{c}\text { Neither } \\ \text { agree or } \\ \text { disagree }\end{array} & \text { Disagree } & \begin{array}{c}\text { Strongly } \\ \text { disagree }\end{array} \\ 0 & \bigcirc & 0 & 0 & 0 \\ 0 & 0 & 0 & 0 & 0 \\ 0 & 0 & 0 & 0 & 0 \\ 0 & 0 & 0 & 0 & 0\end{array}$

4. The MICHIGAN STATE constitution is too controversial to be useful today.

It would not make much difference to me if the MICHIGAN STATE constitution were rewritten or amended.

2. The MICHIGAN STATE constitution favors some groups more than others.

3. If the MICHIGAN STATE constitution continually prevents decisions that the people agree with, it might be better to do away with the Constitution altogether.

5. On a scale of 1 to 5 (with 5 being "strongly approve"), how much do you approve of the MICHIGAN STATE constitution? Please circle your answer.

123

Next, we would like to ask you a few questions about yourself. Remember that your responses will be anonymous and kept confidential.

6. Which best describes your gender?
O Male
Female
Prefer to self-describe (please specify)
Prefer not to say

7. What is your current age (in years)?

8. What race/ethnicity do you primarily identify as? Please select all that apply.

White/Caucasian

Black/African American

Asian American

American Indian or Alaska Native

Native Hawaiian or other Pacific Islander

$\square$ Hispanic/Latino

Other (please specify)

9. What do you consider your family's socioeconomic background?

Working class

$\mathrm{O}$
Middle class

$\mathrm{O}$
Upper-middle class

O
Upper class

$\bigcirc$ 
1. Are you a U.S. citizen?

$\begin{array}{ccc}\text { Yes } & \text { No } & \text { Prefer not to answer } \\ 0 & 0 & 0\end{array}$

2. When you are not attending Wayne State University, do you reside in Michigan or live elsewhere?

$\bigcirc \quad I$ live in Michigan

I live in another state (please specify)

I live in another country 
We now want you to read through a news article on the 2010 Michigan general election. During this election, Michigan voters were asked whether they wanted to hold a constitutional convention.

\section{$\mathbb{T h e}$ Oakland County $\mathbb{Z} \mathfrak{Z} \mathfrak{e} \mathfrak{s}$}

\section{Michigan 2010: State Con-Con Question}

by PATRICIA SNYDER

Every 16 years, Michigan voters get to decide on whether to call for a constitutional convention to rewrite the state Constitution. Opponents argue that the current amendment process is adequate. "Constitutional change can come about amendment by amendment," argues the Michigan Chamber of
Commerce. "Although the present Constitution is not perfect, it contains no fatal flaw."

Others argue now is the time for significant changes. Citizens for Michigan has proposed several reforms, noting that "these recommendations offer the entire state a starting point from which to begin discussions on whether and how Michigan's Constitution should be improved."

If approved, the process for a constitutional convention would start in early 2011 .

1. Given what you have read, how likely would you support a constitutional convention to revise or replace the MICHIGAN STATE constitution?

Very likely Likely

$\mathrm{O}$

$\mathrm{O}$

Neutral

O
Unlikely

O
Very unlikely

O

2. How likely would you support a constitutional convention to revise or replace the FEDERAL constitution? Very likely

Likely

Neutral

Unlikely

Very unlikely

$\mathrm{O}$

O

O

$\mathrm{O}$

O 
[CONDITION 1, "more information"]

We now want you to read through a news article on the 2010 Michigan general election. During this election, Michigan voters were asked whether they wanted to hold a constitutional convention.

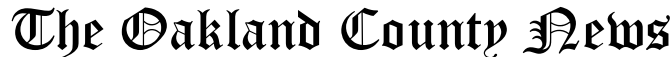

LANSING, MI - MONDAY, NOVEMBER 1, 2010

\section{Michigan 2010: State Con-Con Question}

by PATRICIA SNYDER

Every 16 years, Michigan voters get to decide on whether to call for a constitutional convention to rewrite the state Constitution. Opponents argue that the current amendment process is adequate. "Constitutional change can come about amendment by amendment," argues the Michigan Chamber of Commerce. "Although the present Constitution is not perfect, it contains no fatal flaw."
Others argue now is the time for significant changes. Citizens for Michigan has proposed several reforms, noting that "these recommendations offer the entire state a starting point from which to begin discussions on whether and how Michigan's Constitution should be improved."
Once a convention begins, there is no limit to what delegates may change. While voters must approve any changes, significant rewrites or even replacement of the present 1963 Constitution could happen.

If approved, the process for a constitutional convention would start in early 2011.

1. Given what you have read, how likely would you support a constitutional convention to revise or replace the MICHIGAN STATE constitution?

Very likely Likely

$\bigcirc$

O
Neutral

$\bigcirc$
Unlikely

$\bigcirc$
Very unlikely

O

2. How likely would you support a constitutional convention to revise or replace the FEDERAL constitution? Very likely

Likely

Neutral

Unlikely

Very unlikely
O

O
O
O 
[CONDITION 2, "negative prime"]

We now want you to read through a news article on the 2010 Michigan general election. During this election, Michigan voters were asked whether they wanted to hold a constitutional convention.

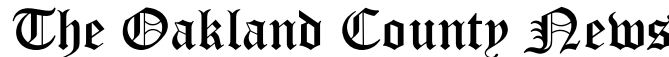

LANSING, MI - MONDAY, NOVEMBER 1, 2010

\section{Michigan 2010: State Con-Con Question}

by PATRICIA SNYDER

Every 16 years, Michigan voters get to decide on whether to call for a constitutional convention to rewrite the state Constitution. Opponents argue that the current amendment process is adequate. "Constitutional change can come about amendment by amendment," argues the Michigan Chamber of Commerce. "Although the present Constitution is not perfect, it contains no fatal flaw."

Others argue now is the time for significant changes. Citizens for
Michigan has proposed several reforms, noting that "these recommendations offer the entire state a starting point from which to begin discussions on whether and how Michigan's Constitution should be improved."

Once a convention begins, there is no limit to what delegates may change. While voters must approve any changes, significant rewrites or even replacement of the present 1963 Constitution could happen.
No constitutional convention has been approved by voters since 1961. Sixteen years ago, voters rejected a constitutional convention by a 72 percent to 28 percent margin. Sixteen years before that, in 1978, voters again rejected the constitutional convention ballot question by a similar margin.

If approved, the process for a constitutional convention would start in early 2011.

1. Given what you have read, how likely would you support a constitutional convention to revise or replace the MICHIGAN STATE constitution?

Very likely Likely

$\mathrm{O}$

$\mathrm{O}$

Neutral

Unlikely

Very unlikely

2. How likely would you support a constitutional convention to revise or replace the FEDERAL constitution? Very likely

Likely

Neutral

Unlikely

Very unlikely

$\mathrm{O}$

O

O

$\mathrm{O}$

O 
[CONDITION 3, "positive prime"]

We now want you to read through a news article on the 2010 Michigan general election. During this election, Michigan voters were asked whether they wanted to hold a constitutional convention.

\section{The OBakland County}

LANSING, MI - MONDAY, NOVEMBER 1, 2010

\section{Michigan 2010: State Con-Con Question}

by PATRICIA SNYDER

Every 16 years, Michigan voters get to decide on whether to call for a constitutional convention to rewrite the state Constitution. Opponents argue that the current amendment process is adequate. "Constitutional change can come about amendment by amendment," argues the Michigan Chamber of Commerce. "Although the present Constitution is not perfect, it contains no fatal flaw."

Others argue now is the time for significant changes. Citizens for Michigan has proposed several reforms, noting that "these recommendations offer the entire state a starting point from which to begin discussions on whether and how Michigan's Constitution should be improved."

Once a convention begins, there is no limit to what delegates may change. While voters must approve any changes, significant rewrites or even replacement of the present 1963 Constitution could happen.

Prior convention calls have been approved by the public. Voters in 1866, 1906, and 1961 approved constitutional conventions, although only the 1906 and 1961 conventions resulted in new constitutions.

If approved, the process for a constitutional convention would start in early 2011.

1. Given what you have read, how likely would you support a constitutional convention to revise or replace the MICHIGAN STATE constitution?

\begin{abstract}
Very likely
\end{abstract}
$\bigcirc$
Neutral

$\mathrm{O}$ $\bigcirc$

\section{Unlikely}

O
Very unlikely

$\bigcirc$

2. How likely would you support a constitutional convention to revise or replace the FEDERAL constitution?

Very likely

$\bigcirc$
Likely

O

\begin{abstract}
Neutral
\end{abstract}
O
Unlikely

O
Very unlikely 
Post-test Instrumentation

We are now going to ask you a few questions concerning your knowledge of the FEDERAL Constitution. Many people don't know the answers to these questions, so if there are some you don't know, select "Don't Know" and move on.

1. How long is the term of a U.S. Senator?
2 years
4 years
6 years
8 years
Don't Know
$\mathrm{O}$
$\mathrm{O}$
$\mathrm{O}$
0
O

2. If Congress passes a law and the President vetoes it, Congress can enact it anyway with a two-thirds majority vote of both houses.
True
False
Don't Know

O

O

O

3. What are the first ten amendments to the U.S. Constitution called? The Rights of Man The Bill of Rights $\begin{gathered}\text { The Declaration of } \\ \text { Independence }\end{gathered}$
and the Citizen

Don't Know

$\mathrm{O}$

$\bigcirc$

$\mathrm{O}$

O

$\bigcirc$

4. Whose responsibility is it to determine if a law is constitutional or not?

congress

President

O

$\bigcirc$
Supreme Court

$\bigcirc$
Department of Justice

O
Don't Know

O

5. Among the rights guaranteed by the First Amendment is the right to:

Free exercise of religion

O
Keep and bear arms

O
Due process of law

O
A speedy and public trial

O
Don't Know

O

6. It is the President's responsibility to nominate federal judges.

True False Don't Know

O 0

O $O$

Now we are going to ask you some questions about the MICHIGAN STATE constitution. For each provision, please indicate whether you think this provision is a part of the MICHIGAN STATE constitution or not. If you are unsure, select "Don't Know" and move on.

7. State judges and supreme court justices serve for life.

IN the
Michigan
Constitution

8. Members of the state legislature serve only a limited number of terms in office before mandatory retirement.

9. The death penalty is prohibited.

10. State government is required to provide free, public primary and secondary (K-12) educational institutions for all residents.

11. The state governor serves for a two-year term.

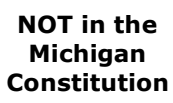

$\mathrm{O}$

$\bigcirc$

$\bigcirc$

$\bigcirc$

$\mathrm{O}$
Don't Know/Unsure

$\bigcirc$

$\bigcirc$

$\bigcirc$

$\bigcirc$

$\bigcirc$ 
Now we are interested in knowing your feelings on the U.S. FEDERAL Constitution. To what extent do you agree with the following statements?

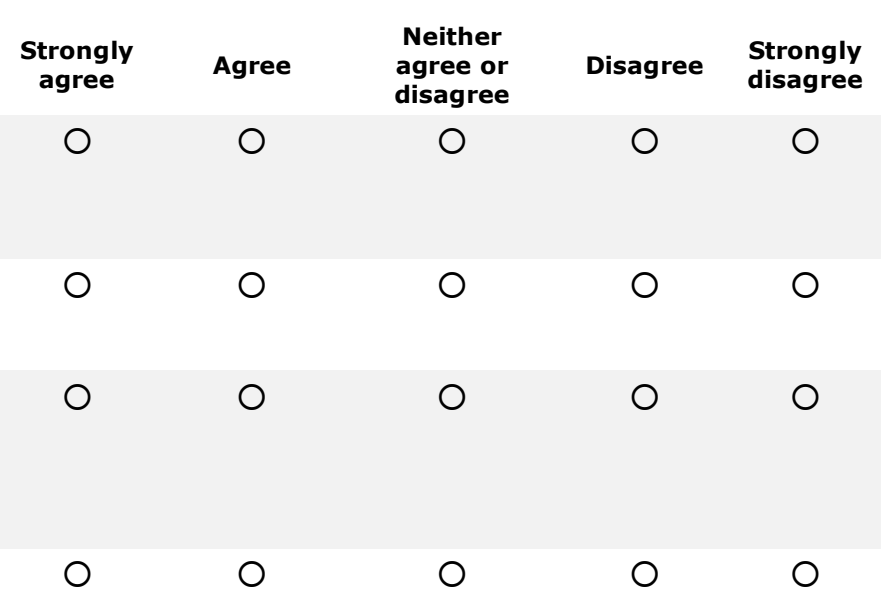

4. The FEDERAL constitution is too controversia to be useful today.

5. On a scale of 1 to 5 (with 5 being "strongly approve"), how much do you approve of the FEDERAL constitution? Please circle your answer.

$$
1
$$$$
2
$$$$
3
$$

4

5

Now we would like to know your feelings on the MICHIGAN STATE constitution. To what extent do you agree with the following statements?

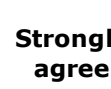

6. It would not make much difference to me if the MICHIGAN STATE constitution were rewritten or amended.

7. The MICHIGAN STATE constitution favors some groups more than others.

8. If the MICHIGAN STATE constitution continually prevents decisions that the people agree with, it might be better to do away with the Constitution altogether.

9. The MICHIGAN STATE constitution is too controversial to be useful today.

$\begin{array}{ccccc}\begin{array}{c}\text { Strongly } \\ \text { agree }\end{array} & \text { Agree } & \begin{array}{c}\text { Neither } \\ \text { agree or } \\ \text { disagree }\end{array} & \text { Disagree } & \begin{array}{c}\text { Strongly } \\ \text { disagree }\end{array} \\ \bigcirc & \bigcirc & \bigcirc & \bigcirc & \bigcirc\end{array}$

$\bigcirc$

$\bigcirc$

O

O

O

$\mathrm{O}$

$\bigcirc$

$\bigcirc$

$\bigcirc$

○

10. On a scale of 1 to 5 (with 5 being "strongly approve"), how much do you approve of the MICHIGAN STATE constitution? Please circle your answer.

\section{1}

Thank you for completing this survey! Please be sure to submit your survey. If you have any questions or concerns, please contact the Primary Investigator, Kevin Lorentz, or his advisor, Dr. Brady Baybeck, at (313) 577-2630. 


\section{APPENDIX B: WAVE 2}

A second survey wave was administered during the Fall 2018 semester. These results are not reported in the main analysis due to substantive departures from Wave 1 . In this section I discuss the "pooled results" (i.e. both survey waves analyzed together), noting differences from Wave 1's findings reported above, and possible explanations for the differences.

\section{Predicting Constitutional Loyalty}

For ease, I report the pooled data regarding the regression analysis using a dummy "Wave" variable (a somewhat fixed-effects regression that notes when Wave 2 significantly differs from Wave 1).

The comprehensive regression models (see Table B-1) from Chapter 6 are reported here. These models include all variables for all four dimensions: demography, political affiliations, institutional attitudes, and civic knowledge (i.e. news consumption habits and constitutional knowledge), plus controls for specific support and survey wave. For federal constitutional loyalty, Trump approval, SCOTUS approval, and federal constitutional knowledge are significant, as well as federal constitutional approval. These findings mirror Wave 1, excepting that constitutional knowledge falls from significance when controlling for federal constitutional approval. 
Table B-1.

Predictors of Constitutional Loyalty

\begin{tabular}{|c|c|c|c|}
\hline & Federal Loyalty & Michigan Loyalty & Michigan Loyalty v.2 \\
\hline \multirow[t]{2}{*}{ Female } & 0.057 & $0.152^{\wedge}$ & $0.109^{\wedge}$ \\
\hline & (0.077) & $(0.081)$ & $(0.066)$ \\
\hline \multirow[t]{2}{*}{ Age } & 0.013 & $0.026 * * *$ & $0.011^{\wedge}$ \\
\hline & (0.01) & $(0.007)$ & $(0.006)$ \\
\hline \multirow[t]{2}{*}{ African American } & -0.099 & -0.053 & 0.098 \\
\hline & (0.113) & (0.117) & $(0.102)$ \\
\hline \multirow[t]{2}{*}{ Other Minority } & -0.074 & -0.043 & 0.041 \\
\hline & $(0.088)$ & (0.089) & $(0.074)$ \\
\hline \multirow[t]{2}{*}{ SES } & -0.065 & -0.025 & 0.005 \\
\hline & (0.055) & $(0.062)$ & (0.041) \\
\hline \multirow{2}{*}{ Partisanship } & 0.021 & 0.004 & -0.003 \\
\hline & $(0.034)$ & $(0.03)$ & $(0.023)$ \\
\hline \multirow[t]{2}{*}{ Ideology } & -0.02 & $0.091^{*}$ & 0.025 \\
\hline & (0.046) & $(0.042)$ & (0.035) \\
\hline \multirow[t]{2}{*}{ Executive Approval } & $0.159 * * *$ & -0.038 & -0.049 \\
\hline & $(0.049)$ & (0.044) & (0.041) \\
\hline \multirow[t]{2}{*}{ Legislature Approval } & -0.069 & 0.006 & 0.033 \\
\hline & $(0.055)$ & (0.077) & $(0.066)$ \\
\hline \multirow[t]{2}{*}{ Court Approval } & $0.146 * *$ & 0.119 & 0.059 \\
\hline & $(0.051)$ & $(0.075)$ & $(0.066)$ \\
\hline \multirow[t]{2}{*}{ Const. Knowledge } & $0.083 * *$ & 0.031 & 0.021 \\
\hline & $(0.029)$ & (0.031) & $(0.025)$ \\
\hline \multirow[t]{2}{*}{ News Attentiveness } & -0.024 & -0.012 & 0.005 \\
\hline & (0.031) & $(0.033)$ & $(0.025)$ \\
\hline \multirow[t]{2}{*}{ Const. Approval } & $0.355^{* * *}$ & $0.283^{* * *}$ & $0.198 * * *$ \\
\hline & $(0.047)$ & $(0.071)$ & (0.049) \\
\hline \multirow[t]{2}{*}{ Fed. Const. Loyalty } & & & $0.459 * * *$ \\
\hline & & & $(0.056)$ \\
\hline \multirow[t]{2}{*}{ Wave dummy } & $0.158^{*}$ & 0.099 & 0.05 \\
\hline & (0.077) & (0.077) & (0.058) \\
\hline \multirow[t]{2}{*}{ Constant } & $1.265^{* * *}$ & $1.224 * * *$ & $0.489^{\wedge}$ \\
\hline & $(0.331)$ & $(0.321)$ & $(0.251)$ \\
\hline$N$ & 298 & 198 & 198 \\
\hline Adjusted $\mathrm{R}^{2}$ & 0.426 & 0.265 & 0.562 \\
\hline
\end{tabular}

Note: Data taken from pre-test measures, excepting constitutional knowledge that was derived from the post-test. Standard errors in parentheses. ${ }^{* * *} p<0.001,{ }^{* *} p<0.01,{ }^{*} p<0.05, \wedge p<0.10$

This departure is reflected in the wave variable, which is significant and positive, denoting that Wave 2 is influencing the results differently than Wave 1. I believe this is due to Wave 2's 
constitutional knowledge base being significantly lower than Wave 1 's $(p=0.01) \cdot{ }^{1}$ Consequently, the pooled results differ on constitutional knowledge because of Wave 2's inclusion.

For Michigan constitutional loyalty, three variables reach traditional levels of significance: age, ideology, and Michigan constitutional approval. Subjects who are older, lean more conservative, and express greater approval of the Michigan constitution all have higher mean constitutional loyalty. These results differ from Wave 1's only with ideology's significance. Importantly, the wave dummy is not significant in this model, noting that neither wave is influencing the results differently. Overall, though, the Michigan model is largely devoid of significant variables; inclusion of federal constitutional loyalty $(p=.000)$ in the Michigan model reflects the dissertation's primary conclusion: Michigan constitutional loyalty is largely informed by one's federal constitutional feelings (the federal "warmglow") given most subjects' lack of knowledge and awareness about the charter.

Overall, these pooled results do not substantially differ from Wave 1's findings nor the dissertation's conclusions as they relate to predictors of Michigan constitutional loyalty (namely that the federal "warmglow" is primarily at work). As for predicting federal constitutional loyalty, the major departure is the continued influence of constitutional knowledge even after controlling for specific support - which bolsters my conclusions of constitutional knowledge's role. This is likely due to the inclusion of Wave 2, but it does align with the larger literature's findings about positivity bias and institutional loyalty. Nonetheless, I conclude that constitutional knowledge did matter given its role in generating specific support through positivity bias: to know more about

\footnotetext{
${ }^{1}$ To determine significance, I ran a t-test between the waves on the mean number of correct responses on the constitutional knowledge scale.
} 
an institution is to love it, generating greater approval and loyalty towards it. The pooled results continue to reflect this conclusion.

\section{Experimental Results}

Wave 1 found that the experiment's priming about periodic conventions affected constitutional approval (specific support) rather than constitutional loyalty (diffuse support). However, significant differences do exist when one controls for constitutional knowledge: subjects with low constitutional knowledge were driving results. Conversely, the pooled analysis indicates initial null findings across the board: the experimental treatment did not appear to influence either constitutional loyalty or approval at either the federal or Michigan level (Chapter 5's analysis). ${ }^{2}$ However, after accounting for constitutional knowledge (Chapter 6's analysis), the pooled results indicate several differences.

I begin with Michigan constitutional support using Michigan constitutional knowledge as a control. First, for likelihood of supporting a Michigan ConCon ballot question, subjects in the high Michigan constitutional knowledge group $(F(3,179)=2.78, p=0.043)$ express less support when exposed to the negative prime $(\bar{y}=2.95, \mathrm{~s}=0.84)$ than subjects encountering the positive prime $(\bar{y}=3.44, \mathrm{~s}=0.96, \mathrm{p}=.05)$. This is in the expected direction as hypothesized by Madison: when priming one to think about constitutional integrity (or assaults upon it), subjects were less likely to support changes - reflecting constitutional status quo bias (see Figure B-1). Conversely, those primed to think that changes are permissible and have been done beforehand have less opposition. That this is occurring among high knowledge subjects, though, is surprising, and not in line with Wave 1's findings that low knowledge persons were more susceptible to the primes.

\footnotetext{
2 This remains true after running one-way ANCOVAs controlling for wave. ANCOVA tables available upon request.
} 
Figure B-1.

Michigan ConCon Ballot Question Support by Constitutional Knowledge

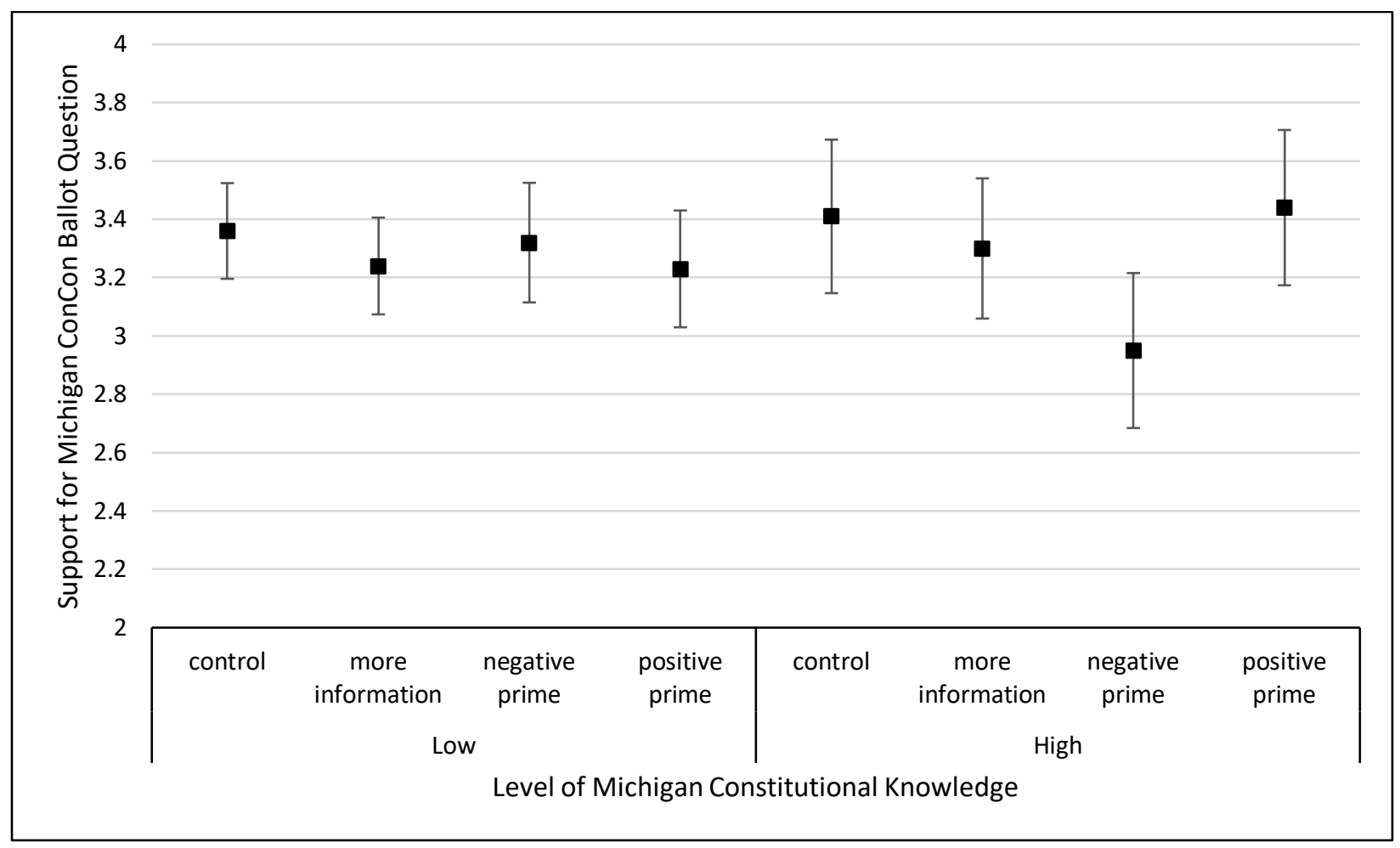

Note: Data based on post-test measures. Higher dependent values indicate greater likelihood of supporting ConCon ballot question. Error bars represent the 95 percent confidence interval.

Second, Michigan constitutional approval $(F(3,297)=2.91, p=0.035)$ is influenced by the negative and positive primes, and in the same manner as Wave 1: negatively primed subjects had lower approval scores $(\bar{y}=2.95, \mathrm{~s}=0.82)$ than those positively primed $(\bar{y}=3.36, \mathrm{~s}=0.72, \mathrm{p}=$ 0.02), and this occurred among subjects with low constitutional knowledge only (see Figure B-2). 
Figure B-2.

Michigan Constitutional Approval by Constitutional Knowledge

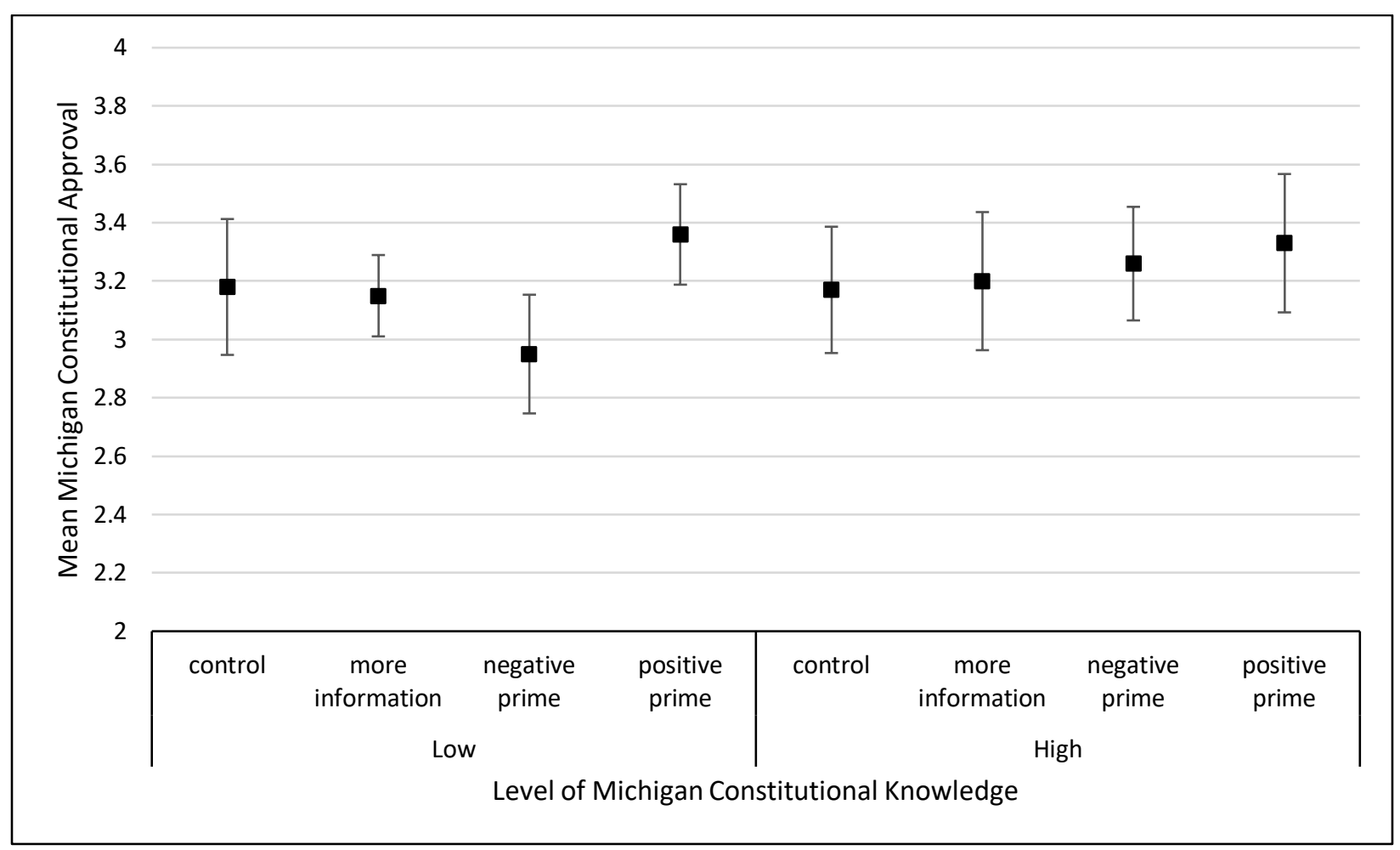

Note: Data based on post-test measures. Constitutional approval measured on five-point scale, with higher numbers indicating greater approval. Error bars represent the 95 percent confidence interval.

Third, Michigan constitutional loyalty (diffuse support) was influenced by the experiment according to the pooled results. Interestingly, constitutional knowledge serves as an important moderator in determining how the negative and positive primes influence persons. Low Michigan constitutional knowledge subjects $(F(3,318)=3.23, p=0.023)$ were more susceptible to the positive prime relative the control $(\bar{y}=2.97, s=0.61, p=0.03)$. Put another way, low knowledge subjects exposed to the positive prime had significantly lower mean constitutional loyalty than the other conditions. Conversely, high knowledge subjects $(F(3,175)=2.55, p=0.05)$ responded to the negative prime, expressing higher average diffuse support relative the more information condition $(\bar{y}=3.39, \mathrm{~s}=0.63, \mathrm{p}=0.06)$ (see Figure $\mathrm{B}-3)$. Taken together, these results suggest that 
primes influence different persons: negative primes have a greater effect upon high knowledge persons (who can likely understand what the implications of constitutional changes are), while low knowledge persons are likely receptive to positive primes that make it seem like constitutional change is "okay" given the optimistic tone. Consequently, Madison's hypothesized relationship receives some empirical backing (and this differs from Wave 1's null finding).

\section{Figure B-3.}

Michigan Constitutional Loyalty by Constitutional Knowledge

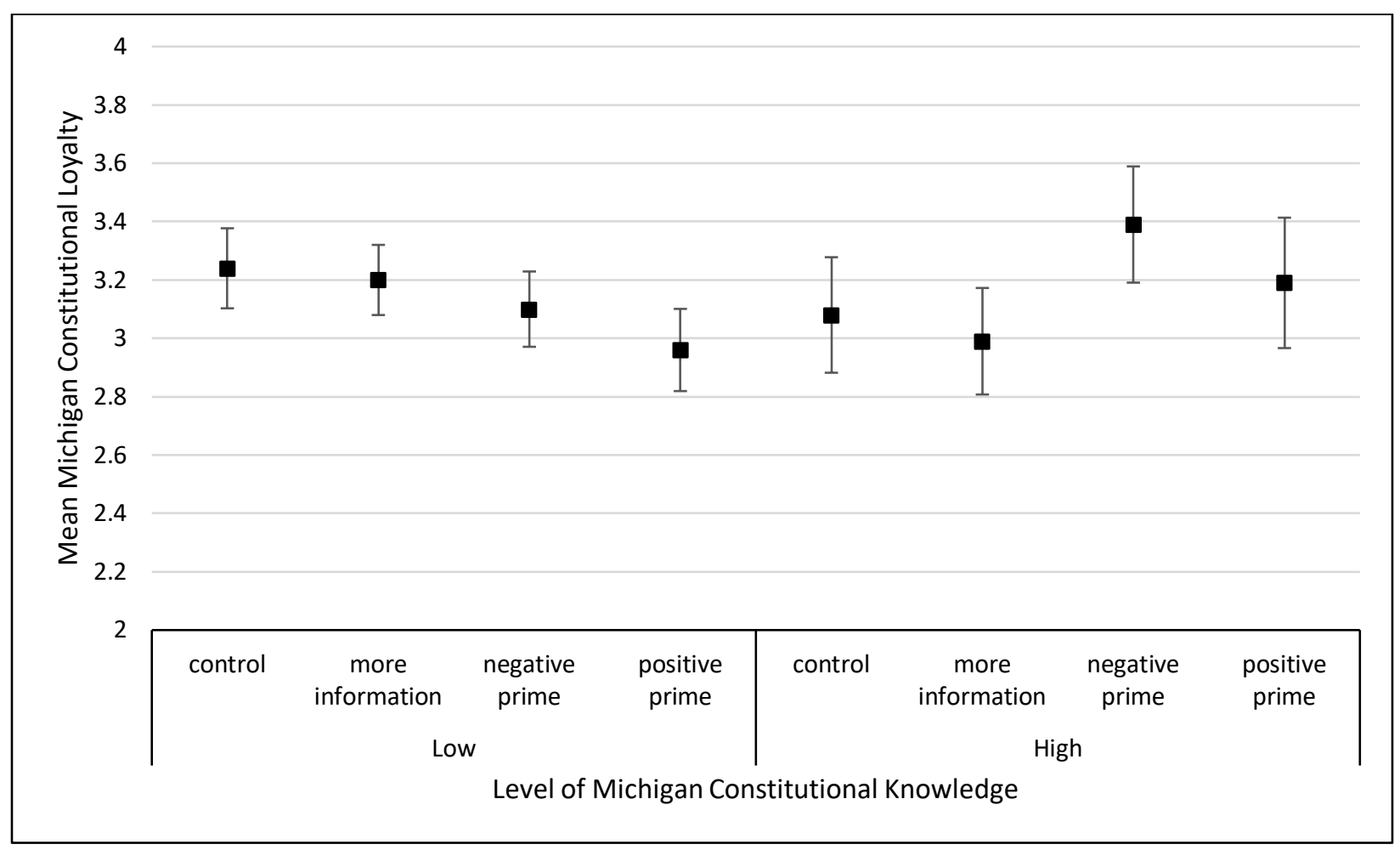

Note: Data based on post-test measures. Constitutional loyalty measured on five-point scale, with higher numbers indicating greater loyalty. Error bars represent the 95 percent confidence interval.

Finally, I explore the "reverse" warmglow noted in Chapter 5 (where the experimental treatment influenced federal constitutional approval, albeit among only persons with low Michigan constitutional knowledge). The pooled results reflect this "reverse" warmglow (see Figure B-4): subjects with low Michigan constitutional knowledge $(F(3,291)=3.27, p=0.02)$ 
differed on mean federal constitutional approval. Specifically, subjects exposed to the negative prime had significantly lower mean approval scores $(\bar{y}=3.1, s=0.85)$ than subjects in the positive prime $(\bar{y}=3.56, s=0.85, p=0.02)$. These results mirror those found in Wave 1 .

Figure B-4.

Federal Constitutional Attitudes and the Reverse "Warmglow" Effect

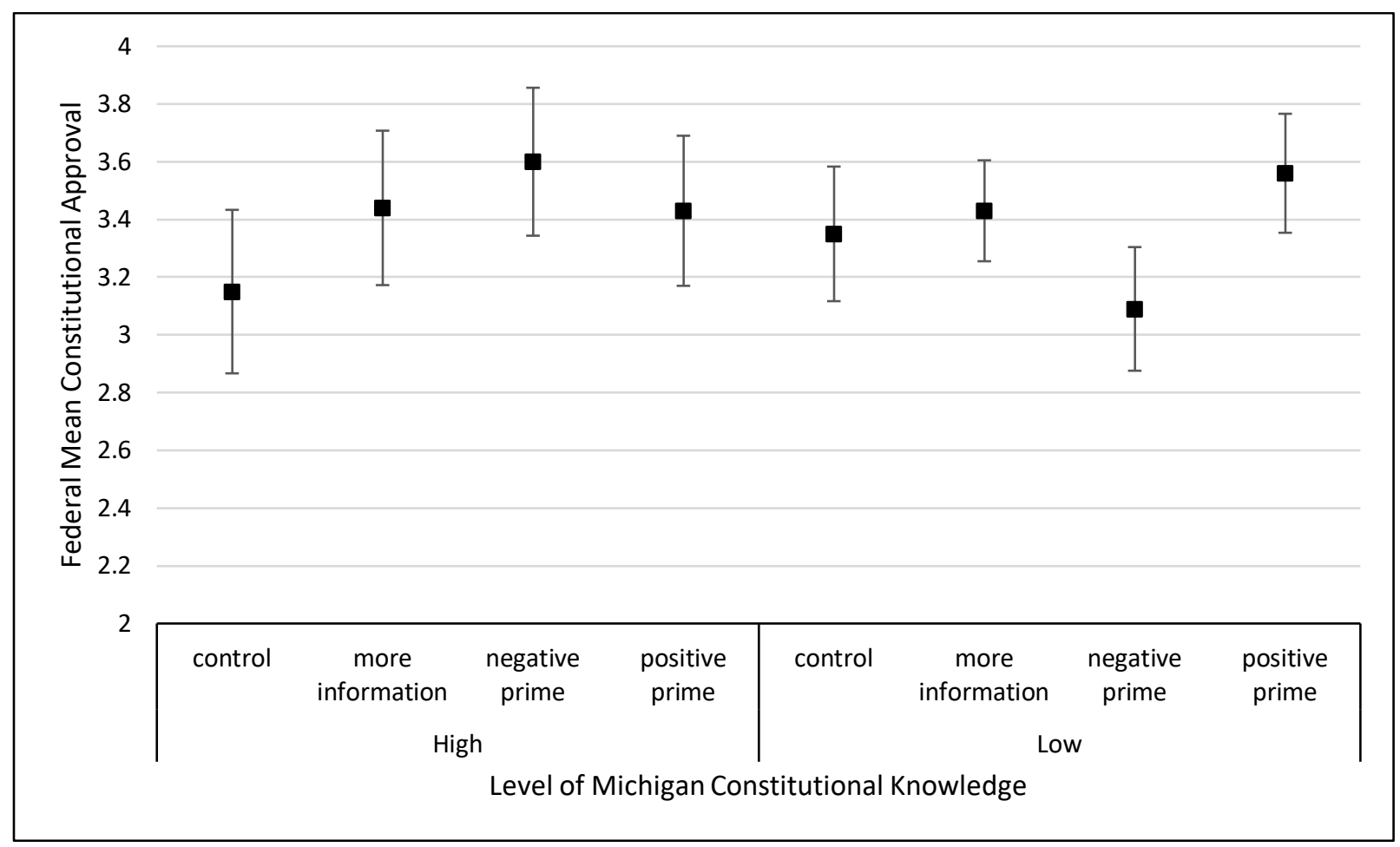

Note: Data based on post-test measures. Constitutional approval presented on a five-point scale, with higher numbers indicating greater approval. Error bars represent the 95 percent confidence interval.

Importantly, I re-run the above analyses using the pooled data using an ANCOVA (analysis of covariance) estimation procedure. ANCOVA controls for pertinent confounders in the normal one-way ANOVAs employed above. Consequently, I can determine whether one survey wave is influencing results differently than the other. While I do not report the ANCOVA tables here, I find that (1) the significant relationships above remain valid after controlling for wave and (2) that the wave variable in these models did not reach statistical significance, suggesting that these 
pooled results' substantive differences with Wave 1 are not being driven by Wave 2's inclusion, at least concerning the experimental treatments.

\section{Discussion}

Given these findings, there are three possible hypotheses that help explain the differences from the dissertation's primary wave. First, the differences may reflect temporal issues and the role of civic education. Each wave was administered during a different semester/academic year, although within the same calendar year (2018). Wave 1 was deployed during the Winter 2018 semester (January-April 2018), while Wave 2 was administered during the Fall 2018 semester (August-December 2018). The waves were also administered during different periods of the semester that may not make them completely comparable: Wave 1 was administered late in the Winter semester, during March and April (weeks 12-14). Wave 2, meantime, was administered much earlier during the Fall semester in early October (weeks 6 and 7).

Consequently, it may be that the differences in waves (especially in federal constitutional knowledge) could be explained by the effect of civic education. Wave 1's higher constitutional knowledge arguably may be contributed to students being much further along in the semester (almost the end) and being exposed to more constitutional topics. Wave 2, meantime, likely had minimal exposure and practice. Thus, the pooled results demonstrate the benefits of civics (constitutional) instruction and how it mediates and possibly enhances the experiment's treatments depending on one's familiarity with the charter.

It could also be that student-level differences are driving results, specifically in the kinds of students taking courses between the semesters. The Fall 2018 semester (Wave 2) likely had a 
greater number of first-time freshmen enrolling in PS 1010 sections, while the Winter 2018 semester (Wave 1) likely did not. This may have somewhat impacted results due to differences in students' experiences, prior knowledge, skills, motivation, etc. There were some significantly departures in terms of Wave 2 having greater institutional support (especially for Trump), although this is likely attributable to Wave 2's greater proportion of conservatives and Republican partisans. (However, the patterns of support do not change between waves for these variables. For example, Trump's average approval score went from 0.6 to 1.0 , a statistically significant but inconsequential difference.) Moreover, balance checks indicate that, once randomly sorted into experimental conditions, there were no significant differences between the groups across waves.

A third and final factor concerns the waves' administrations during different times politically, potentially impacting results. Wave 1 was deployed in the preliminary stages of the federal midterms and Michigan state elections, including the prelude to the 2018 state constitutional amendment ballot contests. Wave 2, on the other hand, was ran during the midterms and state elections. Exposure to these events may have made an imprint during Wave 2 that explains some differences. 


\section{REFERENCES}

Adrian, Charles R. 1968. "Trends in State Constitutions." Harvard Journal on Legislation 5(3): 311.

Angrist, Joshua, and Jorn-Steffen Pischke. 2009. Mostly Harmless Econometrics: An Empiricist's Companion. Trenton: Princeton University Press.

Armaly, Miles T., and Ryan C. Black. 2016. "The State of Political Knowledge in the State of Michigan." Institute for Public Policy and Social Research. http://ippsr.msu.edu/publicpolicy/michigan-wonk-blog/state-political-knowledge-state-michigan (April 13, 2018).

Bailey, Jeremy D. 2012. "Should We Venerate That Which We Cannot Love? James Madison on Constitutional Imperfection." Political Research Quarterly 65(4): 732-44.

Baird, Vanessa A. 2001. "Building Institutional Legitimacy: The Role of Procedural Justice." Political Research Quarterly 54(2): 333-54.

Bello, Daniel et al. 2009. "From the Editors: Student Samples in International Business Research." Journal of International Business Studies 40(3): 361-64.

Benjamin, Gerald. 2001. “The Mandatory Constitutional Convention Question Referendum: The New York Experience in National Context." Albany Law Review 65(4): 1017.

Bialik, Kristen, and Katerina Eva Matsa. 2017. "Key Trends in Social and Digital News Media." Pew Research Center. http://www.pewresearch.org/fact-tank/2017/10/04/key-trendsin-social-and-digital-news-media/ (September 12, 2018).

Blake, William D., and Sanford V. Levinson. 2016. "The Limits of Veneration: Public Support for a New Constitutional Convention." Constitutional Studies 1(2): 1-22. 
Boynton, G. R., and Gerhard Loewenberg. 1973. "The Development of Public Support for Parliament in Germany, 1951-59." British Journal of Political Science 3(2): 169-89.

Brennan, Timothy. 2017. "Thomas Jefferson and the Living Constitution." Journal of Politics 79(3): 936-48.

Caldeira, Gregory A. 1987. “Public Opinion and The U.S. Supreme Court: FDR's Court-Packing Plan." The American Political Science Review 81(4): 1139-53.

Caldeira, Gregory A., and James L. Gibson. 1992. "The Etiology of Public Support for the Supreme Court." American Journal of Political Science 36(3): 635-64.

Campbell, Donald T., and Julian C. Stanley. 1963. Experimental and Quasi-Experimental Designs for Research. Boston: Houghton Mifflin Company.

Cann, Damon M., and Jeff Yates. 2008. “Homegrown Institutional Legitimacy: Assessing Citizens' Diffuse Support for State Courts." American Politics Research 36(2): 297-329.

Chanley, Virginia A., Thomas J. Rudolph, and Wendy M. Rahn. 2000. "The Origins and Consequences of Public Trust in Government: A Time Series Analysis." The Public Opinion Quarterly 64(3): 239-56.

Davidson, Roger H., and Glenn R. Parker. 1972. "Positive Support for Political Institutions: The Case of Congress." The Western Political Quarterly 25(4): 600-612.

Delli Carpini, Michael X., and Scott Keeter. 1993. “Measuring Political Knowledge: Putting First Things First." American Journal of Political Science 37(4): 1179-1206.

- - . 1996. What Americans Know About Politics and Why It Matters. New Haven: Yale University Press. 
Dinan, John J. 2000. “'The Earth Belongs Always to the Living Generation': The Development of State Constitutional Amendment and Revision Procedures." The Review of Politics 62(4): 645.

-- - 2009. The American State Constitutional Tradition. Topeka: University Press of Kansas.

---. 2010. "The Political Dynamics of Mandatory State Constitutional Convention Referendums: Lessons from the 2000s Regarding Obstacles and Pathways to Their Passage." Montana Law Review 71(2): 395.

Druckman, James N., and Cindy D. Kam. 2011. "Students as Experimental Participants: A Defense of the 'Narrow Data Base.'" In Cambridge Handbook of Experimental Political Science, eds. James N. Druckman, Donald P. Green, James H. Kuklinski, and Arthur Lupia. New York: Cambridge University Press.

Druckman, James N., and Kjersten R. Nelson. 2003. “Framing and Deliberation: How Citizens Conversations Limit Elite Influence." American Journal of Political Science 47(4): 729-45.

Durr, Robert H., Andrew D. Martin, and Christina Wolbrecht. 2000. “Ideological Divergence and Public Support for the Supreme Court." American Journal of Political Science 44(4): 76876.

Easton, David. 1965. A Systems Analysis of Political Life. New York: Wiley.

- - . 1975. "A Re-Assessment of the Concept of Political Support." British Journal of Political Science 5(4): 435-57.

Eckles, David L., and Brian F. Schaffner. 2011. “Risk Tolerance and Support for Military Interventions." The Public Opinion Quarterly 75(3): 533-44. 
Eidelman, Scott, and Christian S. Crandall. 2014. "The Intuitive Traditionalist: How Biases for Existence and Longevity Promote the Status Quo." In Advances in Experimental Social Psychology, eds. M. Zanna and J. Olson. Burlington, AL: Academic Press, 53-104.

Eidelman, Scott, Jennifer Pattershall, and Christian S. Crandall. 2010. "Longer Is Better." Journal of Experimental Social Psychology 46(6): 993-98.

Elkins, Zachary, Tom Ginsburg, and James Melton. 2009. The Endurance of National Constitutions. New York: Cambridge University Press.

Ellsworth, Phoebe, and Richard Gonzalez. 2007. "Questions and Comparisons: Methods of Research in Social Psychology." In The SAGE Handbook of Social Psychology: Concise Student Edition, eds. Michael A. Hogg and Joel Cooper. Los Angeles, CA: SAGE, 24-42.

Finkel, Steven E., Thomas M. Guterbock, and Marian J. Borg. 1991. “Race-of-Interviewer Effects in a Preelection Poll: Virginia 1989." The Public Opinion Quarterly 55(3): 313-30.

Franklin, Charles H., and Liane C. Kosaki. 1989. "Republican Schoolmaster: The U.S. Supreme Court, Public Opinion, and Abortion." The American Political Science Review 83(3): 75171.

Gainous, Jason, and Allison M. Martens. 2012. “The Effectiveness of Civic Education: Are 'Good' Teachers Actually Good for 'All' Students?" American Politics Research 40(2): 232-66.

Gerber, Alan S., and Donald P. Green. 2012. Field Experiments: Design, Analysis, and Interpretation. New York: W.W. Norton \& Company.

Gibson, James L. 2012. Electing Judges: The Surprising Effects of Campaigning on Judicial Legitimacy. Chicago: University of Chicago Press. 
Gibson, James L., and Gregory A. Caldeira. 2009a. Citizens, Courts, and Confirmations: Positivity Theory and the Judgments of the American People. Princeton: Princeton University Press.

- - . 2009b. "Knowing the Supreme Court? A Reconsideration of Public Ignorance of the High Court." The Journal of Politics 71(2): 429-41.

- - . 1992. "Blacks and the United States Supreme Court: Models of Diffuse Support." The Journal of Politics 54(4): 1120-45.

- - . 2011. "Has Legal Realism Damaged the Legitimacy of the U.S. Supreme Court?" Law \& Society Review 45(1): 195-219.

Gibson, James L., Gregory A. Caldeira, and Vanessa A. Baird. 1998. “On the Legitimacy of National High Courts." The American Political Science Review 92(2): 343-58.

Gibson, James L., Gregory A. Caldeira, and Lester K. Spence. 2003a. “Measuring Attitudes toward the United States Supreme Court." American Journal of Political Science 47(2): $354-67$.

-- - 2003b. "The Supreme Court and the US Presidential Election of 2000: Wounds, SelfInflicted or Otherwise?" British Journal of Political Science 33(4): 535-56.

Gibson, James L., Gregory A. Caldeira, and Lester Kenyatta Spence. 2005. “Why Do People Accept Public Policies They Oppose? Testing Legitimacy Theory with a Survey-Based Experiment." Political Research Quarterly 58(2): 187-201.

Gibson, James L., and Michael J. Nelson. 2015. "Is the U.S. Supreme Court's Legitimacy Grounded in Performance Satisfaction and Ideology?" American Journal of Political Science 59(1): 162-74. 
Glendon, Mary Ann. 1993. Rights Talk: The Impoverishment of Political Discourse. Reprint edition. New York, NY: Free Press.

Grad, Frank P., and Robert F. Williams. 2006. 2 State Constitutions for the Twenty-First Century. New York: State University of New York Press.

Green, Donald P. et al. 2011. "Does Knowledge of Constitutional Principles Increase Support for Civil Liberties? Results from a Randomized Field Experiment." The Journal of Politics 73(2): 463-76.

Hibbing, John R., and Elizabeth Theiss-Morse. 1995. Congress as Public Enemy: Public Attitudes Toward American Political Institutions. New York: Cambridge University Press.

---. 2002. Stealth Democracy: Americans' Beliefs About How Government Should Work. New York: Cambridge University Press.

Hoekstra, Valerie, and Nicholas LaRowe. 2013. “Judging Nominees: An Experimental Test of the Impact of Qualifications and Divisiveness on Public Support for Nominees to the Federal Courts." The Justice System Journal 34(1): 38.

Holmes, Stephen. 1995. Passions and Constraint: On the Theory of Liberal Democracy. Chicago: University of Chicago Press.

Hunsicker, Jacqueline. 2012. "Critical Veneration and the Art of Constitutional Aspirationalism." Dissertation. The University of Texas at Austin.

Hurd, Ian. 2007. "Legitimacy." Encyclopedia Princetoniensis. https://pesd.princeton.edu/?q=node/255 (December 6, 2017).

Irvine, Charlotte, and Edward M. Kresky. 1962. How to Study a State Constitution. New York, NY: National Municipal League. 
Jefferson, Thomas. 1984. Jefferson: Writings. ed. Merrill D. Peterson. New York: The Library of America.

Jones, David R., and Monika L. McDermott. 2002. "Ideological Distance from the Majority Party and Public Approval of Congress." Legislative Studies Quarterly 27(2): 245-64.

Kahneman, Daniel, Jack L. Knetsch, and Richard H. Thaler. 1991. “Anomalies: The Endowment Effect, Loss Aversion, and Status Quo Bias." The Journal of Economic Perspectives 5(1): 193-206.

Kam, C. D., and E. N. Simas. 2012. “Risk Attitudes, Candidate Characteristics, and Vote Choice." Public Opinion Quarterly 76(4): 747-60.

Kam, Cindy D., Jennifer R. Wilking, and Elizabeth J. Zechmeister. 2007. “Beyond the 'Narrow Data Base': Another Convenience Sample for Experimental Research." Political Behavior 29(4): 415-40.

Kogan, Vladimir. 2010. "Lessons from Recent State Constitutional Conventions." California Journal of Politics and Policy 2(2): 3-13.

Langton, Kenneth P., and M. Kent Jennings. 1968. “Political Socialization and the High School Civics Curriculum in the United States." The American Political Science Review 62(3): 852-67.

LaRowe, Nicholas, and Valerie Hoekstra. 2014. “On and Off the Supreme Court Beat: Differences in Newspaper Coverage of the Supreme Court and the Implications for Public Support." In Covering the United States Supreme Court in the Digital Age, ed. Richard Davis. Cambridge: Cambridge University Press, 126-52. 
Lebo, Matthew J. 2008. “Divided Government, United Approval: The Dynamics of Congressional and Presidential Approval." Congress \& the Presidency 35(2): 1-16.

Levinson, Sanford. 2006. Our Undemocratic Constitution. New York: Oxford University Press.

- - - 2012. Framed: America's 51 Constitutions and the Crisis of Governance. New York: Oxford University Press.

- - - "The Constitution Needs a Reboot." POLITICO Magazine. https://politi.co/2MPhMXV (September 14, 2018).

Lupia, Arthur. 2006. "How Elitism Undermines the Study of Voter Competence." Critical Review 18(1-2): 217-32.

Luskin, Robert C., and John G. Bullock. 2011. “'Don't Know' Means ‘Don't Know:' DK Responses and the Public's Level of Political Knowledge." The Journal of Politics 73(2): 547-57.

Lutz, Donald S. 1995. "Toward a Theory of Constitutional Amendment." In Responding to Imperfection: The Theory and Practice of Constitutional Amendment, ed. Sanford Levinson. Princeton: Princeton University Press, 237-74.

Lyons, Jeffrey, William P. Jaeger, and Jennifer Wolak. 2013. “The Roots of Citizens' Knowledge of State Politics." State Politics \& Policy Quarterly 13(2): 183-202.

Madison, James. 1788. "Federalist 49." In The Federalist Papers, ed. Clinton Rossiter. New York: Penguin Group, 310-14.

May, Janice C. 1987. “Constitutional Amendment and Revision Revisited." Publius 17(1): 15379.

McDermott, Rose. 2002. "Experimental Methods in Political Science." Annual Review of Political Science 5(1): 31-61. 
Minnis, John. 2010. “Proposal 2010-01: State Con-Con Question Generates Heated Opinions." http://www.legalnews.com/Oakland/752715 (October 29, 2017).

Mondak, Jeffery J. et al. 2007. “Does Familiarity Breed Contempt? The Impact of Information on Mass Attitudes toward Congress." American Journal of Political Science 51(1): 34-48.

Mondak, Jeffery J., and Mary R. Anderson. 2004. “The Knowledge Gap: A Reexamination of Gender-Based Differences in Political Knowledge." The Journal of Politics 66(2): 492512.

Mook, Douglas G. 1983. "In Defense of External Invalidity." American Psychologist 38(4): 37987.

Mummolo, Jonathan, and Erik Peterson. 2017. “Demand Effects in Survey Experiments: An Empirical Assessment." Stanford University. https://scholar.princeton.edu/sites/default/files/jmummolo/files/demand_effects_5_17 _2017.pdf (October 19, 2017).

Murphy, Walter F., and Joseph Tanenhaus. 1990. "Publicity, Public Opinion, and the Court." Northwestern University Law Review 84(3-4): 985.

Nie, Norman H., Jane Junn, and Kenneth Stehlik-Barry. 1996. Education and Democratic Citizenship in America. University of Chicago Press.

Niemi, Richard G., and Jane Junn. 1998. Civic Education: What Makes Students Learn. New Haven: Yale University Press.

Olson, Macur. 1982. The Rise and Decline of Nations: Economic Growth, Stagflation, and Social Rigidities. New Haven, CT: Yale University Press. 
Orne, Martin T. 1962. “On The Social Psychology of the Psychological Experiment: With Particular Reference to Demand Characteristics and Their Implications." American Psychologist 17(11): 776-83.

Patterson, Samuel C., Randall B. Ripley, and Stephen V. Quinlan. 1992. “Citizens' Orientations toward Legislatures: Congress and the State Legislature." The Western Political Quarterly 45(2): 315-38.

Pernice, Regina E., Reidar Ommundsen, Kees Van Der Veer, and Knud Larsen. 2008. “On Use of Student Samples for Scale Construction." Psychological Reports 102(2): 459-64.

Peterson, RA, and DR Merunka. 2014. “Convenience Samples of College Students and Research Reproducibility." Journal of Business Research 67(5): 1035-41.

Pew Research Center. 2018. The Public, the Political System and American Democracy.

Revilla, Melanie A., Willem E. Saris, and Jon A. Krosnick. 2014. “Choosing the Number of Categories in Agree-Disagree Scales." Sociological Methods \& Research 43(1): 73-97.

Roeder, Phillip W. 1994. Public Opinion and Policy Leadership in the American States. Tuscaloosa, AL: The University of Alabama Press.

Samuelson, William, and Richard Zeckhauser. 1988. "Status Quo Bias in Decision Making." Journal of Risk and Uncertainty 1(1): 7-59.

Sears, David O. 1986. “College Sophomores in the Laboratory: Influences of a Narrow Data Base on Social Psychology's View of Human Nature." Journal of Personality and Social Psychology 51(3): 515-30.

Singleton, Royce A., and Bruce C. Straits. 2010. Approaches to Social Research. 5th ed. New York: Oxford University Press. 
Smith, Roger M. 1993. "Beyond Tocqueville, Myrdal, and Hartz: The Multiple Traditions in America." The American Political Science Review 87(3): 549-66.

Snider, J.H. 2015. "State Constitutional Conventions since 1776." State Constitutional Convention Clearinghouse. https://concon.info/state-data/590-2/ (September 24, 2018).

- - . 2017. "Does the World Really Belong to the Living? The Decline of the Constitutional Convention in New York and Other US States, 1776-2015." American Political Thought 6(2): 256-93.

Stephanopoulos, Nicholas O., and Mila Versteeg. 2016. "The Contours of Constitutional Approval." Washington University Law Review 94(1): 113-90.

Strauss, David. 2010. The Living Constitution. Oxford: Oxford University Press.

Sturm, Albert L. 1970. Thirty Years of State Constitution-Making, 1938-1968. New York, NY: National Municipal League.

Tanenhaus, Joseph, and Walter F. Murphy. 1981. "Patterns of Public Support for the Supreme Court: A Panel Study." The Journal of Politics 43(1): 24-39.

Tarr, G. Alan. 2014. “Explaining State Constitutional Change.” Wayne Law Review 60(1): 9-30.

- - . 2016. "Explaining State Constitutional Changes." Journal of Constitutional Research $3(2): 9-32$.

The MacArthur Foundation. 2007. "The MacArthur Scale of Subjective Social Status." http://www.macses.ucsf.edu/research/psychosocial/subjective.php (October 29, 2017). The Media Insight Project. 2015a. Breaking Down the Millennial Generation: A Typology of Young News Consumers. Chicago: University of Chicago. 
http://www.mediainsight.org/PDFs/Typology/MillennialTypologyFinal.pdf (July 14, 2018).

- - . 2015b. How Millennials Get News: Inside the Habits of America's First Digital Generation. Chicago: University of Chicago. http://www.mediainsight.org/PDFs/Millennials/Millennials\%20Report\%20FINAL.pdf (July 14, 2018).

Thomas, Norman C. 1968. "The Electorate and State Constitutional Revision: An Analysis of Four Michigan Referenda." Midwest Journal of Political Science 12(1): 115-29.

Tversky, Amos, and Daniel Kahneman. 1991. “Loss Aversion in Riskless Choice: A ReferenceDependent Model." The Quarterly Journal of Economics 106(4): 1039-61.

Weijters, Bert, Elke Cabooter, and Niels Schillewaert. 2010. "The Effect of Rating Scale Format on Response Styles: The Number of Response Categories and Response Category Labels." International Journal of Research in Marketing 27(3): 236-47.

Zackin, Emily. 2013. Looking for Rights in All the Wrong Places: Why State Constitutions Contain America's Positive Rights. Princeton: Princeton University Press.

Zink, James R., and Christopher T. Dawes. 2016. "The Dead Hand of the Past? Toward an Understanding of 'Constitutional Veneration."' Political Behavior 38(3): 535. 


\section{ABSTRACT \\ THE ROLE OF PERIODIC CONVENTIONS IN GENERATING AND UNDERMINING CONSTITUTIONAL LOYALTY}

by

\section{KEVIN G. LORENTZ II}

\section{May 2019}

Advisor: Dr. Brady Baybeck

Major: Political Science

Degree: Doctor of Philosophy

In the U.S., popular support is widespread for both the federal and state constitutional charters, although the former enjoys greater support than the latter. Such support is necessary for maintaining a constitution's legitimacy; popular support for the laws ensures continued obedience to them. However, critics note that blind support, or excessive veneration, may have negative consequences, including saddling a political community with suboptimal institutions. Support must be balanced with the necessity of "periodic repairs," allowing each generation to review the prior's work. In modern parlance, critics advocate for periodic constitutional conventions, permitting constitutional revisions irrespective of tradition or presumed legal permanence.

This dissertation explores the relationship between constitutional loyalty and periodic conventions. Existing scholarship has focused heavily on a constitution's specific support, or an individual's current satisfaction (approval) with the charter's outputs, provisions, and/or performance. Little research has explored the more fundamental feelings of constitutional loyalty, or diffuse support, that forms the bedrock of a charter's institutional legitimacy. 
Individuals who are willing to countenance revisions and/or replace a constitution are expressing little loyalty towards it, permitting fundamental changes to the underlying constitutional and political system. Since periodic conventions represent an existential threat to constitutions, do primes about them influence an individual's constitutional loyalty?

To test this question, I deploy a survey experiment that explores how a person's underlying constitutional loyalty is influenced by knowledge about periodic conventions. Using Michigan's 2010 periodic convention referendum, I expose subjects to various vignettes on the convention using different primes. I also control for various confounders that generate constitutional support, including demographic attributes, sociopolitical characteristics, institutional attitudes, and constitutional knowledge. I find that while a subject's constitutional loyalty appears immune to the experimental treatment, her approval of the charter can be altered depending on how she is primed to think about periodic conventions (e.g. whether prior periodic conventions had been approved or not). My results also indicate that persons less familiar with their constitutional charters are more receptive to the primes than persons more knowledgeable, raising serious concerns about the effects of constitutional ignorance and our political system's legitimacy. 


\section{AUTOBIOGRAPHICAL STATEMENT}

Kevin G. Lorentz II is a Ph.D. candidate at Wayne State University, majoring in American politics with minors in public policy and urban politics. His research focuses broadly on American constitutional law, judicial politics, and civic education, with a specific focus on constitutional attitudes. Kevin's other research focuses on judicial decisionmaking and behavior, civic education and pedagogical practices, and collaborative work on high school students' discourse strategies and responses to experiential learning. Beyond his academic work, Kevin has worked extensively in local government, serving as a member of the Bay County (Michigan) Board of Canvassers (auditing and certifying election results) and as a deputy county clerk. A native of northern Michigan, Kevin received his B.A. from Saginaw Valley State University (University Center, MI) and completed master's coursework at Central Michigan University (Mt. Pleasant, MI). In his free time, Kevin enjoys reading, board games, and spending time with family and friends. He presently resides in Midland, Michigan with his partner, Dr. Nicholas Timmer. 